\title{
YOUTH EMPLOYMENT AND THE PRIVATE SECTOR IN AFRICA
}
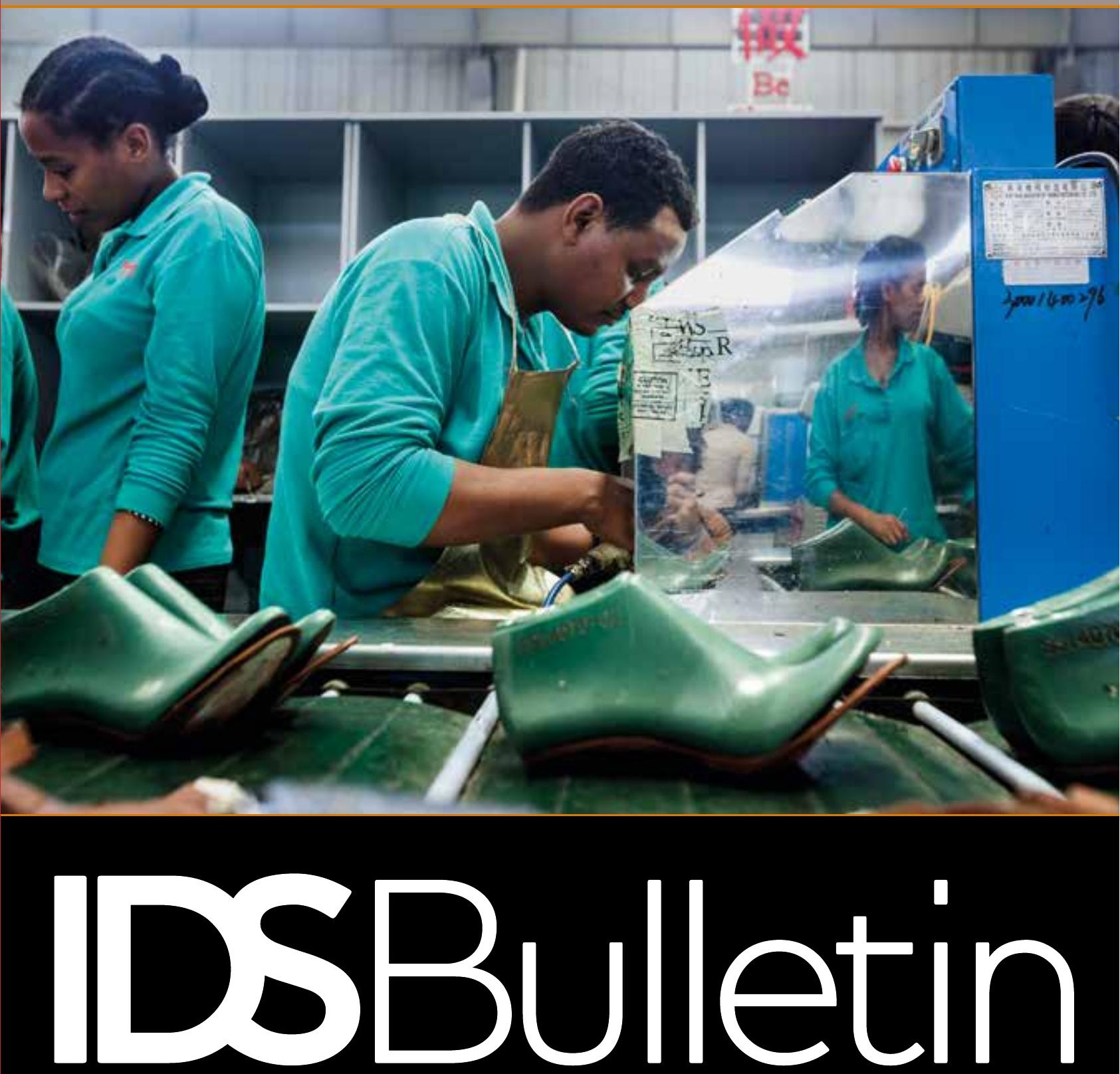

Transforming Development Knowledge 
IDS Bulletin The IDS Bulletin is an open access, peer-review journal exploring emerging international development challenges. It is published bi-monthly and is the flagship publication of the Institute of Development Studies, a leading global institution for research, teaching and learning, and impact and communications, based at the University of Sussex. Progressive economic, social and political change for everyone needs new kinds of action and relationships, shaped by new kinds of research and engagement. The IDS Bulletin aims to transform development knowledge, through its unique thematic issues developed by global learning partnerships that bridge academic, practice and policy discourse.

Publishing Manager/Bulletin Editorial Coordinator Alison Norwood

Production Editor Beth Richard

Marketing and Production Officer Gary Edwards

Publisher The IDS Bulletin is published by the Institute of Development Studies, Library Road, Brighton BN1 9RE, UK. Tel: $+44(0) 1273606261$.

Cover photo Dukem, Oromia State, Ethiopia. Ethiopian staff at the Huajian Group's shoe factory. The Chinese-owned factory produces high-quality shoes for the European and Asian markets.

Photographer Petterik Wiggers/Panos.

Disclaimer The Publisher and Issue Editors cannot be held responsible for errors or any consequences arising from the use of information contained in this journal; the views and opinions expressed do not necessarily reflect those of the Publisher and Issue Editors, neither does the publication of advertisements constitute any endorsement by the Publisher and Issue Editors of the products advertised.

Copyright IDS Bulletin (c) Institute of Development Studies (c) BY-NC This issue is published under a CC BY-NC licence.

This is an Open Access issue distributed under the terms of the Creative Commons Attribution Non Commercial 4.0 International licence (CC BY-NC), which permits use, distribution and reproduction in any medium, provided the original authors and source are credited, any modifications or adaptations are indicated, and the work is not used for commercial purposes. http://creativecommons.org/licenses/by-nc/4.0/legalcode

Online open access This journal is available online at bulletin.ids.ac.uk. Visit the site to search for articles and authors and register for table of contents email alerts.

Information for subscribers The IDS Bulletin is published in six issues per year.

Advertising enquiries Gary Edwards, Marketing and Production Officer, IDS Communications and Engagement Unit, idsbulletin@ids.ac.uk

IDS Bulletin (C) Institute of Development Studies 2018

www.ids.ac.uk

IDS is a charitable company limited by guarantee and registered in England (No. 877338). 


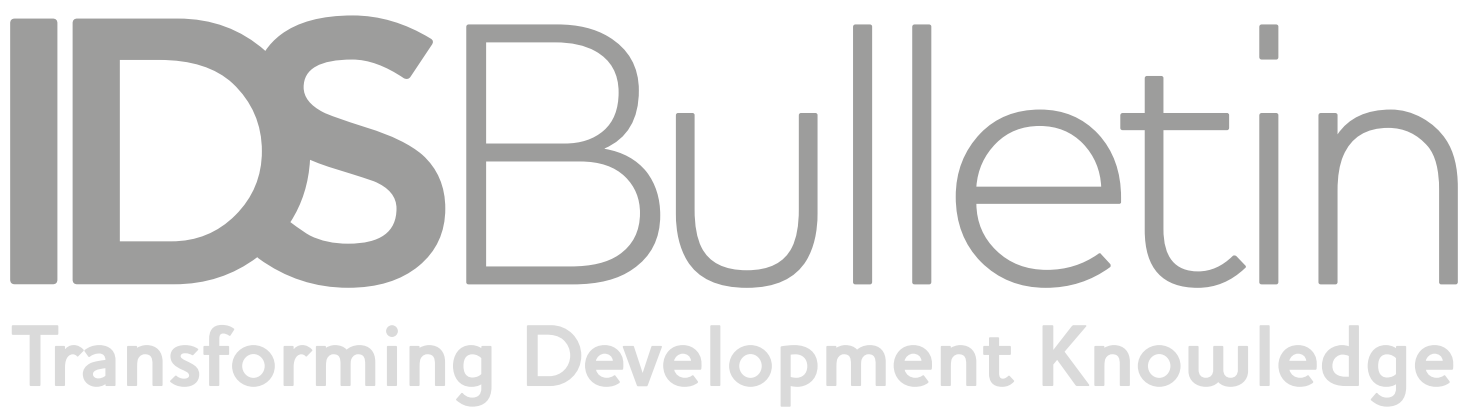

Volume 49 | Number 5 | November 2018

\section{Youth Employment and the Private Sector in Africa}

\section{Editors Seife Ayele, Dominic Glover and Marjoke Oosterom}

Notes on Contributors

Clementina Oluwafunke Ajayi In Memoriam

Introduction: Youth Employment and the Private Sector in Africa

Seife Ayele, Marjoke Oosterom and Dominic Glover

Ethiopia's Agricultural Transformation: Agribusiness' Contribution to Reducing Youth Unemployment

Tesfamicheal Wossen and Seife Ayele

Labour Casualisation and Youth Employment in Ghana's Formal Private Sector Gertrude Dzifa Torvikey

Uganda's National Youth Policy and Job Creation for Youth Rita Makumbi

Skills Gaps and Mismatches: Private Sector Expectations of Engineering Graduates in Ethiopia

Jerusalem Yibeltal Yizengaw

Fostering Agribusiness Entrepreneurship for Kenyan Youth through Practice-Based Education

John Muchira

Navigating Precarious Livelihoods: Youth in the SME Sector in Zimbabwe

Simbarashe Gukurume

Assessing the Effectiveness of Employment Programmes for Ex-Combatants:

A Case Study of Nigeria's Post Amnesty Programme (PAP)

Tarila Marclint Ebiede

Glossary 


\section{Acknowledgements}

We are grateful for the valuable contributions of colleagues who peer-reviewed the articles in this IDS Bulletin, including Justin Flynn, Eyob Balcha Gebremariam, Shittu Ayodele Ibrahim, Monica Lambon-Quayefio, Phil Mader, Grace Mwaura, Victoria Namuggala, Santiago Ripoll, Patrick Schröder, Maurice Sikenyi, Shova Thapa Karki, Jodie Thorpe, and Thomas Yeboah. We also thank our colleagues Jim Sumberg, Vivienne Benson, Beth Richard, and Alison Norwood for their support with the Matasa Fellows programme and the production of this IDS Bulletin.

\section{Funder acknowledgements}

This issue of the IDS Bulletin was produced in partnership with Mastercard Foundation. Mastercard Foundation works with visionary organisations to provide greater access to education, skills training, and financial services for people living in poverty, primarily in Africa. As one of the largest private foundations, its work is guided by its mission to advance learning and promote financial inclusion to create an inclusive and equitable world. Based in Toronto, Canada, its independence was established by Mastercard when the Foundation was created in 2006. For more information and to sign up for the Foundation's newsletter, please visit www.mastercardfdn.org. Follow the Foundation at @MastercardFdn on Twitter.

Vol. 49 No. 5 November 2018:

'Youth Employment and the Private Sector in Africa'

DOI: $10.19088 / 1968-2018.167$ 


\section{Notes on Contributors}

Seife Ayele is a development economist with over 20 years' experience in research, teaching, and development practice, mainly in Africa and Asia. His work focuses on agricultural innovations and development, technology access and adoption, youth employment, and enterprise development. He is currently a Fellow in the Business, Markets and the State Cluster at IDS. Prior to joining IDS, he directed programmes in Ethiopia promoting access to and adoption of improved agricultural technologies by smallholder farmers. He was a Research Scientist at the International Livestock Research Institute (ILRI), Nairobi, and a Research Fellow at the Open University, UK.

Tarila Marclint Ebiede is currently a Technical Expert with Conflict Management Consulting, Brussels and Research Fellow at the Centre for Research on Peace and Development, KU Leuven, Belgium. Tarila has previously worked as a researcher at the European Centre for Development Policy Management, Maastricht and the Centre for the Study of the Economies of Africa, Abuja. Tarila's current research is focused on the reintegration of ex-combatants, youth employment programmes, and security and governance in communities affected by armed conflicts. Tarila holds a PhD in Social Sciences (KU Leuven, Belgium). He has received a Marie Curie Fellowship from the European Union.

Dominic Glover is an IDS Fellow at the University of Sussex, Brighton, UK and a member of the Economic and Social Research Council (ESRC) Social, Technological, and Environmental Pathways to Sustainability (STEPS) Centre. He is an interdisciplinary social scientist working in international development studies, using conceptual frameworks and methodological approaches drawn from science, technology, and society studies; geography; sociology; and anthropology. Dominic has over 18 years' experience in research, teaching, and communication, with a focus on technology and agrarian change in small-scale farming systems in low- and middle-income countries including India, the Philippines, Madagascar, Nepal, Kenya, and Ethiopia.

Simbarashe Gukurume is a $\mathrm{PhD}$ candidate at the Institute for Humanities in Africa (HUMA), University of Cape Town and a Matasa Fellow. Simbarashe is finalising his $\mathrm{PhD}$ in Sociology. His thesis explores the complex entanglements between young people's futures, politics, and religiosity within university spaces, examining how young people's political, religious, and aspirational subjectivities are reconfigured in contexts of socioeconomic and political crisis and uncertainties. Simbarashe also holds an MSc in Sociology and Social Anthropology and a BSc in Sociology from the University of Zimbabwe. His research interests focus more broadly on the politics of young people's everyday lives and livelihoods in various spaces. 
Rita Makumbi is the Director of the Quality Assurance directorate at Ndejje University. She is also the Chairperson of the Uganda Universities Quality Assurance Forum and the President of the East African Quality Assurance Network. Previously, she was the Director of the Graduate School at Ndejje University. Rita graduated with a PhD in Management at Nkumba University, Uganda. Her research interests are economic growth and development, education value and youth enhancement, and policy management. The focus of her $\mathrm{PhD}$ project was to find the extent to which the National Youth Policy was able to create jobs for the youth in Uganda.

John Muchira is a $\mathrm{PhD}$ candidate in Sociocultural and International Development Education Studies, Florida State University, completing his dissertation on Kenyan entrepreneurship education. Gurrently, he is working in the Office of the Provost and Executive Vice-President of Academic Affairs in the Critical Thinking Initiative. John is a recipient of several scholarships and awards, including the Fulbright scholarship. He is also a Business Model competition finalist at the Jim Moran Institute for Global Entrepreneurship, and won a scholarship to participate in the European Entrepreneurship Summer School, the Netherlands. His research interests are in entrepreneurship development, innovation, youth livelihoods, policy experimentation, and curriculum reforms.

Marjoke Oosterom (PhD) is a Research Fellow at IDS, and has a background in comparative politics and development studies. Her research concentrates on the effects of experiences of conflict, violence, and displacement on citizenship and agency, with a specific focus on youth. Within the IDS Youth Employment and Politics theme, her research has focused on the politics of the informal economy and youth employment interventions, in east and southern Africa. Marjoke is involved in advisory services for policymakers and international NGOs working on governance and citizen participation, youth politics and security, and civic space.

Gertrude Dzifa Torvikey is a year four $\mathrm{PhD}$ student at the Institute of Statistical, Social and Economic Research (ISSER), University of Ghana where she is pursuing Development Studies. She holds an MPhil in Migration Studies and a BA in French. She previously worked as a teaching assistant at the Centre for Gender Studies and Advocacy at the University of Ghana and as a research assistant on projects such as Land and Agricultural Commercialisation in Africa (LACA), Agriculture Policy Research in Africa (APRA), DEMETER, and Migrating out of Poverty (MoP) amongst others. Her research interests include agrarian livelihoods, migration, gender, and youth-related issues.

Tesfamicheal Wossen is an economist at the International Institute of Tropical Agriculture (IITA), Nairobi, Kenya. His research interests cover development economics issues including adoption and impact of agricultural technologies, analysis of climate change impacts, 
impact evaluation with applied econometrics, and the development of entrepreneurship. Tesfamicheal has a BA in Economics (Mekelle University, Ethiopia, 2006). He received his MSc in 2010 and $\mathrm{PhD}$ in 2015 (University of Hohenheim, Germany). Prior to joining IITA in 2015, he was a postdoctoral Fellow with the International Center for Tropical Agriculture (CIAT), and consultant with the Food and Agriculture Organization of the United Nations (FAO).

Jerusalem Yibeltal Yizengaw is a $\mathrm{PhD}$ graduate from Addis Ababa University in the field of International and Comparative Education (ICE). Jerusalem is an alumna of the World Bank's McNamara Scholarship programme, and formerly Head of the college Gender Office, Addis Ababa University. She now works full-time as an Assistant Professor of ICE and is co-founding a PhD programme in Bahir Dar University. She holds an MA in Curriculum and Instruction, and has received an award from the Research Institute of the Federal Supreme Court, Addis Ababa. Her areas of research interest include the graduate labour market, youth employment, globalisation, aid, gender, and educational policies. 


\section{Clementina Oluwafunke Ajayi In Memoriam}

Clementina Oluwafunke Ajayi was a Matasa Fellow of our second cohort, selected in December 2017 alongside seven other talented young African scholars from a competitive field of nearly 200 applicants.

Clementina was working as the Coordinator of the Agropreneurial Laboratory, and was a staff member of the Department of Agricultural and Resource Economics at the Federal University of Technology, Akure, Nigeria (FUTA). She was completing her PhD thesis on Food Insecurity Transitions among Rural Households in Nigeria.

Before embarking on her PhD studies, Clementina worked for nine years in the banking sector, where she could have pursued a successful and remunerative professional career. She decided to take a different direction.

Clementina greatly impressed the Matasa selectors with the clarity and coherence of her application, her compassion for the young Nigerians with whom she worked, and her commitment to work hard for the sustainable development of her country and all Africans.

Clementina's Matasa article was to be about the potential of Nigeria's poultry sector to create jobs for young people and stimulate private sector growth.

Clementina Ajayi died from complications during childbirth on 10 May 2018. She was buried in her home town, Ife. Her baby, a son, survived.

Messages of condolence received from members of the Matasa 2 cohort spoke warmly about their new friend Clementina, as well as their shock and sadness at losing her companionship part way through the Matasa journey. The messages celebrated and mourned the loss of Clementina's energy, enthusiasm, intelligence, determination, diligence, kindness, and lively humour.

On behalf of everyone involved in the Matasa Fellows Network, we offer our sincere condolences to Clementina's husband and family. 


\title{
Introduction: Youth Employment and the Private Sector in Africa" ${ }^{*}$
}

\section{Seife Ayele, ${ }^{1}$ Marjoke Oosterom ${ }^{2}$ and Dominic Glover ${ }^{3}$}

\begin{abstract}
This introductory article of the IDS Bulletin maps out the African youth employment challenge from a policy perspective. While policymakers have endorsed the role of the private sector as a job generator, it remains unclear whether, and under what conditions, the formal private sector generates enough and decent jobs. This IDS Bulletin begins to fill that gap. Contributors address questions including: to what extent do formal private enterprises create decent, secure jobs for young people? What obstacles do young adults face when trying to access jobs in the formal private sector? What additional difficulties are present in fragile and conflict-affected settings? And, how can policies ensure the formal private sector does not reproduce and entrench insecure and vulnerable employment? The articles in this issue demonstrate the importance of effective policy measures to ensure that private sector growth creates sufficient numbers of decent, secure jobs to provide employment to African youth.
\end{abstract}

Keywords: unemployment, underemployment, formal and informal jobs.

\section{Introduction}

Around the world, policy actors worry about youth unemployment and underemployment ${ }^{4}$ (e.g. World Bank 2015; ILO 2012; OECD 2013). Almost 43 per cent of the global youth labour workforce is either unemployed, or working but nonetheless living in poverty. On the African continent, 12 million young people enter the labour force each year, while annually only 3 million new jobs are created (AfDB 2017). Especially in sub-Saharan Africa, the challenge is not so much youth unemployment as it is underemployment. ${ }^{5}$ Few young people in Africa can afford to remain idle and the vast majority are working very hard, maintaining several livelihood activities (Munive 2010; Mwaura 2017). They are, however, mainly engaged in informal employment and entrepreneurship, with low productivity, insecure incomes, and low rates of pay (AfDB et al. 2012). Policymakers express a sense of urgency about getting youth into productive work, and preferably into formal jobs, in order to seize the potential 'demographic dividend' of a comparatively young population (Canning, Raja and Yazbeck 2015). Policymakers 
outside Africa are also eager to see young Africans enter employment, based on the assumed linkages between youth unemployment, regional instability, and out-migration, particularly to Europe (Oosterom 2018).

A dominant policy approach to youth unemployment and underemployment has been the funding of skills-building programmes that seek to enhance the employability of young jobseekers (AfDB 2016, 2017; Blattman and Ralston 2015; Fox and Kaul 2017). This approach implies that Africa's youth employment challenge is primarily a problem stemming from the unemployability of young people, rather than a problem of too few jobs. Economic growth to date has, however, not contributed significantly to the creation of formal jobs in the private sector. In the low- and lower-middle-income countries of sub-Saharan Africa, 50 per cent of formal wage jobs are still in the public sector (Filmer and Fox 2014). The outlook for the region is uncertain. Even if sub-Saharan African countries continue to experience sustained economic growth, most of them start from such a low base that they will struggle to absorb the rapidly growing labour force (ibid.).

The private sector has an important role to play in economic transformation, and there is an emerging shift within donors and institutions such as the African Development Bank Group (AfDB) to involve the private sector in addressing youth unemployment (AfDB 2016). In fact, in 2013, the AfDB stated that 'A vibrant private sector is the engine of growth which generates decent jobs...' (AfDB 2013b: 1). However, it is unclear to what extent private sector growth generates jobs for youth; whether youth have any specific disadvantages when it comes to accessing formal employment in the private sector; and to what extent the private sector will generate decent jobs (Blattman and Dercon 2016; Filmer and Fox 2014: 44). ${ }^{6}$ These are issues addressed by the contributors to this IDS Bulletin.

The articles in this issue have been authored by the second cohort of young African scholars who are part of the Matasa Fellows Network, convened by the Institute of Development Studies (IDS) in collaboration with Mastercard Foundation. ${ }^{7}$ The first group of Matasa Fellows examined the youth employment challenge in Africa from several perspectives, including critically engaging with the policy focus on youth entrepreneurship (IDS Bulletin 48.3, 2017 $)$. In this round, seven early-career academics from Ethiopia, Ghana, Kenya, Nigeria, Uganda, and Zimbabwe were selected from a strong field of applicants to consider the role that could be played by the formal private sector in job creation. They have unpacked and interrogated a range of conceptual and practical issues that policy actors will need to be aware of when aiming to support the private sector for the purpose of creating jobs for youth.

The rest of this article is organised as follows. The next section explains the policy environment of current youth employment interventions, especially for Africa. Section 3 examines the potential and actual role of the private sector in addressing youth unemployment and underemployment, and Section 4 introduces the individual articles in this IDS Bulletin. 


\section{From a 'crisis of youth' to a 'crisis of jobs'}

Globally, governments, development agencies, and inter-governmental institutions such as the development banks have spent millions of dollars on youth-oriented programmes, particularly skills-building interventions that seek to enhance the employability of youths, or build their entrepreneurial capabilities. For instance, the World Bank Group and its recipient governments invested nearly US $\$ 9$ billion in over 90 skills-training projects between 2002 and 2012 (Blattman and Ralston 2015). Such programmes are relatively easy to design and implement, and their 'impacts' can be measured in terms of a tally of youths who participated in training. ${ }^{9}$ However, the majority of skills-building programmes have failed to create employment or increase earnings, particularly in the medium and longer term (Blattman and Dercon 2016; Blattman and Ralston 2015; Fox and Kaul 2017).

Matasa Fellows have highlighted other problems: many African youths face barriers to access such programmes; the programmes often fail to meet young adults' aspirations; and programme implementation is frequently disrupted by corruption and 'micropolitics' (Mgumia 2017; Sikenyi 2017). Furthermore, there is little evidence that youth employment interventions have a 'spillover effect' in reducing violence in fragile and conflict-affected settings (FGAS) (Brück et al. 2016). Typically, youth employment interventions do not integrate the challenging political and institutional factors that characterise fragile settings, and lack an adequate theory of change (ibid.; Cheema 2017).

Policy actors are becoming more aware of the shortcomings of skills-building interventions and efforts are underway to shift the attention to focusing on how to promote productivity, boost the private sector, and generate the kind of growth that could create jobs (Flynn et al. 2016). This raises new questions. One immediate challenge relates to the architecture of governments and donor agencies, as departments and agencies dealing with youth issues need to engage with those focusing on trade, private sector development, and economic growth. Since there is little evidence on specific issues and needs of youth in relation to the private sector, it is unclear how private sector growth strategies can respond to youth-specific challenges. To our knowledge, only a few studies have systematically compared employment outcomes for youths recruited into formal employment and those that were not offered jobs (Blattman and Dercon 2016).

One study, which focused on expanding new industries in Ethiopia, showed that youth recruited into jobs with firms were likely to leave formal employment within a matter of months, due to low wages and hazardous working conditions. Many of the youths who had pursued other options were better off than those who had spent more time in employment with firms, and some explicitly preferred to take up informal, entrepreneurial activities that offered them greater flexibility and, in some cases, better money (ibid.). A fundamental question is thus whether the private sector will generate jobs of sufficient quantity, 
security, and quality. The next section will contextualise the role of the private sector in job generation in Africa.

\section{The private sector and youth employment}

In many African countries, the private sector started to grow shortly after independence, while some African governments promoted state-owned and state-led enterprise (AfDB 2011; Page 2017). In Ethiopia, for example, nationalisation of land and relatively large-scale manufacturing and service enterprises by the 1974-91 socialist government left a diminutive formal private sector, with a large informal sector running alongside it (Ayele et al. 2016). This experience was echoed across a large part of Africa (Page 2017). However, improved macroeconomic conditions and private sector liberalisation since the late 1980s are said to have contributed to the new growth of private sector enterprises (AfDB 2011; Page 2017). Rapid economic growth in Africa, in combination with poverty reduction, over the period 2000-14, fuelled optimism that Africa would emerge as a prosperous continent and enjoy the fruits of development (see e.g. Filmer and Fox 2014). However, rates of unemployment and underemployment, particularly among youth, remain high.

The private sector evidently has a key role to play in the eventual structural transformation of African economies (Fox and Thomas 2016). It is also widely accepted that private enterprises play an important role in job creation (ILO 2017b). However, there is a lack of data on the size and characteristics of the private sector, both at national and continental levels. One of the few continental-level studies shows that the informal and formal private sectors combined account for over three-quarters of the continent's production, two-thirds of its investment, and 90 per cent of its employment (AfDB 2011). In 2011, Kenya had around 11 million people employed in the private and public sector, but only 2 million of these were in formal employment, of which some 68 per cent (or 1.4 million jobs) were within the formal private sector (AfDB 2013a). The great majority of private sector activities in Africa are, however, informal, of which household enterprises of various kinds constitute a large part (Filmer and Fox 2014: 15).

The International Labour Organization's (ILO) most recent report identifies enterprise size as a key factor determining the private sector's contributions to the generation of jobs (ILO 2017b). This is not surprising, as size is an important factor in shaping a firm's internal and external strategy - its organisation of inputs and production, including its human resource strategies. However, criteria and thresholds for enterprise size vary by country (and within countries, by sector), and different classifications are used by different international organisations (ILO 2017b; AfDB 2017). Often, enterprises are categorised as micro, small, medium and large (and sometimes as compounds of two or three sizes, such as the commonly used category 'small- and medium-sized enterprises' (SMEs). 
For the purposes of this IDS Bulletin, we do not endorse any particular system of size classification; however, to take an example, the ILO's definition is that micro-enterprises are firms with fewer than five employees, small enterprises are firms with between five and 19 employees, medium-sized enterprises are firms with between 20 and 99 employees, and large enterprises are those with 100 or more employees (ILO 2017b). Most of the youths employed in Africa are working in family businesses, whether formal or informal, which are typically in the micro and small enterprise range. Some workers in such enterprises are paid wages, while others receive payment in-kind or no payment at all (ibid.). Labour-intensive manufactured exports, which can potentially drive employment creation and economic transformation, are typically not significant in most parts of Africa (Fox and Kaul 2017; Fox, Senbet and Simbagenavi 2016).

In low- and lower-middle-income countries of Africa, formal employment exists primarily in the public sector; it is mainly in middle-income countries that the private sector produces more than half of the wage jobs (Filmer and Fox 2014). Filmer and Fox write that: 'over the next 10 years, at best only one in four of sub-Saharan Africa's youth will find a wage job, and only a small fraction of those jobs will be "formal" jobs in modern enterprises. Most young people will end up working where their parents do - in family farms and household enterprises' (2014: 5).

A more recent development is the introduction of digital platforms by private companies, which are transforming how youth are engaging in the private sector. In East African countries such as Kenya and Uganda, private sector transport companies such as Uber and Taxify have become involved in a large sector that was previously almost wholly informal: motorcycle taxis (Rosen 2017). While policy actors are enthusiastic about this formalisation of an informal sector of the economy, the implications for the young workers typically employed in the motorbike taxi industry are unclear. Often, the contractual terms and conditions of these companies and platforms do not meet the criteria for 'decent work' (ILO 2017a; Graham, Hjorth and Lehdonvirta 2017). These facts offer a sobering perspective on emerging policy narratives that promote private sector growth as the key to addressing the youth employment challenge. It is important to specify which sectors of private enterprise activity, in which economic contexts, are likely to generate secure and decent jobs for youth.

Analysts believe that investments in agricultural productivity (in smallholder farms and rural household enterprises) could enable the formal private sector to grow (Filmer and Fox 2014). A majority of African youths find themselves working in the agricultural sector in some capacity, while growing up and as adults. As with other sectors of the economy, interventions are often based on the assumption that fixing problems among youths is central to addressing the employment challenge. This is to ignore structural constraints that impede agricultural 
transformation, including the lack of policies and investments that can drive innovation and productivity improvements in rural areas (Sumberg et al. 2015; Sumberg and Okali 2013). There is also limited evidence on the long-term impacts of interventions that offer access to skills training and loans for rural youth (Sumberg et al. 2012).

Rarely are youth employment strategies linked to a discussion of political context. Youth employment challenges often look different in lower-income countries compared to resource-rich and middle-income countries (Filmer and Fox 2014; Fox and Kaul 2017). In middle-income countries where structural transformation of the economy is underway, the demand for labour (including youth labour) can be stimulated by policies and projects that increase enterprise growth and productivity. However, countries that are classified as 'fragile' and those with rentier economies are unlikely to develop formal enterprises at scale, and here it may be futile to offer skills trainings to young people for wage jobs that are unlikely to emerge (Fox and Kaul 2017). Especially in FCAS, uncertainty due to political instability and the absence of strong state regulation discourages private sector investment, except for those actors who possess economic and political power (Blattman and Ralston 2015). This politicisation of economic life in FCAS shapes access to employment opportunities by youth, who are often at the mercy of rent-seeking behaviour by more powerful economic actors (Enria 2015; Utas 2012). In countries where dominant parties control economic resources and access to government schemes, including those earmarked for youth, young people have limited freedom to grow their businesses independently from politically linked patronage systems (Gebremariam 2017; Hansen 2010; Oosterom forthcoming, 2019).

\section{Introduction to the articles}

Empirical research on youth employment in the private sector is sparse (Filmer and Fox 2014). The contributors to this IDS Bulletin explore the scope of the research and policy challenges in three specific areas: agribusiness and youth employment; skills gaps and youth employability; and youth employment in fragile and conflict-affected settings, discussing case studies from Ethiopia, Ghana, Kenya, Nigeria, Uganda, and Zimbabwe. While some aspects of the youth employment challenge are common to all six countries, the local contexts and situations are unique. In particular, the dynamics of youth employment are sectoral.

Three of the articles deal with agribusinesses and agricultural value chains. Agricultural and other livelihoods in rural areas have received relatively less attention (Sumberg and Okali 2013). However, the fact remains that a majority of young people in Africa find themselves working in agriculture at some point and in some capacity. Tesfamicheal Wossen and Seife Ayele (this IDS Bulletin) use macroeconomic evidence to explore the growth of the agribusiness sector and its links to youth employment in Ethiopia. The article tracks the movement of labour from subsistence or small-scale family farming into agribusiness enterprises, as well as into the manufacturing and service sectors. 
Emerging agribusinesses are generating more jobs for youth, but a number of challenges such as low wages, skills gaps, and inflexible systems of land ownership and transfer put a brake on growth and job creation. Targeted policy reforms could incentivise private agribusiness investments, address sectoral constraints, target skills and wage gaps, and improve institutions that govern land ownership and tenure.

Gertrude Dzifa Torvikey (this IDS Bulletin) uses a case study of the Blue Skies company, a processor and exporter of fruit products, to consider the connections between private sector growth, youth employment, and labour casualisation in Ghana. The casualisation of formal employment is in tension with the assumption that private sector growth is likely to generate decent jobs, encompassing aspects such as health and safety, job security, autonomy, and fair wages, which young people seek from paid work (Blattman and Dercon 2016; Filmer and Fox 2014: 44). Torvikey shows that, in spite of the company's success in creating jobs for youths, particularly for young women, global competition in fruit production and export has undermined the company's ability to sustain secure jobs for the bulk of its workforce.

The article by Rita Makumbi (this IDS Bulletin) scrutinises Uganda's Youth Livelihood Programme and Youth Livelihood Fund, which are intended to support youth enterprise and job creation by extending grants to small groups of young entrepreneurs, to start small businesses that are expected to grow and provide employment. Makumbi focuses particularly on the maize value chain in Uganda, and shows that the Programme and Fund have fallen short of their goals in various respects, due largely to design problems and weaknesses in the administration of the scheme. She recommends that the Ugandan government be more proactive in identifying opportunities within the maize value chain to create higher skilled and more remunerative employment for youth. Additional measures are needed in a range of areas, such as raising awareness of job opportunities in the maize value chain; enhancing vocational and entrepreneurial skills; and also improving the functioning of higher-level actors in the chain.

The next two articles in this IDS Bulletin examine the skills gaps that limit the employability of university graduates and school leavers, but in ways that move beyond the assumption that young people need to be targeted with employability skills-building programmes. Jerusalem Yibeltal Yizengaw (this IDS Bulletin) investigates the causes and consequences of skills gaps and skills mismatches among engineering graduates in the private construction sector in Ethiopia. Sustained growth in the Ethiopian economy has created demand for jobs in the construction sector, yet despite the number of engineering graduates seeking employment, employers complain about skills gaps that hinder their employability. Rather than argue that a special skills programme is needed, Yizengaw suggests that the problem should be solved by correcting weaknesses in the design and delivery of technical and engineering disciplines in higher education, which focus on theoretical 
knowledge. She also points out that macroeconomic instability contributes to precarity in the Ethiopian construction sector, which further limits graduate employment opportunities in that industry. Yizengaw recommends that education providers collaborate with employers to make the engineering curriculum fit for purpose.

John Muchira (this IDS Bulletin) makes a similar argument in relation to high school leavers in rural parts of Kenya. In that country, a lack of formal wage opportunities pushes school leavers into precarious and informal entrepreneurial activities, rather than formal employment. The principal problem is not that the job seekers lack skills, but that the jobs do not exist. As acquiring employable skills is a key factor for youth to progress, either as an employee or entrepreneur, Muchira argues for building partnerships between secondary schools in rural Kenya and agribusinesses to foster skills-building that will enable young people to start entrepreneurial activities in the agricultural sector.

The last two articles in this collection address youth employment in FCAS. Simbarashe Gukurume (this IDS Bulletin) outlines how Zimbabwe's protracted socioeconomic and political crisis over two decades has led to company closures, retrenchments, unemployment, and informalisation. Drawing on his studies of the experiences of youths working in SMEs in the retail and clothing sector in Harare, Gukurume argues that young people depend on their own resourcefulness and ingenuity to 'get by' in a context of highly insecure and precarious employment. Gukurume's analysis highlights the politically sensitive nature of the SME sector in Zimbabwe, which requires young people to navigate partisan politics as well.

Finally, Tarila Marclint Ebiede (this IDS Bulletin) examines the potential of Nigeria's Post Amnesty Programme (PAP) to support the employment of ex-combatants in the oil-rich Niger Delta region. Generating sustainable employment is an important part of the disarmament, demobilisation, and reintegration of young ex-combatants. Ebiede explains how the PAP has focused on training and skills development, while the design and implementation of the programme have allowed it to become an open-ended subsidy to support the incomes of unemployed and underemployed youth. Ebiede argues that the design and implementation of the programme were not informed by an adequate understanding of the local private sector in the Niger Delta, which has created a mismatch between the kind of training provided and the types of jobs actually available locally.

Overall, the articles in this IDS Bulletin underline the complexities of each country, reminding us that claims about the private sector's role in job creation are never straightforward, and that discussions need to be based on specific and contextualised understandings of what the private sector is, the nature of the jobs it creates, and its potential contribution to the economy and the livelihood opportunities of young people. 


\section{In memoriam}

Matasa Fellow Clementina Ajayi passed away suddenly in May 2018, due to complications during childbirth. We dedicate this IDS Bulletin to her memory. Readers are invited to read our tribute to Clementina on page vii.

\section{Notes}

* This issue of the IDS Bulletin was produced in partnership with Mastercard Foundation.

† We are grateful for the valuable contributions of colleagues who peer-reviewed the articles in this IDS Bulletin, including Justin Flynn, Eyob Balcha Gebremariam, Shittu Ayodele Ibrahim, Monica Lambon-Quayefio, Phil Mader, Grace Mwaura, Victoria Namuggala, Santiago Ripoll, Patrick Schröder, Maurice Sikenyi, Shova Thapa Karki, Jodie Thorpe and Thomas Yeboah. We also thank our colleagues Jim Sumberg, Vivienne Benson, Beth Richard, and Alison Norwood for their support with the Matasa Fellows programme and the production of this IDS Bulletin.

1 Institute of Development Studies, UK.

2 Institute of Development Studies, UK.

3 Institute of Development Studies, UK.

4 The definition of youth varies by country and international organisation. Unsurprisingly, contributors to this IDS Bulletin used statistical criterion which defines youth as those between 15 and 35 years. The previous IDS Bulletin on youth employment in Africa discussed the different criteria used to define youth, and the notions of unemployment and underemployment (see Ayele, Khan and Sumberg 2017).

5 Unemployment rates in sub-Saharan Africa are relatively lower than in other regions of the world, averaging 11.6 per cent across the region. Youth unemployment rates are highest in North Africa and the Middle East (30.5 per cent and 28.2 per cent respectively), and lowest in East and South Asia (10.6 per cent and 9.9 per cent respectively) (ILO 2015). Underemployment rates, on the other hand, are 'peak[ing] at just over half of youth, excluding students, in low income countries' (AfDB 2016).

6 The ILO definition of decent work includes a fair income, security in the workplace and social protection for families, better prospects for personal development and social integration, freedom for people to express their concerns, organise and participate in the decisions that affect their lives, and equality of opportunity and treatment for all women and men.

7 In 2015, Mastercard Foundation and IDS jointly launched the Matasa Fellows Network initiative, to build a network of young African researchers with the skills and commitment to engage in policy-oriented research around the challenges of youth employment in Africa. The initiative attracts talented researchers under 40 years of age, with recent $\mathrm{PhDs}$ or $\mathrm{PhDs}$ nearing completion, and supports them to develop skills of communication, policy analysis, and 
communications that are not covered in a typical $\mathrm{PhD}$ training programme. See www.matasafn.org/ for further details.

8 See Ayele, S., Khan, S. and Sumberg, J. (eds) (2017) 'Africa's Youth Employment Challenge: New Perspectives', IDS Bulletin 48.3, May 2017, http://bulletin.ids.ac.uk/idsbo/issue/view/225 (accessed 15 October 2018).

9 This point was clearly articulated by donor actors at the Wilton Park conference on 'Boosting Youth Employment in Sub-Saharan Africa: Creating Opportunities and Building Skills', South Africa, 11-23 July 2018 .

\section{References}

AfDB (2017) Fobs for Youth in Africa Strategy, Regional Ministerial Conferences on Youth Employment and Entrepreneurship in Africa, Engagement with the Regional Member Countries 18 October 2016-27 February 2017, Report, African Development Bank Group, www.afdb.org/fileadmin/uploads/afdb/Documents/GenericDocuments/Ministerial_Conferences_Report_En.pdf (accessed 18 October 2018)

AfDB (2016) Jobs for Youth in Africa. Strategy for Creating 25 Million Fobs and Equipping 50 Million Touth, 2016-2025, African Development Bank Group, www.afdb.org/fileadmin/uploads/afdb/Documents/ Boards-Documents/Bank_Group_Strategy_for_Jobs_for_Youth_in_ Africa_2016-2025_Rev_2.pdf (accessed 15 October 2018) AfDB (2013a) The State of Kenya's Private Sector, Tunis: African

Development Bank Group, http://kenyachamber.co.ke/wp-content/ uploads/2017/02/The_State_of_Kenya_s_Private_Sector.pdf (accessed 29 September 2018)

AfDB (2013b) Supporting the Transformation of the Private Sector in Africa:

Private Sector Development Strategy, 2013-2017, Africa Development Bank Group, www.afdb.org/fileadmin/uploads/afdb/Documents/ Policy-Documents/2013-2017_-_Private_Sector_Development_ Strategy.pdf (accessed 26 July 2018)

AfDB (2011) Private Sector Development as an Engine of Africa's Economic Development, African Development Report 2011, Tunis: Africa

Development Bank Group, www.afdb.org/fileadmin/uploads/afdb/ Documents/Publications/African \%20Development $\% 20$ Report $\% 20$ 2011.pdf (accessed 26 July 2018)

AfDB, OECD, UNDP and UNECA (2012) African Economic Outlook 2012, Special Theme: Promoting Youth Employment, Paris: OECD Publishing, www.undp.org/content/dam/rba/docs/Reports/ African\%20Economic\%20Outlook\%202012\%20En.pdf (accessed 18 October 2018)

Ayele, S.; Khan, S. and Sumberg, J. (2017) 'Introduction: New Perspectives on Africa's Youth Employment Challenge', IDS Bulletin 48.3: 1-12, http://bulletin.ids.ac.uk/idsbo/article/view/2878 (accessed 15 October 2018)

Ayele, S.; Mader, P. and Thorpe, J. with Gu, J.; Morales, M.M. and Reed, P. (2016) State-Business Relations Beyond Growth: Bringing in 
Development, IDS Evidence Report 215, Brighton: IDS, https://opendocs.ids.ac.uk/opendocs/handle/123456789/12686 (accessed 18 October 2018)

Blattman, C. and Dercon, S. (2016) Occupational Choice in Early Industrializing Societies: Experimental Evidence on the Income and Health Effects of Industrial and Entrepreneurial Work, NBER Working Paper 22683, Cambridge MA: National Bureau of Economic Research, www.nber.org/papers/w22683.pdf (accessed 15 October 2018)

Blattman, C. and Ralston, L. (2015) Generating Employment in Poor and Fragile States: Evidence from Labour Market and Entrepreneurship Programs, www.povertyactionlab.org/sites/default/files/publications/ Blattman_Employment\%20Lit\%20Review.pdf (accessed 15 October 2018)

Brück, T; Ferguson, N.T.N.; Izzi, V. and Stojetz, W. (2016) Jobs Aid Peace: A Review of the Theory and Practice of the Impact of Employment Programmes on Peace in Fragile and Conflict-Affected Countries, Berlin: International Security and Development Centre, http://isd-center.org/wpcontent/uploads/2016/09/Employment-Interventions-and-PeaceFinal-Report-Final-Version-2016-09-16.pdf (accessed 18 October 2018)

Canning, D.; Raja, S. and Yazbeck, A.S. (2015) Africa's Demographic Transition: Dividend or Disaster?, Washington DC: World Bank, https://elibrary.worldbank.org/doi/abs/10.1596/978-1-4648-0489-2 (accessed 3 October 2018)

Cheema, A. (2017) The Political Economy of Economic Empowerment: Bringing Politics and Society Back In, IDS Working Paper 484, Brighton: IDS, www.ids.ac.uk/publications/the-political-economy-of-economicempowerment-bringing-politics-and-society-back-in/ (accessed 18 October 2018)

Enria, L. (2015) 'Love and Betrayal: The Political Economy of Youth Violence in Post-War Sierra Leone', Journal of Modern African Studies 53.4: $637-60$

Filmer, D. and Fox, L. (2014) Youth Employment in Sub-Saharan Africa, Washington DC: World Bank, https://openknowledge.worldbank. org/bitstream/handle/10986/16608/9781464801075.pdf (accessed 18 October 2018)

Flynn, J.; Mader, P.; Oosterom, M. and Ripoll, S. (2016) Failing Young People? Addressing the Supply-Side Bias and Individualisation in Youth Employment Programming, IDS Evidence Report 216, Brighton: IDS, www.ids.ac.uk/publications/failing-young-people-addressingthe-supply-side-bias-and-individualisation-in-youth-employmentprogramming/ (accessed 15 October 2018)

Fox, L. and Kaul, U. (2017) The Evidence is In: How Should Youth Employment Programs in Low-Income Countries be Designed?, Washington DC:

USAID, http://conference.iza.org/conference_files/

GLMLICNetwork_2017/fox_14959.pdf (accessed 18 October 2018)

Fox, L. and Thomas, A. (2016) 'Africa's Got Work To Do: A Diagnostic of Youth Employment Challenges in Sub-Saharan Africa', fournal of African Economies 25.suppl 1: i16-i36, https://academic.oup.com/ 
jae/article-abstract/25/suppl_1/i16/1750383 (accessed 18 October 2018)

Fox, L.; Senbet, L.W. and Simbagenavi, W. (2016) 'Youth Employment in Sub-Saharan Africa: Challenges, Constraints and Opportunities', Fournal of African Economies 25.suppl 1: i3-i15, https://academic.oup.com/jae/article/25/suppl_1/i3/1750431 (accessed 18 October 2018)

Gebremariam, E. (2017) 'The Politics of Youth Employment and Policy Processes in Ethiopia', IDS Bulletin 48.3: 33-50, http://bulletin.ids.ac.uk/idsbo/article/view/2868 (accessed 15 October 2018)

Graham, M.; Hjorth, I. and Lehdonvirta, V. (2017) 'Digital Labour and Development: Impacts of Global Digital Labour Platforms and the Gig Economy on Worker Livelihoods', Transfer: European Review of Labour and Research 23.2: 135-62

Hansen, K.T. (2010) 'Changing Youth Dynamics in Lusaka's Informal Economy in the Context of Economic Liberalization', African Studies Quarterly 11.2-3: 13-27, http://sites.clas.ufl.edu/africa-asq/files/ Hansen-Voll 1Is2-3.pdf (accessed 18 October 2018)

ILO (2017a) Decent Work and the 2030 Agenda for Sustainable Development, Geneva: International Labour Organization, www.ilo.org/wcmsp5/ groups/public/---dgreports/---dcomm/documents/publication/ wcms_436923.pdf (accessed 19 September 2018)

ILO (2017b) World Employment and Social Outlook 2017: Sustainable Enterprises and Fobs: Formal Enterprises and Decent Work, Geneva: International Labour Office, www.ilo.org/wcmsp5/groups/ public/---dgreports/---dcomm/---publ/documents/publication/ wcms_579893.pdf (accessed 26 July 2018)

ILO (2015) Global Employment Trends for Youth 2015: Scaling Up Investments in Decent fobs for Youth, Geneva: International Labour Office, www.ilo.org/wcmsp5/groups/public/---dgreports/---dcomm/--publ/documents/publication/wcms_412015.pdf (accessed 15 October 2018)

ILO (2012) The Touth Employment Crisis: A Call for Action, Resolution and Conclusions of the 101st Session of the International Labour Conference, Geneva, 2012, Geneva: International Labour Office, www.ilo.org/wcmsp5/groups/public/---ed_norm/---relconf/ documents/meetingdocument/wcms_185950.pdf (accessed 18 October 2018)

Mgumia, J.H. (2017) 'Programme-Induced Entrepreneurship and Young People's Aspirations', IDS Bulletin 48.3: 155-70, http://bulletin.ids.ac.uk/idsbo/article/view/2876 (accessed 15 October 2018)

Munive, J. (2010) 'The Army of Unemployed Young People', Young 18.3: 321-38

Mwaura, G. (2017) 'The Side Hustle: Diversified Livelihoods of Kenyan Educated Young Farmers', IDS Bulletin 48.3: 51-66, http://bulletin.ids.ac.uk/idsbo/article/view/2869 (accessed 15 October 2018) 
OECD (2013) The OECD Action Plan for Youth: Giving Youth a Better Start in the Labour Market, Paris: Organisation for Economic Co-operation and Development, www.oecd.org/els/emp/Youth-Action-Plan.pdf (accessed 18 October 2018)

Oosterom, M. (forthcoming, 2019) 'Youth and Social Navigation in Zimbabwe's Informal Economy: "Don't End up on the Wrong Side" ', African Affairs

Oosterom, M. (2018) Youth Employment $\Xi$ Citizenship: Problematising Theories of Change, K4D Emerging Issues Report, Brighton: IDS, https://opendocs.ids.ac.uk/opendocs/handle/123456789/13620 (accessed 15 October 2018)

Page, J. (2017) 'Industrial Policy in Africa: From State Leadership to the Investment Climate', in Joseph Stiglitz et al. (eds), Industrialize Africa: Strategies, Policies, Institutions, and Financing, Abidjan: African Development Bank Group

Rosen, J. (2017) 'Uganda's "Uber for Motorcycles” Focuses On Safety', MIT Technology Review, 3 April, www.technologyreview. $\mathrm{com} / \mathrm{s} / 604013 /$ ugandas-uber-for-motorcycles-focuses-on-safety/ (accessed 3 October 2018)

Sikenyi, M. (2017) 'Does Kenya's Youth Enterprise Development Fund Service Young People?', IDS Bulletin 48.3: 127-40, http://bulletin.ids.ac.uk/idsbo/article/view/2874 (accessed 15 October 2018)

Sumberg, J. and Okali, C. (2013) 'Young People, Agriculture, and Transformation in Rural Africa: An "Opportunity Space" Approach', Innovations 8.1-2: 259-69, https://opendocs.ids.ac.uk/ opendocs/handle/123456789/3150 (accessed 18 October 2018)

Sumberg, J. et al. (2015) 'Young People, Agriculture and Employment in Rural Africa', in D. Resnick and J. Thurlow (eds), African Youth and the Persistence of Marginalization: Employment, Politics and Prospects for Change, Abingdon and New York NY: Routledge

Sumberg, J.; Anyidoho, N.A.; Leavy, J.; te Lintelo, D.J.H. and Wellard, K. (2012) 'Introduction: The Young People and Agriculture "Problem" in Africa', IDS Bulletin 43.6: 1-8, http://bulletin.ids.ac.uk/idsbo/article/view/265 (accessed 15 October 2018)

Utas, M. (ed.) (2012) African Conflicts and Informal Power: Big Men and Networks, London: Zed Books, www.diva-portal.org/smash/get/ diva2:506340/FULLTEXT01.pdf (accessed 18 October 2018)

World Bank (2015) Toward Solutions for Youth Employment: A 2015 Baseline Report-Overview, Washington DC: World Bank, https://openknowledge.worldbank.org/handle/10986/23262 (accessed 15 October 2018) 


\title{
Ethiopia's Agricultural Transformation: Agribusiness' Contribution to Reducing Youth Unemployment
}

\author{
Tesfamicheal Wossen ${ }^{1}$ and Seife Ayele ${ }^{2}$
}

\begin{abstract}
This article explores empirical evidence on the relationship between agricultural transformation, ownership structure of agribusinesses, and employment creation in Ethiopia. It draws on secondary data to present evidence of Ethiopia's agricultural transformation, employment trends, and the agribusiness sector's contribution to employment generation. The country's agricultural sector has shown signs of transformation in the form of both labour movement to the more productive manufacturing and services sectors, and productivity growth through the commercialisation and creation of agribusinesses. The findings suggest that the growing number of agribusinesses are generating more jobs for youth but also reveal a number of challenges to overcome, such as skills gaps, low pay in the private sector, and inflexible land ownership and transfer processes. The study suggests targeted policy reforms to incentivise efficient and competitive private agribusinesses, and to address agribusiness-related constraints, skills and wage gaps, as well as land ownership and rental market constraints.
\end{abstract}

Keywords: agribusiness, private sector, youth, (un)employment, agricultural transformation, land ownership, agriculture, labour productivity, micro and small enterprises.

\section{Introduction}

Africa has the largest youth population (15-35 years old) in the world (AfDB 2016), representing 35 per cent (approximately 420 million individuals) of the continent's 1.2 billion population. Each year, 10-12 million youths join the continent's labour force (AfDB 2016; Fox and Thomas 2016) but only 3 million formal jobs are created annually (AfDB 2016). This mismatch between labour demand and supply in the formal sector poses a significant challenge to policymakers as the youth population is expected to double to over 830 million by 2050, a phenomenon commonly referred to as the 'youth bulge' (Evoh 2012; 
AfDB 2016; Ayele, Khan and Sumberg 2017). In fact, in sub-Saharan Africa (SSA), youth are three times more likely to be unemployed compared to adults (AfDB 2016; Fox and Thomas 2016). Even among employed youth, only 17 per cent are in paid employment whereas the rest are engaged in vulnerable employment such as unpaid family work and self-employment activities (AfDB 2016).

In Ethiopia, youth (persons aged 15-29) unemployment is a major concern (CSA 2015a; Gebremariam 2017). Data from the Central Statistical Agency also suggest that youth, particularly in urban areas, are four times more likely to be unemployed than adults (CSA 2014). Seventy per cent of youth live in rural areas where agriculture forms the basis of livelihoods (Bezu and Holden 2014). In this regard, it is critical to examine how the agribusiness sector - which encompasses the full range of activities such as input suppliers, farm producers, and agri-processors to wholesalers and retailers - could drive job opportunities for youth, given the importance of Ethiopia's agricultural sector. As the country's growing number of agribusinesses are generating more jobs, understanding the role of agribusiness is also vital as future employment generation and expansion are expected to be in this sector (AfDB 2016; Moller 2015; World Bank 2016).

Prior to 1991, the private sector in Ethiopia played an insignificant role in employing youth due to the government's centralised recruitment and deployment of employees to publicly owned companies (Blattman and Dercon 2018). Moreover, nationalisation of land and large-scale manufacturing and service industries by the 1974-91 socialist government left a diminutive formal private sector, with a large informal sector running alongside it (Ayele et al. 2016). In fact, during this time, more than 75 per cent of the youth in formal wage work were employed by the public sector (Krishnan 1996). Since 1991, the government has undertaken two main reforms: (1) privatisation of state-owned enterprises, and (2) giving special incentives to the private sector to promote growth, in the form of subsidised credit services, tax breaks, and preferential land leases (Moller 2015; World Bank 2016; Blattman and Dercon 2018). Because of such incentives and other factors, the number of privately owned agribusinesses has increased; for example, the number of farms in the cut flower sector grew from five to over 100 (Schaefer and Abebe 2015; Ayele et al. 2016). However, the role that such private enterprises have played in creating employment opportunities for youth is not well documented.

This article views agricultural transformation as: (1) within- and between-sector productivity growth, and (2) a process that drives job creation and economic diversification in agriculture-dependent countries such as Ethiopia (Dercon and Gollin 2014; Ligon and Sadoulet 2018; Diao, Hazell and Thurlow 2010). While between-sector productivity growth, a term commonly referred to as 'structural transformation', is driven by labour mobility out of the agricultural sector (to high-productivity sectors such as manufacturing and services), 
within-sector productivity growth is driven by technological changes as well as commercialisation of the agricultural sector (McMillan and Rodrik 2011). As a result, productivity growth in the agricultural sector is considered as central to development that is based on poverty reduction and food security outcomes (see e.g. Irz et al. 2001; Dercon and Gollin 2014; Ligon and Sadoulet 2018; Diao et al. 2010; McMillan and Rodrik 2011; Gollin, Lagakos and Waugh 2014; Barrett et al. 2017). In this regard, previous studies (e.g. Christiaensen, Demery and Kuhl 2011; Diao et al. 2010) have documented that agricultural transformation, especially within-sector productivity growth, is effective in reducing poverty since the agricultural sector is the largest employer of the poor. For example, Christiaensen et al. (2011) reported that growth in the agricultural sector is two to three times more effective in reducing poverty compared to the same magnitude of growth in other sectors of the economy in SSA.

Besides its role in poverty reduction, we see agricultural transformation as the main driver of job creation for youth in many ways. Higher productivity in the agricultural sector increases the supply of commodities required by agro-processors; which allows agro-processors and other industries to expand production and create additional jobs. Since such industries are more labour-intensive, they might offer better employment opportunities for the youth. In addition, agricultural transformation leads to more diversified value chains and stronger integration of producers into international, regional, and local markets (Irz et al. 2001; Moller 2015; World Bank 2016). Further, because of agricultural transformation, new institutional arrangements in the contracting and marketing of agricultural products could emerge. The emergence of such institutions along with increased local demand creates new activities and consolidates value chains, which are important drivers of job creation (O’Higgins 2017; Losch 2016; Ripoll et al. 2017). Despite the above theoretical assertions, the empirical evidence on the relationship between agricultural transformation and youth employment opportunities is very scant. This article therefore explores this relationship using empirical data from Ethiopia. Specifically, the article examines the extent of agricultural transformation in Ethiopia, and the role the emerging agribusiness sector plays in addressing the youth unemployment problem in Ethiopia.

The remainder of this article is structured in three sections. Section 2 describes the data sources and methodology used in the study. Section 3 presents and discusses the main findings. Section 4 concludes and suggests some policy recommendations.

\section{Methods and data sources}

This article employs a quantitative approach that involves analysis of agricultural transformation and youth (un)employment data. Main sources include: (1) the World Bank Development Indicators (WDI) database (World Bank 2018), which is used to generate and present evidence of agricultural transformation; (2) the National Labor Force 


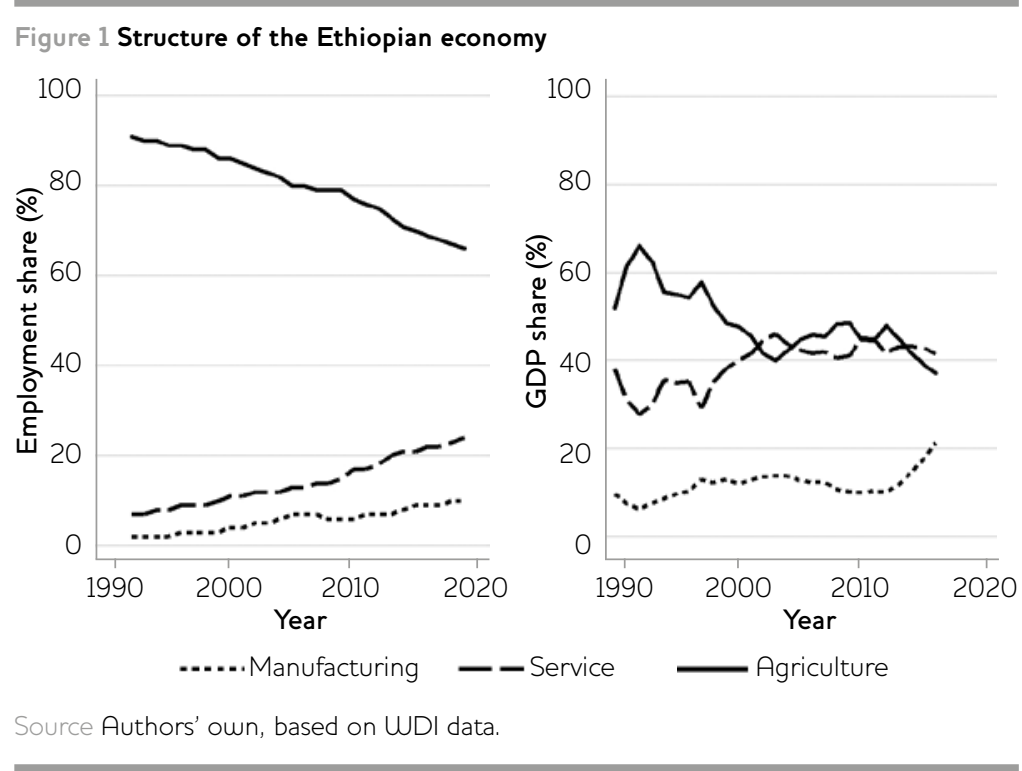

Surveys (NLFS) and Urban Employment Unemployment Surveys (UEUS), which show current employment trends in Ethiopia; (3) data from the Ethiopian Horticulture Producer Exporters Association, and surveys on small-scale manufacturing industries and largeand medium-scale manufacturing and electricity industries, which examine the relative importance of the agribusiness sector in terms of employment generation; and (4) Ethiopian Socioeconomic Survey (ESS) data, which provide micro-level evidence on youth employment and agricultural transformation. The ESS data contain detailed information about farm and non-farm activities from 5,000 Ethiopian households. The approach employed in the article provides correlations and associations but not necessarily causal links.

\section{Findings and discussion}

\subsection{Evidence of agricultural transformation in Ethiopia}

Between 2005/06 and 2015/16, Ethiopia recorded a real gross domestic product (GDP) growth rate of 10.3 per cent (Moller 2015). During the same period, real agricultural output grew by approximately 8 per cent and the incidence of poverty declined from 43 per cent to 29.6 per cent (Bachewe et al. 2018). The growth in agricultural productivity was largely due to public investments in modern inputs such as improved seeds and fertiliser, extension services, and the development of agribusiness (ibid.). As shown in Figure 1, agriculture currently contributes roughly 37 per cent to GDP and 68 per cent to employment. Between 1991 and 2016, the sector's contribution to GDP declined by 23 percentage points; however, despite this significant decline, its employment share remained high, a clear sign that the productivity of the sector is relatively low. Over the same period, the employment share of the manufacturing and service sectors increased by 8 percentage and 17 percentage points respectively. 
Figure 2 Labour productivity in the agriculture, manufacturing, and service sectors, 1991-2016

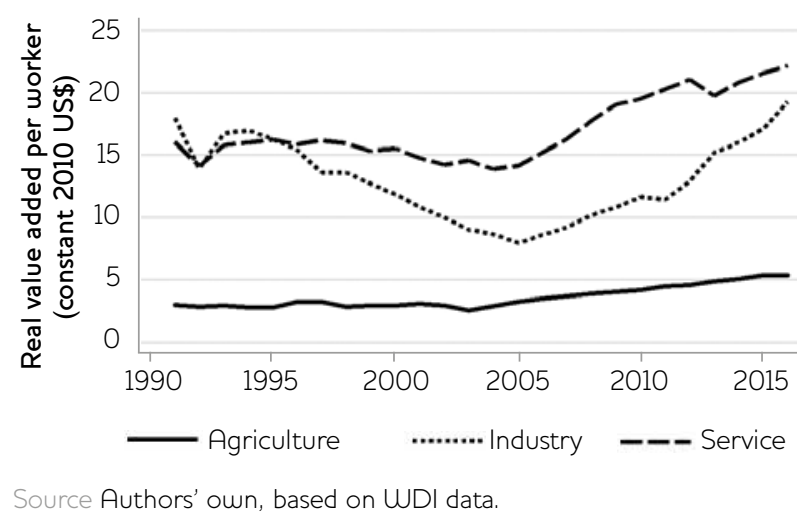

The contributions of the manufacturing and service sectors to GDP also increased during the period, by 15 percentage and 14 percentage points respectively. The changes in these two sectors, and the agricultural sector's reduced share of employment and output, are indicative of structural transformation in the country.

Figure 2 shows that real value added per worker, which measures labour productivity, increased steadily across all three sectors during the same period: ${ }^{3}$ labour productivity in the three sectors grew by an average rate of 5.9 per cent. ${ }^{4}$ However, labour productivity in the agricultural sector is still low compared to other sectors of the economy, with the manufacturing and service sectors showing 3.6 and 4.2 times higher productivity respectively in 2016; in the literature this is commonly referred to as the agricultural productivity gap (McMillan and Rodrik 2011; Gollin et al. 2014). ${ }^{5}$ However, recent evidence (McCullough 2017) suggests that the large productivity gap between the agricultural and other sectors of the economy is due to differences in hours worked across the sectors. McCullough's results suggest that agricultural workers supply fewer hours of labour per year than do workers in other sectors, underscoring the prevalence of underemployment in the agricultural sector (ibid.). Therefore, efficient agribusiness, that has a potential to reduce underemployment, would be as productive as the manufacturing and services sectors.

Further breakdown of the overall labour productivity growth from 1991 to 2016 by the World Bank suggests that 17 per cent was due to structural change (labour mobility from agriculture to other sectors); 72 per cent was due to rising labour productivity in the agriculture, manufacturing, and service sectors; and 11 per cent was due to changes in the employment rate and demographic structures (Moller 2015). Overall, the results suggest evidence of both within- and between-sector productivity growth. 


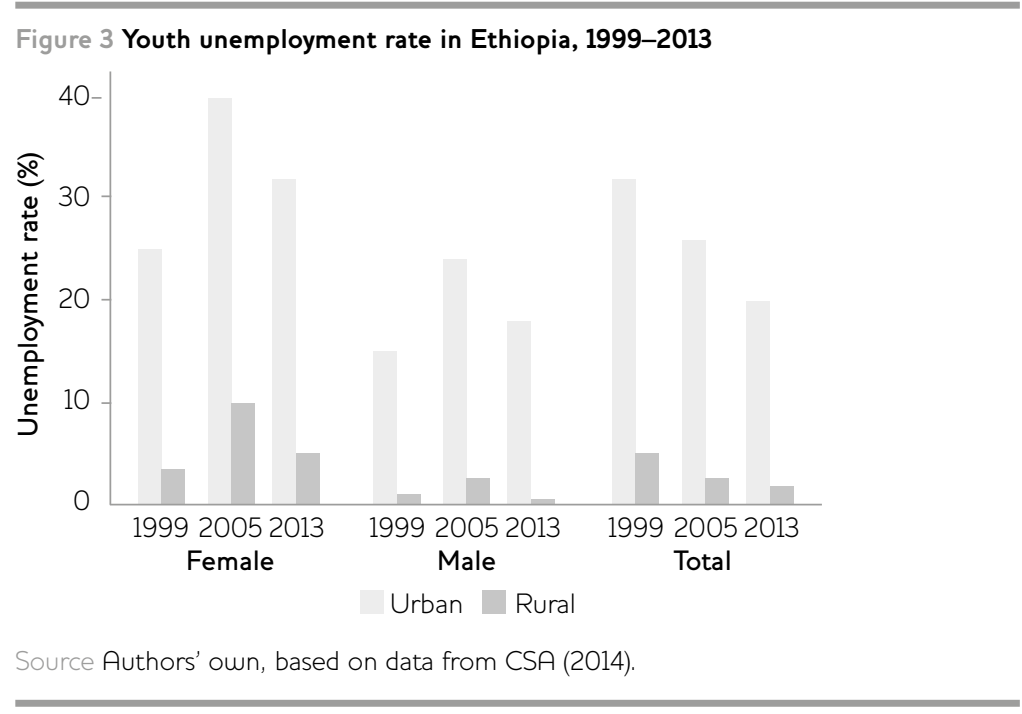

\subsection{Status of general and youth unemployment in Ethiopia}

Records show that between 1999 and 2013, the general unemployment rate in Ethiopia declined from 9 per cent to approximately 5 per cent (CSA 2014). The unemployment rate in rural areas is quite low (below 3 per cent as of 2013), due mostly to the prevalence of unpaid family work and self-employment activities; however, CSA (2014) data suggest that 27 per cent of the employed individuals in rural areas are underemployed. Urban unemployment is much higher (approximately 20 per cent in 2013). In Ethiopia, only a very small percentage of individuals work in paid employment, particularly in the rural areas. Those who are not in paid employment are either self-employed or unpaid workers in family ventures. According to CSA (2015a), at the national level, only 10 per cent of people are in paid employment.

This composition is different between urban and rural areas: in rural areas, only 4 per cent of the employed individuals are in paid employment whereas this rate is approximately 45 per cent in urban areas. While the share of self-employment is largely similar (40 per cent in rural areas and 39 per cent in urban areas), the share of unpaid family work is disproportionately higher in rural areas (55 per cent) compared to urban areas (13 per cent). The unemployment problem in the country seems to be largely an urban phenomenon, with the high urban unemployment rate due mostly to high job-searching costs, mismatch between labour demand and supply, high rural-urban migration, and skills mismatches (World Bank 2016).

Since the manufacturing and service sectors are more skill-intensive than the agricultural sector, the higher rate of urban unemployment might be due to a lack of skilled job seekers. However, data from CSA (2015a) suggest an inverted-U relationship between unemployment and education. Unemployment is relatively lower among the less-skilled and highly skilled individuals compared to those with primary and 
secondary school qualifications. In fact, the rate of unemployment is the highest among secondary school certificate holders. Further, most urban unemployed individuals (approximately 40 per cent), have been unemployed at least for a year (ibid.).

Youth unemployment is very high in urban areas and among women (see Figure 3). Between 1999 and 2013, the youth unemployment rate in urban areas declined from 32 per cent to approximately 20 per cent. In the same period, the rate in rural areas declined from 5 per cent to 3 per cent (CSA 2014). Like the general unemployment problem, youth unemployment is also an urban phenomenon. In addition to unemployment, underemployment is also a major challenge among youth; ${ }^{6}$ in fact, those employed in urban areas are mostly engaged in the informal sector. In 2013, 25.8 per cent of the urban employed individuals were in the informal sector, reduced from 50.6 per cent in 1999, and 38.5 per cent in 2005 (CSA 2014).

\subsection{The role of the private sector in addressing the youth unemployment challenge}

The development of the private sector can be key in addressing the youth employment challenge (Broussar and Tekleselassie 2012). For example, of the urban employees engaged in paid employment, only 20 per cent are employed in the public sector (World Bank 2016). According to CSA (2015a), a comparison of the skill sets of employees in the private and public sector suggests that the public sector is more skill-intensive than the private sector. For example, approximately 62 per cent of the employees of the public sector hold at least post-secondary educational qualifications in comparison to 14 per cent in the private sector. The share of unskilled employees in the public sector is close to zero, while this share is approximately 18 per cent in the private sector. Further, about 32 per cent of private employees hold only primary education, while this rate is only 12 per cent in the public sector (ibid.).

\subsection{Macro-level evidence on agricultural transformation and youth employment}

In this subsection, we provide macro-level evidence focusing on the cut flower sector and micro and small enterprises (MSEs). We focus on these two sectors as they represent the agribusiness sector that emerged from agricultural transformation. As discussed below, these sectors are involved not only in primary production but also in value addition. They are also well-integrated into the international market. Besides, the jobs created in these sectors are mostly paid and full-time.

\subsubsection{The floriculture sector in Ethiopia}

An important feature of agricultural transformation is within-sector productivity growth, driven by the agribusiness sector. An example of such transformation is the floriculture sector in Ethiopia, which has shown remarkable growth in the last 20 years. Between 2002 and 2016, the number of flower farms increased from five to over 100. This growth was mostly due to favourable government policies such as exemptions from paying income and export taxes and import duties, 
Table 1 Jobs created by micro and small enterprises in Ethiopia, 2013/14

\begin{tabular}{|c|c|c|c|}
\hline Industry group & No. of establishments & No. of employees & $\begin{array}{c}\text { Employees permanently } \\
\text { employed (\%) }\end{array}$ \\
\hline Food produce (excl. grain mills) & 25,430 & 373,171 & 41.5 \\
\hline Grain mill & 35,430 & 540,339 & 35 \\
\hline Textiles & 3,416 & 49,280 & 47 \\
\hline Wearing apparel, drying of fur & 18,199 & 246,062 & 40 \\
\hline Leather products & 1,113 & 16,182 & 44 \\
\hline Wood products (excl. furniture) & 1,548 & 13,348 & 38 \\
\hline Non-metallic minerals & 1,709 & 29,155 & 39 \\
\hline Metal products & 12,531 & 182,115 & 37 \\
\hline Machinery and equipment & 58 & 941 & 31 \\
\hline Furniture & 17,693 & 289,853 & 35 \\
\hline Others & 182 & 3,024 & 38 \\
\hline Total & 117,309 & $1,743,470$ & \\
\hline
\end{tabular}

Source Authors' own, based on CSA (2015c).

as well as better access to credit from banks (Schaefer and Abebe 2015; EHPEA 2018). ${ }^{7}$ In addition to local private entrepreneurs, a good number of these farms are owned by foreign companies (mainly from the Netherlands, the United Kingdom, Israel, and India).

This sector is largely labour-intensive, especially during the processing and post-harvest phases, and mainly requires less-skilled labour (Schaefer and Abebe 2015). As a result of this growth, a significant number of jobs were created for less-skilled individuals. Current estimates suggest that, over the past 15 years, the flower farms along with fruit and vegetable farming created an employment opportunity for more than 180,000 individuals (EHPEA 2018). Approximately 85 per cent of the jobs created in the cut flower sector are taken up by women, and due to the labour-intensive nature of these jobs, most of the employees are the youth (ibid.). To put this into context, in 2016/17, the all-time employment record for the textile sector was only 49,280 individuals. Another interesting aspect is the striking difference in labour-land ratio between these agribusiness and large-scale commercial farms in Ethiopia. According to CSA (2017), the average household landholding in Ethiopia is 1.38 hectares. Given that the average household size in rural Ethiopia is 4.8 persons, a hectare in a smallholder system supports at least four people, which is mostly in the form of unpaid family labour. Large-scale farms create only 0.05 permanent jobs per hectare and 4.9 jobs for temporary workers (Ali, Deininger and Harris 2017). However, a hectare in the flower, fruit, 
Table 2 Ownership structure of agriculture-related MSEs in Ethiopia, 2013/14

\begin{tabular}{lcccccc}
\hline Industry group & Private (\%) & $\begin{array}{c}\text { Partnership } \\
\text { (\%) }\end{array}$ & $\begin{array}{c}\text { Share } \\
\text { company (\%) }\end{array}$ & $\begin{array}{c}\text { Limited } \\
\text { company (\%) }\end{array}$ & $\begin{array}{c}\text { Cooperatives } \\
\text { (\%) }\end{array}$ & $\begin{array}{c}\text { Government } \\
\text { (\%) }\end{array}$ \\
\hline Food produce (excl. grain mills) & 91.24 & 5.85 & 0.38 & 0.19 & 1.89 & 0.23 \\
\hline Grain mill & 88.04 & 8.67 & 0.14 & 0.11 & 0.89 & 0.05 \\
\hline Textiles & 83.20 & 7.99 & 2.20 & 0.56 & 5.80 & 0.26 \\
\hline Wearing apparel, drying of fur & 90.95 & 4.91 & 0.31 & 0.26 & 2.32 & 0.36 \\
\hline Leather products & 71.16 & 21.11 & 1.44 & 0.72 & 4.22 & 0.00 \\
\hline Wood products (excl. furniture) & 77.26 & 11.43 & 2.58 & 0.00 & 7.62 & 0.00 \\
\hline Furniture & 67.07 & 19.43 & 0.49 & 0.76 & 11.56 & 0.06 \\
\hline Average & 86.1 & 10.9 & 0.6 & 0.3 & 2.1 & 0.04
\end{tabular}

Source Authors' own, based on data from CSA (2015c).

and vegetable farming sector supports approximately ten individuals through paid employment. This suggests that the floriculture sub-sector is playing a significant role in creating paid jobs for youth. It also generated US\$245 million in export earnings in the 2016/17 fiscal year (EHPEA 2018).

While the jobs in this sector are attractive at a managerial level, the pay is rather low at the entry level. As of 2013, the average monthly salary at the management level was 8,258 Ethiopian birr (approximately US $\$ 450$ ) while the pay for production workers such as land preparation, fertilisation, and harvesting was only 760 Ethiopian birr (US\$40) (Schaefer and Abebe 2015). Blattman and Dercon (2018) also reported that the working conditions in the cut flower sector are unpleasant and hazardous to health. In addition, the sector is facing several challenges. For example, accessing suitable land close to the airport is a challenge (Schaefer and Abebe 2015), and power outages, especially during storage, have resulted in significant revenue and job losses (Schaefer and Abebe 2015).

\subsubsection{The agri-food processing sector}

As part of the so-called 'micro and small enterprises' (MSEs), the agri-food processing sector has contributed significantly to alleviating the unemployment problem in Ethiopia. ${ }^{8}$ The small-scale manufacturing industries survey of $2013 / 14$ shows that 1.7 million people were employed in this sector at the time (see Table 1). The top three employers were grain mills, food processing industries, and manufacturers of wearing apparel and the drying of fur. In fact, more than 85 per cent of the jobs in MSEs were created by enterprises related to the agribusiness sector.

The data further suggest that from the 117,000 MSEs registered at the time, more than 70 per cent were engaged in activities directly related 
to the agricultural sector. In addition, 38 per cent of the employees in this sector were permanent paid workers while 22 per cent were in paid apprenticeships (CSA 2015c). Compared to small-scale enterprises, large- and medium-scale industries are largely ineffective in creating job opportunities (CSA 2015b). For example, in 2013/14, only 0.3 million individuals were employed by such industries. Thirty-nine per cent of these industries are in the agricultural sector $(27$ per cent in the food products and beverages sector and 12 per cent in the furniture industry), again suggesting the important role of agriculture-related activities. ${ }^{9}$

Table 2 presents the ownership structure of agriculture-related MSEs. More than 86 per cent of the small-scale industrial establishments are owned by private individuals, whereas government ownership is very limited. This suggests that the private sector is the major employer of individuals in the MSE sector. Another important driver of job creation is trade in agriculture-related activities: data from CSA (2014) suggest that a significant number of individuals - approximately 5.4 per cent of employed individuals in Ethiopia - are engaged in wholesale and retail trades, mostly for cereals. This rate is much higher in urban areas (20 per cent) compared to rural areas (2.9 per cent). This suggests that, as agricultural transformation intensifies, jobs can be created along the value chain.

Improving value addition remains an important area of intervention. For example, while high-income countries have a value addition of US $\$ 180$ per tonne for agricultural products, African countries' value addition is only US $\$ 40$ per tonne (World Bank 2016). In addition, the sector is also facing significant credit, land, and electricity-related constraints. The 2013/14 small-scale manufacturing industries survey identified the most important obstacles faced by agribusiness and the MSE sector to be: access to finance and land, shortage of electricity and water, as well as a lack of sufficient market information. In this regard, re-organising the agribusiness sector into special cluster zones would create areas where different types of agribusiness are agglomerated into one area. This would facilitate marketing and distribution and improve the supply of infrastructure and electricity-related services, which are critical in increasing productivity. As productivity increases, more jobs will be created for the youth in the agribusiness sector.

\subsection{Micro-level evidence on the role of the private sector and youth employment}

Here we provide further evidence on the relationship between agricultural transformation and youth employment using ESS data (CSA 2017). ${ }^{10}$ We draw employment rates from microdata, based on the following question: 'At any time over the last 12 months, were you employed in any kind of job, including part-time labour, for wage, salary, commission or any payment in kind, for anyone who is not a member of the household?' This question is mostly about paid employment (i.e. excluding self-employment and unpaid family work). Our analysis suggests that 8.7 per cent of the respondents were 
Table 3 Paid employment in Ethiopia by sector, from the 2015/16 ESS data

\begin{tabular}{lc|ccc}
\hline Type of employer & All & \multicolumn{3}{c}{ Youth } \\
\hline Main employers & Total (\%) & Total (\%) & Rural youth (\%) & Urban youth (\%) \\
\hline Private company & 23.93 & 25.81 & 20.90 & 27.40 \\
\hline Private individual & 24.15 & 31.50 & 23.30 & 34.20 \\
\hline Government & 43.66 & 37.40 & 45.70 & 34.70 \\
\hline State-owned enterprise & 3.21 & 2.66 & 5.40 & 1.80 \\
\hline Church/religious organisation & 2.90 & 1.30 & 1.50 & 1.20 \\
\hline
\end{tabular}

in paid employment, which is close to the country's 10 per cent paid employment rate (CSA 2014). When the ESS data were disaggregated by location, and youth status, we found some interesting results. Only 2.9 per cent of the respondents in rural areas were engaged in paid employment; however, this rate was 12.5 per cent in small towns and 24.2 per cent in medium and large towns. According to the survey, 8.6 per cent of youths were in paid employment (3.3 per cent in rural areas and 18.2 per cent in urban areas). Table 3 shows that for the sample as a whole, 48 per cent of paid employment came from the private sector (both companies and individuals) and 47 per cent from the public sector (both government and state-owned enterprises). Fifty-seven per cent of the paid youths were employed in the private sector, with 44 per cent in rural areas and 62 per cent in urban areas. This suggests that the private sector is playing a critical role in reducing youth unemployment in Ethiopia.

Despite the importance of the private sector in terms of job creation, the average wage paid by the private sector is much lower than public organisations. According to the ESS data, the average pay per hour in the government sector was 32 birr, whereas the rate in the private sector was 15 birr. However, public sector employees had a higher level of education; for example, 4.5 per cent of the youth employed in a paid government role had only a primary education qualification, whereas this rate was 41 per cent in the private sector.

Finally, as the youth population is set to grow, and with 70 per cent of the youth living in rural areas, addressing key constraints, especially those related to land would be vital. Empirical evidence also suggests that landlessness among rural youth is increasing (Kosec et al. 2017; Bezu and Holden 2014). In fact, attracting youth into agribusiness requires addressing land-related constraints (AfDB 2016; Kosec et al. 2017; Bezu and Holden 2014). Even though Ethiopia's land tenure and inheritance laws guarantee equal land acquisition and use rights for all rural citizens wishing to engage in agriculture, youth typically 
Table 4 Land ownership by age group, from the 2015/16 ESS data

\begin{tabular}{lc}
\hline Age group & \% access to land \\
\hline$<15$ & 0.07 \\
\hline Youth (15-29) & 4.2 \\
\hline $30-64$ & 46 \\
\hline$>64$ & 93 \\
\hline Source Authors' own, based on data from CSA (2017).
\end{tabular}

rely on inheritance and informal rental markets to access land (Kosec et al. 2017; Bezu and Holden 2014). However, the average farm sizes of smallholders have declined over the last decade and relying on inheritance is becoming less feasible. In fact, only 3 per cent of young women in Ethiopia have access to land (Bezu and Holden 2014). Due to limited formal land market opportunities, the youth can neither buy nor rent land on a long-term basis from other farmers. Therefore, there is a vital need to address land market-related constraints. In fact, previous studies (e.g. Bezu and Holden 2014) have suggested that young people in Ethiopia abandon agriculture due to limited access to agricultural land. Similarly, Kosec et al. (2017) documented that youth's high expectation of land inheritance negatively affects rural-urban migration and employment in the non-agricultural sector. In particular, their results suggest that a 10 per cent increase in inheritance size reduces rural-to-urban migration and employment in the non-agricultural sector by 4.8 and 4.1 per cent respectively. Table 4 shows land ownership in Ethiopia by age group, based on the ESS data (CSA 2017). The data show that only 4.2 per cent of the youth own land. Therefore, institutional arrangements and land market reforms that improve youth's access to land are crucial, if youth are to be the drivers of agribusiness.

\section{Conclusion and policy recommendations}

The evidence presented in this article suggests signs of agricultural transformation in Ethiopia, in the form of both labour movement to more productive sectors such as manufacturing and services, and productivity growth through the creation of agribusinesses. In particular, labour productivity growth, especially within-sector growth, has been strong. However, modernising and improving the productivity of the sector needs to push forward as large productivity gaps remain when compared to the manufacturing and service sectors. High unemployment remains, despite the emerging transformation, especially in urban areas and among youth. The impact of agribusiness development on youth employment outcomes was positive - as agribusinesses have expanded and grown, more jobs have been created for the youth. However, it was found that the jobs created in such private enterprises were low-paying and less skill-intensive. There are also major barriers related to access to electricity and suitable land that 
need to be addressed to ensure, firstly, that agribusinesses can continue to create jobs for young people and, secondly, that the youth are in a position to take them up. Inflexible land transfer and ownership processes have limited youth's access to land.

Based on these findings, we make the following policy recommendations:

Investment in infrastructure: A considerable number of jobs are being lost in the agribusiness sector due to infrastructure and power outages. Improving existing infrastructure and continued investment would make agribusinesses more competitive and reliable.

Improve productivity of existing and new agribusiness: Special agricultural cluster zones would create areas where different types of agribusiness are agglomerated into an area. This would facilitate marketing and distribution and improve the supply of infrastructure and electricity-related services, which are critical in increasing productivity.

Address the wage and skills gap: Since the jobs created in the agribusiness sector are largely low-paying and less skill-intensive, the following interventions could help to improve the pay for work in the private sector:

Introducing minimum wages in the private sector;

Unionisation of the workforce could improve the bargaining power of the youth for better wages;

- Provision of employment and skill services could reduce a mismatch between job seekers and suppliers. Improving the skill set of existing employees through on-the-job vocational training would also be crucial.

Improve the youth's access to land through policy reforms to support them to be drivers of agribusiness, including mechanisms that:

Allow landowners to transfer their land use right to others, especially for the youth who wish to engage in agribusiness-related activities, by sale or in exchange;

Relax restrictions on long-term rental markets.

In conclusion, as Ethiopia moves towards further privatisation, the government needs to launch an agribusiness strategy with the aim of exploiting the opportunities that may arise from agricultural and value chain transformations. 


\section{Notes}

* This issue of the IDS Bulletin was produced in partnership with Mastercard Foundation.

1 International Institute of Tropical Agriculture (IITA), Kenya.

2 Institute of Development Studies, UK.

3 Since our focus is on employment share, we focus on labour productivity instead of other productivity measures such as land productivity.

4 Calculated by weighting labour productivity in each sector by the labour share of each respective sector.

5 The focus of this article is not to examine the causes of this productivity gap but to understand the extent to which (1) such productivity gaps shape youth unemployment, and (2) labour productivity growth within the agricultural sector (however small it may be) affects the development of agribusiness (e.g. textile, flower, garment, and brewery companies, etc.).

6 Defined as the proportion of workers who are available and ready to work more hours.

7 http://ehpea.com/GeneralInfo.aspx\#medialink.

8 The Ethiopian government designed the Micro and Small Enterprises Development Strategy in 2004. MSEs are those industries engaging fewer than ten persons and which use power-driven machinery.

9 Another sector that we could have considered would be the input supply sector (fertiliser and improved seed), but the public sector is still the main player here and data are not available on jobs created in this sector. However, as agricultural transformation has intensified in the country in the past few years, a significant number of jobs may have been created by the input sector.

10 The ESS data are collected by the Central Statistical Authority (CSA) of Ethiopia and the World Bank Living Standards Measurement Study-Integrated Surveys on Agriculture (LSMS-ISA) team. For this article, data from the 2015/16 survey round are used. These data contain detailed information from approximately 5,000 households. Of these, 66 per cent are from rural areas and 9 per cent from small towns.

\section{References}

AfDB (2016) Fobs for Youth in Africa: Strategy for Creating 25 Million Fobs and Equipping 50 Million Youth 2016-2025, Abidjan: African Development Bank

Ali, D.A.; Deininger, K.W. and Harris, C.A.P. (2017) 'Using National Statistics to Increase Transparency of Large Land Acquisition: Evidence from Ethiopia', World Development 93: 62-74

Ayele, S.; Khan, S. and Sumberg, J. (2017) 'Introduction: New Perspectives on Africa's Youth Employment Challenge', IDS Bulletin 48.3: 1-12

Ayele, S.; Mader, P. and Thorpe, J. with Gu, J.; Maestre, M. and Reed, P. (2016) State-Business Relations Beyond Growth: Bringing in Development, IDS Evidence Report 215, Brighton: IDS

Bachewe, F.N.; Berhane, G.; Minten, B. and Taffesse, A.S. (2018) 'Agricultural Transformation in Africa? Assessing the Evidence in Ethiopia', World Development 105: 286-98 
Barrett, C.B.; Christiaensen, L.; Sheahan, M. and Shimeles, A. (2017) 'On the Structural Transformation of Rural Africa', Fournal of African Economies 26.suppl 1: i1-i35

Bezu, S. and Holden, S. (2014) 'Are Rural Youth in Ethiopia Abandoning Agriculture?' World Development 64: 259-72

Blattman, C. and Dercon, S. (2018) 'The Impacts of Industrial and Entrepreneurial Work on Income and Health: Experimental Evidence from Ethiopia', American Economic Fournal: Applied Economics 10.3: $1-38$

Broussar, N.H. and Tekleselassie, T.G. (2012) Youth Unemployment: Ethiopia Country Study, Working Paper 12/0592, London: International Growth Centre

Christiaensen, L.; Demery, L. and Kuhl, J. (2011) 'The (Evolving) Role of Agriculture in Poverty Reduction: An Empirical Perspective', Fournal of Development Economics 96.2: 239-54

CSA (2017) 'Ethiopia Socioeconomic Survey 2015-2016, Wave 3', World Bank, http://microdata.worldbank.org/index.php/ catalog/2783 (accessed 13 August 2018)

CSA (2015a) 'Statistical Report on the 2015 Urban Employment Unemployment Survey', Central Statistical Agency, www.csa.gov.et/component/phocadownload/category/98-ueues-2015 (accessed 13 August 2018)

CSA (2015b) 'Report on Large and Medium Scale Manufacturing and Electricity Industries Survey', Central Statistical Agency, www.csa.gov.et/ survey-report/category/56-lmmis-2014 (accessed 13 August 2018)

CSA (2015c) 'Small-Scale Manufacturing Industries Survey', Central Statistical Agency, www.csa.gov.et/survey-report/category/269ssis-2014 (accessed 13 August 2018)

CSA (2014) 'Analytical Report on the 2013 National Labour Force', Central Statistical Agency, www.csa.gov.et/survey-report/category/34nlfs-2013 (accessed 13 August 2018)

Dercon, C. and Gollin, D. (2014) 'Agriculture in African Development: Theories and Strategies', Annual Review of Resource Economics 6.1: 471-92

Diao, X.; Hazell, P. and Thurlow, J. (2010) 'The Role of Agriculture in African Development', World Development 38.10: 1375-83

EHPEA (2018) 'Sector Information', Ethiopian Horticulture Producer Exporters Association, http://ehpea.com/GeneralInfo.aspx\#medialink (accessed 13 August 2018)

Evoh, C.J. (2012) 'Taming the Youth Bulge in Africa: Rethinking the World Bank's Policy on Technical and Vocational Education for Disadvantaged Youth in the Knowledge Economy', in C.S. Collins and A.W. Wiseman (eds), Education Strategy in the Developing World: Revising the World Bank's Education Policy (International Perspectives on Education and Society, Volume 16), Bingley: Emerald Group Publishing

Fox, L. and Thomas, A. (2016) 'Africa's Got Work to Do: A Diagnostic of Youth Employment Challenges in Sub-Saharan Africa', Fournal of African Economies 25.suppl 1: i16-i36

Gebremariam, E.B. (2017) 'The Politics of Youth Employment and Policy Processes in Ethiopia', IDS Bulletin 48.3: 33-50 
Gollin, D.; Lagakos, D. and Waugh, M.E. (2014) 'The Agricultural Productivity Gap', Quarterly Journal of Economics 129.2: 939-93

Irz, X.; Lin, L.; Thirtle, C. and Wiggins, S. (2001) 'Agricultural Productivity Growth and Poverty Alleviation', Development Policy Review 19.4: 449-66

Kosec, K.; Ghebru, H.; Holtemeyer, B.; Mueller, V. and Schmidt, E. (2017) 'The Effect of Land Access on Youth Employment and Migration Decisions: Evidence from Rural Ethiopia', American fournal of Agricultural Economics 100.3: 931-54

Krishnan, P. (1996) 'Family Background, Education and Employment in Urban Ethiopia', Oxford Bulletin of Economics and Statistics 58.1: 167-83

Ligon, E. and Sadoulet, E. (2018) 'Estimating the Relative Benefits of Agricultural Growth on the Distribution of Expenditures', World Development 109: 417-28, http://dx.doi.org/10.1016/ j.worlddev.2016.12.007 (accessed 13 August 2018)

Losch, B. (2016) Structural Transformation to Boost Youth Labour Demand in Sub-Saharan Africa: The Role of Agriculture, Rural Areas and Territorial Development, Employment Working Paper 204, Geneva: International Labour Office

McCullough, E.B. (2017) 'Labor Productivity and Employment Gaps in Sub-Saharan Africa', Food Policy 67: 133-52

McMillan, M. and Rodrik, D. (2011) Globalization, Structural Change and Productivity Growth, NBER Working Paper 17143, Cambridge MA:

National Bureau of Economic Research

Moller, L.C. (2015) Ethiopia's Great Run: The Growth Acceleration and How to Pace it, Washington DC: World Bank Group, http://documents.worldbank.org/curated/en/693561467988949839/ Ethiopia-s-great-run-the-growth-acceleration-and-how-to-pace-it (accessed 13 August 2018)

O'Higgins, N. (2017) Rising to the Youth Employment Challenge: New Evidence on Key Policy Issues, Geneva: International Labour Office

Ripoll, S.; Andersson, J.; Badstue, L.; Büttner, M.; Chamberlin, J.; Erenstein, O. and Sumberg, J. (2017) 'Rural Transformation, Cereals and Youth in Africa: What Role for International Agricultural Research?', Outlook on Agriculture 46.3: 168-77

Schaefer, F. and Abebe, G. (2015) The Case for Industrial Policy and its Application in the Ethiopian Cut Flower Sector, EDRI Working Paper 12, Addis Ababa: Ethiopian Development Research Institute

World Bank (2018) World Development Indicators, https://data.worldbank.org/products/wdi (accessed 13 August 2018)

World Bank (2016) 5th Ethiopian Economic Update: Why So Idle?

Wages and Employment in a Crowded Labor Market, Washington DC:

World Bank Group, http://documents.worldbank.org/curated/ en/463121480932724605/5th-Ethiopia-economic-update-why-soidle-wages-and-employment-in-a-crowded-labor-market-draft-forpublic-launch (accessed 13 August 2018) 


\title{
Labour Casualisation and Youth Employment in Ghana's Formal Private Sector
}

\author{
Gertrude Dzifa Torvikey ${ }^{1}$
}

Abstract This article explores the link between labour casualisation and youth employment in Ghana's formal private sector. It uses the case of Blue Skies Holdings Ltd, an agro-processing company in Ghana. The article shows the contribution of Blue Skies to youth employment in Ghana. However, changes in the global production of the company's primary export commodity and local shocks created new challenges for the company. The article explains how local economic realities, global competition, and local shocks impact on the company's ability to maintain permanent employment for its workers. It recommends that government must design policies to incentivise successful companies to create more jobs but without consigning youth to insecure employment conditions.

Keywords: Ghana, youth employment, labour casualisation, private sector, Blue Skies Holdings Ltd.

\section{Introduction}

This article explores casualisation of youth ${ }^{2}$ labour and the precarity of employment in Ghana's formal private sector, through a case study of Blue Skies Holdings Ltd, an agro-processing firm. Like many other African countries, Ghana is experiencing 'jobless growth', where economic growth is not matched with job creation in the formal sectors of the economy (Aryeetey and Baah-Boateng 2016). The jobless growth phenomenon shows up more in the casualisation of jobs and their vulnerability to shocks, rather than extremely high levels of general joblessness. Some analysts argue that this makes the situation particularly serious, because the insecure nature of jobs in the formal sector hides the gravity of the country's youth unemployment crisis (Alagidede, Baah-Boateng and Nketiah-Amponsah 2013). The 'youth bulge' compounds the unemployment challenge where an estimated 20 per cent of the population is between 15 and 24 years old (Ghana Statistical Service 2014). These interconnected opportunities and problems have seen the implementation of training programmes for youth to transition into the job market (Darkwah 2013). 
Since the 1980s, Ghana has implemented economic reforms that have transformed the nature of its economy in significant ways. The World Bank-inspired Structural Adjustment Programmes (SAPs), which were known in Ghana as Economic Recovery Programmes (ERPs), reduced the state's involvement in direct production, with the expectation that the private formal sector would drive economic growth and create jobs. Since the 2000s, Ghana's economy has seen positive growth, especially in 2011 when commercial oil production started. Both public and private sectors have seen marginal increases in employment, but job creation in the formal private sector has been described as negligible (Obeng-Odoom 2012; Francis and Honorati 2016). A pattern of employment informalisation and labour casualisation has spread from the private informal sector to the formal sector as well.

Another significant feature of Ghana's economic growth trajectory is the decline in the contribution of the agriculture sector to the national economy. In 1998, the agriculture sector contributed 30.72 per cent to GDP while in 2015, the figure was 20.28 per cent. Economic growth in agriculture was 5.1 per cent in 1998 and 7.4 per cent in 2008, but declined to only 2.5 per cent in 2015 . There are important linkages between growth in the agricultural private sector and job creation, especially where companies are linked to industrial production and exports (Baah-Boateng 2013; Fox et al. 2013; Hanson and Leautier 2013; World Bank 2018). Aykut et al. (2017) contend that the agriculture sector in Ghana remains highly relevant as an engine of job creation, notwithstanding the government's tilt towards the extractive sector. However, as this article will show, the agricultural sector is susceptible to stresses and periodic shocks that are related to a plethora of factors, including land use changes, crop failures, and low rates of investment, among others. These factors have an impact on the employmentgenerating capacity of the agricultural sector, which employs about 42 per cent of economically active people in the country (Ghana Statistical Service 2013).

This article uses the case of Blue Skies as a lens to study casualisation and youth employment in Ghana. Blue Skies is a formal private sector company that employs both skilled and unskilled labour. It processes fruits, which are sourced primarily from smallholder growers. The company's products are marketed locally, but principally exported to international markets. Blue Skies has expanded considerably over the last two decades and has demonstrated the capacity to be a key employer of youth, especially young women. This makes it an important case to study how the realities of private enterprise shape youth employment in Ghana.

\section{Methods and data sources}

Data were drawn from previous research under the Land and Agriculture Commercialisation in Africa (LACA) Ghana Country Project, which was conducted between 2013 and 2015. This project examined different agricultural commercialisation models and their 
implications for employment, labour, land, and gender relations (see Torvikey, Yaro and Teye 2016). During the period, company officials and workers were interviewed. Other primary data included statistics on employment trends in the company. To bring the research up to date and address additional questions, an in-depth interview was conducted in July 2018 with a Blue Skies official, to understand recent developments in the company's operations and their implications for employment in the company. Secondary data sources included statistics on the performance of various sectors of the economy obtained from the Ghana Statistical Service and a review of national policy and programme documents on agriculture investments, exports, and trade regimes in the country.

The structure of the article is as follows: Section 3 provides a conceptual perspective on labour casualisation and Section 4 gives a brief description of Blue Skies, including the historical and macroeconomic context of its growth. This material is then reviewed briefly in Section 5 to draw out insights relating to the private sector's role in job creation, and the role of government policy frameworks that enabled the company to launch and grow. This is followed by a discussion in Section 6 of specific vulnerabilities Blue Skies was exposed to and its response, and also an analysis of its employment trends and patterns. Section 7 concludes by emphasising lessons and policy insights from the case.

\section{Labour casualisation and youth employment}

Research on youth employment and unemployment has focused on the inability of youth to find work; limited attention has been paid to underemployment (Ayele, Khan and Sumberg 2017), including a variety of casual, outsourced, contract, temporary, and seasonal work. Generally, this type of work is known as nonstandard work, in contrast to standard work, which connotes full-time employment (ILO 2015). This article focuses particularly on an increasing trend towards temporary, casual, and contract work, in order to explore the link between job casualisation in the private sector and the prospects for youth employment in Ghana.

The trend towards casual and non-permanent employment in the private formal sector has been mapped since the late 1970s in developed countries such as the USA, when it was yet to be a feature in many developing countries. In African countries, precarious employment has largely been associated with the informal sector (see Gukurume, this IDS Bulletin). In Ghana, the concern about the incidence of nonstandard work has rightly focused on the informal sectors of the economy. Hart's (1973) seminal work, which examined the relationship between the formal and informal sectors in Ghana, is a watershed in the discussion of the features of different types of work in the country. Hart (ibid.) highlighted the prevalence of informal work by formal wageworkers, which helped them to cope with the low wages paid in the formal sector. Yeboah (2017) also explored the expansion of nonstandard work in the informal sector, emphasising the precarity of migrant youths' working 
conditions in urban Ghana. Tsikata (2011) has explained how specific sectors of the informal economy, characterised by nonstandard work patterns, are being institutionalised by recruitment agencies.

Theron (2010) has two kinds of informality in relation to employment. 'Informality from below' is associated with self-employment in the informal sector. 'Informality from above' refers to the involvement of labour contractors in the recruitment and management of labour for and on behalf of the formal private sector. In the latter form, while the worker provides labour for the principal, such workers do not become employees of the principal. Precarious employment conditions are becoming more evident in the formal private sector, where work contracts are increasingly being casualised (Aye 2017). This strategy is an alternative to the use of a standard permanent contract to recruit youths (Anyidoho and Adomako Ampofo 2015). This trend has been observed in the formal private sectors of developing countries where there are weak labour laws. For example, Houeland (2015) has found that casualisation of labour is an increasing trend in Nigeria's oil industry. This has contributed to grievances against private sector employers within the industry, often leading to protests and the increasing involvement of labour unions in politics, as they seek to improve job security for employees (Lawrence 2018). In this article, I argue that informalisation from above is a strategy, adopted by companies within the private sector, to cope with economic uncertainty and fluctuations in the business cycle.

In Ghana, the trend towards nonstandard work has been traced back to the labour layoffs that began in the 1980s on the back of the SAPs. The trend has also been driven by an oversupply of labour and low rates of growth in the private sector (Fox, Senbet and Simbanegavi 2016). Casualisation of working conditions has become common for both skilled and unskilled youth labour. Businesses use casualisation to avoid the stringent labour laws that protect permanent employees, which helps them to reduce production costs and cope with a challenging business environment. This has consequences for youth employees in terms of job insecurity and underemployment, contributing to the overall youth unemployment challenge in Ghana.

Casualisation has been observed as a persistent problem in export processing zones (EPZs), where governments create special regulatory frameworks to stimulate the establishment and growth of export-oriented businesses. Obeng, Wrigley-Asante and Teye (2015) in a study of EPZs in Ghana found that while many jobs are created in the zones, jobs are also lost at the same rate. Labour casualisation as well as contract working are becoming normal in several sectors of the Ghanaian economy, such as the financial, mining, and telecommunications sectors (Boampong 2005). This article focuses on a firm in the agro-based sector, which is a particularly important employer of youths. 


\section{The Blue Skies company}

Blue Skies Holdings Ltd was established in 1998 by Anthony Pile, a British businessman, and Dei Tumi, a Ghanaian entrepreneur. The company was created to process fruits for export. It was one of the first private sector enterprises to establish a factory in an EPZ in Doboro, near Nsawam in Ghana's Eastern Region. This was a remarkable venture at a time when other companies were exporting only unprocessed raw fruits. Blue Skies represented a daring attempt to upgrade the performance of a Ghanaian raw materials producer and participate in value addition. Participation in higher links of the value chain of basic commodities is recognised to have a positive impact on employment generation for developing countries (Bammann 2007).

Today, Blue Skies accounts for over 90 per cent of cut fresh fruit exports from Ghana (Gatune et al. 2013). The company supplies freshly-cut fruit products to major European retailers such as Spar, Marks and Spencer, Carrefour, Ocado, Waitrose, Co-op Food, Sainsbury's, Asda, and Monoprix in destinations in the UK, Switzerland, Sweden, France, Italy, and The Netherlands, among others.

The successful establishment and growth of Blue Skies was enabled and facilitated by a number of policy and regulatory measures. In 1975, the Lomé Convention granted special concessions allowing African, Caribbean, and Pacific (ACP) producers to export some products, including agricultural products, into European Economic Community (EEC) markets, at a zero rate of import duty (Koning 1995; Laaksonen, Mäki-Fränti and Virolainen 2007). During the 1980s, export diversification was identified as a solution to reduce Ghana's exposure to price fluctuations of commodities such as cocoa, and the horticultural sector was a beneficiary of the new thinking, among other sectors (Agyei-Sasu et al. 2013). In 1995, Ghana's Free Zone Act (Act 504) (GoG 1995) established a number of EPZs across the country, which were designed to attract investors to the export processing and manufacturing sectors through the provision of specialised incentives such as a ten-year tax exemption, and other concessions, such as the freedom to repatriate profits. The entrepreneurs behind Blue Skies were direct beneficiaries of this new dispensation, and the company was established just three years after the Act was passed. Between 2004 and 2010, at least seven donor-sponsored programmes invested a total of US $\$ 1$ billion to boost horticulture production, marketing, and export in the country (Jaeger 2011).

The Blue Skies company location, close to the Doboro-Nsawam enclave, is also significant for the success of the new venture. The area had become an important pineapple-producing hub after a state-owned company (SOC), Nsawam Cannery Ltd, was established there in 1965. Nsawam Cannery Ltd was privatised in 1995 as part of a liberalisation policy, and the newly privatised company did not survive long; however, the local area continued its active production of pineapples for the local market. 


\section{Growth, competition, and crisis in the 2000s}

Traditionally, Smooth Cayenne and Sugarloaf were the major pineapple varieties grown in Ghana up to the early 2000s. Smooth Cayenne is an export variety that was popular with consumers in Europe. Blue Skies exported the Smooth Cayenne variety to Europe principally in fresh-cut pieces, which were the company's most important export product. In 1996, the Del Monte Company introduced the MD2 or Super Sweet pineapple variety, also known as Del Monte Gold, which was designed explicitly to break into the European market. MD2 was immediately popular with consumers and processors, with a 'uniform bright gold colour, sweeter taste, four times vitamin C content, lower fibre, lower acidity, thinner skin, smaller fruits at an average of 1.5kg each, and longer shelf life' (bin Thalip, Tong and Ng 2015: 2). While the quality of MD2 was considered comparable to Smooth Cayenne, its extended shelf life and suitability for sea transport made it possible for efficient, industrialised pineapple growers in Costa Rica to rapidly seize a significant share of the European market (Whitfield 2017; bin Thalip et al. 2015; Danielou and Ravry 2005).

The effect on Ghanaian pineapple producers and exporters was dramatic. Between 1994 and 2004, Ghana's pineapple exports to the European Union (EU) recorded a cumulative growth of 172 per cent, reaching an annual volume of 71,000 metric tonnes (MT). Just four years later, in 2008, Ghanaian pineapple exports had plummeted to 35,000MT per annum. Blue Skies was significantly affected. Many of the smallholder farmers who were the company's suppliers were pushed out of business and their lands were acquired by companies engaged in large-scale production and export. Since the switch from Smooth Cayenne to MD2 involved a capital investment, only resource-endowed farmers and pineapple-exporting companies that ran their own farms were equipped to adopt the new variety (Achaw 2010; Mensah 2014; Whitfield 2017). However, the decline in pineapple production after the mid-2000s coincided with an increase in consumer demand for mangoes in the EU, especially in the UK and France (CBI 2009; Araújo, and Garcia 2012). Blue Skies seized the opportunity to shift the bulk of its production from pineapple to mango. Once again, the company's location in the Eastern Region placed it close to the most important mango production hub in Ghana, in the Yilo Krobo District, where projects implemented by the Adventist Development and Relief Agency (ADRA) and the United States Agency for International Development (USAID) had supported farmers to produce mangoes for export and the domestic market (Yidu and Dzorgbo 2016).

Having successfully navigated the competitive threat posed by MD2, after 12 years of fluctuating growth, in 2010 Blue Skies experienced a series of shocks that tested its resilience and its capacity for sustained growth and employment creation. First, agricultural problems appeared in key supply areas. Papaya production in the country was hit by an outbreak of papaya mosaic disease. Meanwhile, mango production failed in Senegal, which is one of the West African regional sources 
of the crop when Ghana's production is off-season. Second, British Airways workers went on a three-day strike in May 2010 which affected the daily air-freight of products. The most devastating problem occurred when an Icelandic volcano erupted, creating a huge ash cloud that disrupted all flights to and from Europe between 15 April and 21 April, with severe consequences for exports of perishable goods. Oxford Economics (2010) estimated the loss to countries such as Ghana, Kenya, and Zambia as US\$65 million in perishable goods export revenue. Blue Skies were reported to have lost $£ 100,000$ per day during the crisis, amounting to an estimated total cost to the company of around $£ 3$ million. While the company made profits before tax of Ghc 2.37 million in 2008 and Ghc 3.36 million in 2009, in 2010 the company incurred a loss of Ghc 712,431 (see Blue Skies 2011). At the height of the crisis, Blue Skies shut down its processing unit, and 1,500 of its workers were temporarily laid off (New Agriculturalist 2010).

\section{Coping in times of crisis: the road to labour casualisation in the Blue Skies company}

Blue Skies started with good prospects for growth and job creation, including employment opportunities for youth. The workforce rose from 35 in 1998 to about 4,000 in June 2018. ${ }^{3}$ Almost 70 per cent of the firm's employees work in its production unit, which is the nerve centre of the company. ${ }^{4}$ Sixty per cent of Blue Skies workers are women; the company's workforce also has a very youthful structure, with 65 per cent of employees falling within the 18-29 age category and 20 per cent in the 30-49 age group, while those above 50 years of age account for 15 per cent. ${ }^{5}$ The company has built an extensive supply chain with 150 smallholder farmers, from whom it obtains the bulk of its fruits for processing. The inclusion of smallholder farmers in the supply chain also has an impact on youth employment in farming communities (Torvikey et al. 2016).

Initially, the International Labour Organization's (ILO) Conventions ${ }^{6}$ on workers' rights governed employment regulations in the Free Zones. The conventions called on ratifying member states to ensure job security for workers (Demaret 2013). Consequently, companies such as Blue Skies signed permanent or fixed contracts with most of its employees.

Table 1 Blue Skies personnel statistics for Week 24 (2007-13)

\begin{tabular}{|c|c|c|c|c|c|c|c|c|c|c|c|c|c|c|}
\hline \multirow{2}{*}{$\begin{array}{l}\text { Employment } \\
\text { type }\end{array}$} & \multicolumn{14}{|c|}{ Production year } \\
\hline & 2007 & $\%$ & 2008 & $\%$ & 2009 & $\%$ & 2010 & $\%$ & 2011 & $\%$ & 2012 & $\%$ & 2013 & $\%$ \\
\hline Permanent & 600 & 35 & 678 & 34 & 767 & 52 & 701 & 43 & 472 & 28 & 433 & 25 & 420 & 23 \\
\hline Contract & 441 & 26 & 1,099 & 55 & 22 & 2 & 26 & 2 & 48 & 3 & 76 & 5 & 86 & 5 \\
\hline Casual & 678 & 39 & 209 & 11 & 675 & 46 & 887 & 55 & 1,145 & 69 & 1,193 & 70 & 1,313 & 72 \\
\hline Total & 1,719 & 100 & 1,986 & 100 & 1,464 & 100 & 1,614 & 100 & 1,665 & 100 & 1,702 & 100 & 1,819 & 100 \\
\hline
\end{tabular}


However, the past decade has seen a decisive shift in the composition of the company's workforce, which is now predominantly casualised (Table 1). Casual employees are hired on short-term contracts of five months while contract workers on the other hand are employed on similar pay and conditions as permanent workers, but may be laid off when the company needs to cut production. Permanent workers have greater job security.

The number of people employed by Blue Skies fluctuates routinely during the year. This is due to fluctuations in the volume of processing and packaging to be done. The company's production schedule is governed by the seasonality of fruit production in source regions and consumption patterns in Europe; for example, mango and pineapple production peaks from April to September, while the peak summer period for sales in Europe starts in June. Consequently, the workforce statistics are usually presented weekly rather than monthly or annually. Week 24, in mid-June, is usually the peak period for the company's processing plants, therefore Table 1 presents the one-week snapshot for that week in each year from 2007 to $2013 .{ }^{7}$ The statistics show that the number and proportion of contract workers and permanent employees in the workforce has declined substantially, especially in the period since 2009.

The trend towards casualisation can be explained with reference to policies on economic development and labour laws. Firstly, casualisation coincided with the expiration of the company's ten-year tax holiday allowed under the Free Zone Act. Currently, upon expiration of the tax concession, Free Zone companies pay 25 per cent and 15 per cent on incomes earned from foreign and domestic sales respectively (PwC 2017). This change in fiscal status reduced the company's profit margins.

Casualisation was one strategy that the company adopted to cope with tighter operating conditions. Part 74(1) of the Labour Act 2003 (Act 651) (GoG 2003) stipulates that temporary (contract) workers must be made permanent once they have worked for the same employer continuously for six months. Part 73(1) of the same piece of legislation states that 'an employer may hire a worker on terms that suit the operations of the enterprise' (GoG 2003: 27). Casual contracts of no more than six months' duration could be synchronised with the seasonality of production, so that workers could be hired to work during the annual peak of production and laid off at the end of the season. This group of seasonal workers is likely to include many of the youth who constitute the majority of the Blue Skies workforce.

According to company representatives, the transition to more casual terms of employment was also driven by concerns about worker agitation and court action against the company. Over time, the company had experienced a gradual change in the educational background of its workers. Youths with university degrees began to seek and gain employment with Blue Skies. At the same time, trade 
unions acted upon the enactment of the Labour Act 2003 by educating workers about their employment rights. Educated youths in the Blue Skies workforce began to agitate for permanent employment status. To forestall potential court action, the company management decided to prioritise casual working arrangements that would suit the seasonal nature of its operations. ${ }^{8}$

The decline in Ghanaian pineapple production also affected the yearround availability of fruits for local processing. A company official explained,

We now import MD2 pineapple from Costa Rica into the UK to be processed there, since we do not have enough in Ghana. Currently, 60 per cent of our MD2 is processed in the UK and the rest in Ghana. ${ }^{9}$

At the same time, the company had to commit resources to start its own farming operations, reversing its previous business plan of sourcing fruits from smallholder farmers. As a result, Blue Skies operates 1,800 acres of pineapple production and 100 acres of mango farms, in various regions. Youths are employed on these farms, but only as casual wage labourers.

The Blue Skies case demonstrates two dimensions that affect youth employment and casualisation. On the one hand, the fact that the company continues to operate, and to employ 4,000 people, including a majority of female youths, suggests a story of success in entrepreneurship, technological upgrading, export market development, and job creation. On the other hand, the casualisation trend, in response to various structural stresses and shocks, has allowed the company to achieve the flexibility it believes it needs to hire and fire workers in response to fluctuations in its business cycle. For the many workers employed by the company, including many youths, this means less job security.

\section{Conclusions and policy insights}

Employment casualisation is an aspect of the youth employment challenge that is not well handled in policy frameworks and programme documents. Demand- and supply-side challenges, such as skills mismatches and low rates of absorption by firms of unemployed people, dominate debates on the youth employment challenge in Ghana and across sub-Saharan Africa. The policy prescription is often simplified into a call for more jobs for the teeming youth population. Policymakers' focus on unemployment conceals the pervasive problem of job casualisation, which is gradually taking root in the formal private sector.

Blue Skies emerged and sustained itself by exploiting specific policy provisions and opportunities. However, the trend towards casualisation ten years after the company's establishment exposes gaps in policies that are intended to create decent and secure jobs. Employment regulations that were designed to protect employees from exploitation also created an incentive for firms such as Blue Skies to avoid awarding permanent or regular contracts to many of its employees. Blue Skies and other 
private sector businesses have adopted this strategy to cope with internal and external shocks and stresses, and even to manage normal fluctuations in their business cycles. This has resulted in the burden of flexible employment being transferred onto workers, including large numbers of youth. This problem may also occur in countries where no strict laws limit casualisation of employment.

My analysis of employment casualisation within Blue Skies has a number of implications for policymakers and other stakeholders. Firstly, the Government of Ghana should consider the creation of incentives that would reward companies for employing a proportion (such as 50 per cent) of their workers at all levels, including youths and women, on permanent contracts. Secondly, the government should support horticultural production in the country, in order to ensure that companies like Blue Skies can continue production and processing, which would lead to sustained employment for youths. Thirdly, vulnerability to shocks in key export markets could be reduced if export-oriented businesses expand into regional and larger Africa-wide markets. The African Union's Continental Free Trade Area (CFTA) and Action Plan on Boosting Intra-African Trade (BIAT) provide opportunities for Ghanaian producers and exporters to increase horticultural production and diversify their export markets, with the potential to create sustainable jobs for youth along the value chain.

\section{Notes}

* This issue of the IDS Bulletin was produced in partnership with Mastercard Foundation.

1 Institute of Statistical, Social and Economic Research, University of Ghana.

2 Age-based definitions of youth, such as the ones used by the United Nations Department of Economic and Social Affairs (UN DESA) (2015) and the African Union Commission (AUC 2006), define youth as people between 15 and 35 years of age. Contextual definitions recognise that youth issues transcend age, such as the one used by Honwana (2012) who sees youth as 'people-in-waiting' or transiting to socioeconomic independence.

3 Official communication, Blue Skies official, 16 July 2018.

4 Official communication, Blue Skies official, 5 May 2013.

5 Official communication, Blue Skies official, 16 July 2018.

6 www.ilo.org/global/standards/introduction-to-international-labourstandards/conventions-and-recommendations/lang--en/index.htm.

7 I was unable to obtain the workforce statistics for the years 1998-2006 or 2014-18.

8 Official communication, Blue Skies official, 16 July 2018.

9 Official communication, Blue Skies official, 16 July 2018. 


\section{References}

Achaw, M.A. (2010) 'The Impact of Large-Scale Pineapple Companies on Rural Livelihoods in the Akuapim South Municipality of Ghana', MPhil thesis, Culture, Environment and Sustainability, Centre for Development and the Environment, University of Oslo, www.duo.uio.no/bitstream/handle/10852/32604/FinalxThesis_ MarkxAchawxAkanko.pdf? sequence $=1$ (accessed 8 October 2018) Agyei-Sasu, F.; Egyir, I.S.; Osei-Asare, Y.B. and Anaman, K.A. (2013) 'Horticultural Exports and Measures of Export Success: Lessons and Policy Implications from Ghana', Journal of International Marketing and Exporting 18.1: 44-65

Alagidede, P.; Baah-Boateng, W. and Nketiah-Amponsah, E. (2013) 'The Ghanaian Economy: An Overview', Ghanaian fournal of Economics 1: 4-34 Anyidoho, N.A. and Adomako Ampofo, A. (2015) " "How Can I Come to Work on Saturdays When I Have a Family?": Ghanaian Women and Bank Work in a Neoliberal Era', in C. Rodriguez, D. Tsikata and A. Adomako Ampofo (eds), Transatlantic Feminisms: Women and Gender Studies in Africa and the Diaspora, Lanham MD: Lexington Books

Araújo, J.L.P. and Garcia, J.L.L. (2012) 'A Study of the Mango Market in the European Union', Technical-Scientific Documents 43.2: 281-96

Aryeetey, E. and Baah-Boateng, W. (2016) Understanding Ghana's Growth Success Story and Fob Creation Challenges, UNU-WIDER Working Paper 2015/140, Helsinki: United Nations University World Institute for Development Economics Research, www.wider.unu.edu/ publication/understanding-ghana $\% \mathrm{E} 2 \% 80 \% 99$ s-growth-successstory-and-job-creation-challenges (accessed 8 October 2018)

AUC (2006) African Youth Charter, Addis Ababa: African Union Commission, www.un.org/en/africa/osaa/pdf/au/african_youth_ charter_2006.pdf (accessed 8 October 2018)

Aye, B. (2017) 'NUPENGASSAN': Combatting Precarious Work in the Nigerian Oil Industry, Working Paper 50, Geneva: International Labour Office

Ayele, S.; Khan, S. and Sumberg, J. (2017) 'Introduction: New Perspectives on Africa's Youth Employment Challenge', IDS Bulletin 48.3: 1-12, http://bulletin.ids.ac.uk/idsbo/article/view/2866 (accessed 17 October 2018)

Aykut, D. et al. (2017) Fiscal Consolidation to Accelerate Growth and Support Inclusive Development: Ghana Public Expenditure Review, Washington DC: World Bank

Baah-Boateng, W. (2013) 'Determinants of Unemployment in Ghana', African Development Review 25.4: 385-99

Bammann, H. (2007) 'Participatory Value Chain Analysis for Improved Farmer Incomes, Employment Opportunities and Food Security', Pacific Economic Bulletin 22.3: 113-25

bin Thalip, A.A.; Tong, P.S. and Ng, C. ( 2015) 'The MD2 "Super Sweet" Pineapple (Ananas comosus)', Utar Agriculture Science fournal 1.4: 15-17

Blue Skies (2011) 13 Years of Blue Skies in Ghana, presentation, http://nyuafricahouse.org/wp-content/uploads/2012/09/ blueskiespdf.pdf (accessed 28 March 2018)

Boampong, O. (2005) 'Formalising the Informal: Recruiting through 
Intermediaries in Tema: A Way Out or a Way to the Bottom?' MPhil thesis, Development Geography, Department of Sociology and Human Geography, University of Oslo

CBI (2009) The EU Market for Mango, CBI Market Survey: Fresh Fruit and Vegetables, The Hague: Centre for the Promotion of Imports (CBI), www.siicex.gob.pe/siicex/resources/estudio/887993922rad726FD.pdf (accessed 16 October 2018)

Danielou, M. and Ravry, C. (2005) The Rise of Ghana's Pineapple Industry: From Successful Takeoff to Sustainable Expansion, Africa Region Working Paper Series 93, Washington DC: World Bank

Darkwah, A.K. (2013) 'Keeping Hope Alive: An Analysis of Training Opportunities for Ghanaian Youth in the Emerging Oil and Gas Industry', International Development Planning Review 35.2: 119-34

Demaret, L. (2013) 'ILO Standards and Precarious Work: Strengths, Weaknesses and Potential', International fournal of Labour Research 5.1: 9-21

Fox, L.; Haines, C.; Muñoz, J.H. and Thomas, A. (2013) Africa's Got Work to Do: Employment Prospects in the New Century, IMF Working Paper WP/13/201, Washington DC: International Monetary Fund African Department

Fox, L.; Senbet, L.W. and Simbanegavi, W. (2016) 'Youth Employment in Sub-Saharan Africa: Challenges, Constraints and Opportunities', Fournal of African Economies 25.suppl 1: i3-i15

Francis, D.C. and Honorati, M. (2016) Deepening Without Broadening? Jobs in Ghana's Private Sector, Policy Research Working Paper 7835, Washington DC: World Bank

Gatune, J.; Chapman-Kodam, M.; Korboe, K.; Mulangu, F. and Rakotoarisoa, M.A. (2013) Analysis of Trade Impacts of the Fresh Pineapple Sector in Ghana, FAO Commodity and Trade Policy Research Working Paper 41, Rome: Food and Agriculture Organization of the United Nations

Ghana Statistical Service (2014) 2010 Population and Housing Census Report: Population Projections and Prospects, Accra: Ghana Statistical Service, www.statsghana.gov.gh/docfiles/2010phc/Mono/Ghana\%20 Population \%20Prospects.pdf (accessed 16 October 2018)

Ghana Statistical Service (2013) 2010 Population \&̊ Housing Census: National Analytical Report, Accra: Ghana Statistical Service, www.statsghana.gov.gh/docfiles/2010phc/National_Analytical_ Report.pdf (accessed 8 October 2018)

GoG (2003) 'Labour Act, 2003 (Act 651)', Government of Ghana, www.melr.gov.gh/wp-content/uploads/2015/11/LABOURACT-2003.pdf (accessed 8 October 2018)

GoG (1995) 'Free Zone Act, 1995 (Act 504)', Government of Ghana, http://images.mofcom.gov.cn/gh/accessory/201212/ 1354895042040.pdf (accessed 8 October 2018)

Hanson, K.T. and Leautier, F. (2013) 'Jobless Economic Growth in Africa: Is there a Role for Agriculture?', Journal of African Development 15.2: $1-17$

Hart, K. (1973) 'Informal Income Opportunities and Urban Employment 
in Ghana', Fournal of Modern African Studies 11.1: 61-89

Honwana, A.M. (2012) The Time of Touth: Work, Social Change, and Politics in Africa, Boulder CO: Kumarian Press

Houeland, C. (2015) 'Casualisation and Conflict in the Niger Delta: Nigerian Oil Workers' Unions between Companies and Communities', Revue Tiers Monde 224.4: 25-46

ILO (2015) Non-Standard Forms of Employment, Report for Discussion at the Meeting of Experts on Non-Standard Forms of Employment (Geneva, 16-19 February 2015), MENSFE/2015, Geneva: International Labour Office

Jaeger, P. (2011) Horticulture Exports from Ghana: A Strategic Study, Agriculture and Rural Development \& Africa Region Joint Discussion Paper 66880, Washington DC: World Bank

Koning, A. (1995) The Impact of European Union Policies on Fruit and Vegetable Imports from Sub-Saharan Africa, Economics and Sociology Occasional Paper 2211, Columbus OH: Ohio State University

Laaksonen, K.; Mäki-Fränti, P. and Virolainen, M. (2007) Lomé Convention, Agriculture and Trade Relations between the EU and the ACP Countries in 1975-2000, Working Paper 06/20, Helsinki: Pellervo Economic Research Institute

Lawrence, A. (2018) 'The Role of Labor in Transforming Nigerian Oil Politics', in T. Atabaki, E. Bini and K. Ehsani (eds), Working for Oil: Comparative Social Histories of Labor in the Global Oil Industry, Cham: Palgrave Macmillan

Mensah, A. (2014) 'Performance of the Fruit Crop Industry in Ghana: Empirical Results and Policy Implications', PhD dissertation, Agricultural Sciences, Faculty of Agricultural Sciences, GeorgAugust-University Goettingen, https://d-nb.info/106377649X/34 (accessed 10 October 2018)

New Agriculturalist (2010) 'Cloud over Africa's Horticultural Exports', May, www.new-ag.info/en/developments/devItem.php?a=1619 (accessed 4 July 2018)

Obeng, F.A.; Wrigley-Asante, C. and Teye, J.K. (2015) 'Working Conditions in Ghana's Export Processing Zone and Women's Empowerment', Work Organisation, Labour and Globalisation 9.2: 64-78

Obeng-Odoom, F. (2012) 'Neoliberalism and the Urban Economy in Ghana: Urban Employment, Inequality, and Poverty', Growth and Change 43.1: 85-109

Oxford Economics (2010) The Economic Impacts of Air Travel Restrictions Due to Volcanic Ash, a report prepared for Airbus, Oxford: Oxford Economics

PwC (2017) Navigating Taxation: A Quick Guide to Taxation in Ghana, Accra: $\mathrm{PwC}$, www.pwc.com/gh/en/assets/pdf/tax-facts-and-figures-2017.pdf (accessed 10 October 2018)

Theron, J. (2010) 'Informalization from Above, Informalization from Below: The Options for Organization', African Studies Quarterly 11.2-3: 87-105 
Torvikey, G.D.; Yaro, J.A. and Teye, J. (2016) 'Farm to Factory Gendered Employment: The Case of Blue Skies Outgrower Scheme in Ghana', Agrarian South: Fournal of Political Economy 5.1: 77-97

Tsikata, D. (2011) 'Employment Agencies and the Regulation of Domestic Workers in Ghana: Institutionalizing Informality?', Canadian Fournal of Women and the Law 23.1: 213-34

UN DESA (2015) The World Population Prospects: 2015 Revision, New York NY: United Nations Department of Economic and Social Affairs

Whitfield, L. (2017) 'New Paths to Capitalist Agricultural Production in Africa: Experiences of Ghanaian Pineapple Producer-Exporters', Journal of Agrarian Change 17.3: 535-56

World Bank (2018) World Development Report, 2019: The Changing Nature of Work, working draft, Washington DC: World Bank, www.worldbank.org/en/publication/wdr2019 (accessed 10 October 2018)

Yeboah, T. (2017) 'Navigating Precarious Employment: Social Networks among Migrant Youth in Ghana', IDS Bulletin 48.3: 79-94, http://bulletin.ids.ac.uk/idsbo/article/view/2871 (accessed 17 October 2018)

Yidu, P.K.D. and Dzorgbo, D.S. (2016) 'The State and Mango Export Crop Production in Ghana', Ghana Social Science Fournal 13.2: 185-208, http://ss.ug.edu.gh/sites/ss.ug.edu.gh/files/journals/ GSSJ-\%20December $\% 202016-V_{0 l} \% 2013 \% 20$ Issue $\% 202 \% 20$ $\% 281 \% 29$. compressed.pdf (accessed 10 October 2018) 


\title{
Uganda's National Youth Policy and Job Creation for Youth"
}

\author{
Rita Makumbi ${ }^{1}$
}

\begin{abstract}
Uganda's Youth Livelihood Programme (YLP) and the consequent Youth Livelihood Fund (YLF) are government programmes established under the National Youth Policy (NYP), designed to support young people to find employment by extending grants and other support to small groups of young entrepreneurs, to help them to start small businesses and thus create employment for other young jobseekers. Drawing on a study involving 177 rural and urban youths, this article discusses the design and implementation of the YLP. It argues that the NYP has fallen short in several respects. In addition to funding, employment generation requires additional support for youth in a range of areas, including awareness-raising about employment opportunities, enhancing vocational and entrepreneurial skills, and providing advice and guidance on starting up small businesses.
\end{abstract}

Keywords: youth employment, Africa, Uganda, National Youth Policy, value addition.

\section{Introduction}

Like other countries in Africa, Uganda faces the challenge of generating economic growth and providing employment for youths. Youths make up a third of the global population (World Bank 2015) and Africa and Asia share high dependency ratios of people younger than 15 and older than 64 (Kilimani 2017). Moreover, Africa has the world's youngest population and accounts for close to half of the entire world's unemployed youth (Atinc et al. 2005). A youth in Uganda is a person who is aged 18-30 years (UBOS 2017), and the Ugandan Bureau of Statistics (UBOS) for 2015 shows that while 74.5 per cent of the youth were employed, the remaining 25.5 per cent were either unemployed (4.9 per cent) or inactive (20.6 per cent) (UBOS 2015). Research also shows that approximately 400,000 Ugandan youths enter the job market annually to compete for approximately 9,000 available jobs (Magelah and Ntambirweki-Karugonjo 2014). Urban youth are more likely to be unemployed than rural youth, and young women are twice as likely to be unemployed as young men (Ahaibwe and Mbowa 2014). The prevalent unemployment and underemployment could be a source 
of many social, economic, and fiscal problems in the future, placing a heavy burden on public revenues (Makumbi 2018).

The Ugandan government has adopted a number of policies and initiatives that are intended to address the youth employment challenge. Among the most important is the National Youth Policy (NYP), which was adopted in 2001. The NYP has focused on agriculture and associated industries (Republic of Uganda 2001), because that sector has been the main source of livelihood for Ugandans. Out of a national population of approximately 41 million people, 83.2 per cent live in rural areas (Aghasili 2015). Uganda also has a large agricultural economy which contributes more than 20 per cent of the gross domestic product (GDP) growth (Dalipagic and Elepu 2014). Small-scale agriculture is a major source of employment (Diao 2010), and several analysts still agree that commercial food crops have the potential to generate economic opportunities (Kumar and Kalita 2017; Ranum, Peña-Rosas and Garcia-Casal 2014; Nabbumba and Bahiigwa 2003).

The Government of Uganda has identified private enterprise development as a critical strategy for economic growth and job creation in the country (Vision Reporter 2018). In 1995, the government established the Private Sector Foundation Uganda (PSFU) to oversee the growth of the private sector. The role of PSFU involves encouraging an environment that allows creation of jobs, generation of revenue, and enhancement of exports. The PSFU is continuously challenged to look out for new opportunities in the private sector so as to be able to match the dynamics in the economy (ibid.).

The Youth Livelihood Programme (YLP) and Youth Livelihood Fund (YLF) were created as vehicles for the promotion of youth enterprise development, through the provision of entrepreneurship training, information services, and microcredit facilities to the youth. Support for micro projects was informed by a policy consensus that funding for small enterprises could drive job creation and stimulate economic growth (Reeg 2015; Edquist 2011; Karnani 2007). However, a decade and a half after the NYP was inaugurated, the youth unemployment and underemployment situation remains a pressing problem.

Drawing on a study involving 177 rural and urban youths, this article discusses the design and implementation of the YLP. It argues that the NYP has fallen short in several respects. In addition to funding, employment generation requires additional support for youth in a range of areas, including awareness-raising about employment opportunities, enhancing vocational and entrepreneurial skills, and providing advice and guidance on starting up small businesses. To help focus the analysis, the article concentrates particularly on data relating to job creation and youth-led enterprises within the maize value chain in Uganda. Agricultural value chains have been identified as an important source of employment for large numbers of young people (Brooks et al. 2013). Analysts believe that the maize value chain could generate many jobs 
for youths, if they are assisted to engage in value-adding activities (Adesugba and Mavrotas 2016; Kluve 2016).

The rest of the article is organised as follows: Section 2 reviews the NYP and its core elements, the YLP and the YLF. While Section 3 outlines data sources, Section 4 presents the analysis and discussion of data. Section 5 concludes with implications for youth employment policy.

\section{Uganda's National Youth Policy, Youth Livelihood Programme, and Youth Livelihood Fund}

Uganda adopted the NYP in 2001, with the specific goal of enhancing the economic contributions of youth. The policy was a reaction to worsening youth conditions, where an increase in rural to urban youth migration was not accompanied by job creation. A growing number of the youth were dropping out of school, and there was a lack of government funding to support them. The YLP and YLF were created to provide funding and other support to small enterprises led by youth. The aim was not only to support small business development, but also job creation (Republic of Uganda 2001; Makumbi 2018).

The Government of Uganda allocated UGX 265 billion (US\$71.42 million) to the YLP/YLF for the period 2014-18. The funds were assigned to support youth-led small enterprise development in different sectors, to include grain-milling, metal fabrication, clay products, carpentry, bakery, tailoring, soap-making, the manufacture of fuel briquettes, fishing, poultry production, arts and crafts, music and drama, and beauty. To apply for support from the YLP/YLF, youths were invited to form small groups, known as youth interest groups (YIGs) and to complete a project interest form (PIF) (Makumbi 2018).

In 2017, it was reported that the YLF had disbursed US\$17.38 million, representing only 24 per cent of the approved budget, at an average rate of approximately US\$620,000 every month. However, in January 2017, the government suspended the disbursement of YLF loans, because the Fund was experiencing a large shortfall in the expected repayments. The YLF was designed as a revolving fund, so that the capacity to make new loans was dependent upon the receipt of timely loan repayments from existing recipients. However, repayments were running far behind expectations; for example, recipients in Kampala had paid back only US\$61,641, leaving US\$138,464 outstanding. In Mukono District, US $\$ 10,740$ had been repaid, but US\$56,021 was still outstanding (Semakula and Kashaka 2017).

Nonetheless, at the time the YLF was suspended, it was claimed that it had supported the creation of 114,471 jobs for youth over the preceding three years (Table 1). The agricultural sector had received the largest share of YLF loans, amounting to US\$7.41 million or 42.7 per cent. Thus, 43 per cent of the reported new jobs were in the agricultural sector and a further 3 per cent in agro-industry. Trade and services also represented substantial shares of the jobs that were said to have been created (30 per cent and 10 per cent, respectively). 


\begin{tabular}{llcc} 
Table 1 Jobs created under the National Youth Policy, 2014-17 & \\
\hline \multicolumn{1}{l}{ Sector } & $\begin{array}{c}\text { Number of jobs } \\
\text { created }\end{array}$ & Percentage \\
\hline 1 & Agriculture & 49,695 & 43 \\
\hline 2 & Trade & 33,771 & 30 \\
\hline 3 & Services & 11,979 & 10 \\
\hline 4 & Industry & 7,028 & 6 \\
\hline 5 & Vocational skills & 6,071 & 5 \\
\hline 6 & Agro-industry & 3,981 & 3 \\
\hline 7 & Agro-forestry & 1,180 & 1 \\
\hline 8 & Information Communication Technology & 625 & $<1$ \\
\hline 9 & Creative industry & 137 & $<1$ \\
\hline Total & & 114,467 & 100 \\
\hline
\end{tabular}

Source Makumbi (2018).

\section{Data sources}

This article draws upon data generated as part of a doctoral study into youth employment and job creation in Uganda (Makumbi 2018). A survey was carried out with 177 respondents, 43 per cent female and 57 per cent male, as well as focus group discussions (FGDs) and interviews with key informants. The participants in the research were YLF funded recipients involved in youth-led micro projects at various stages of the maize value chain, in both urban and rural areas (the city of Kampala and Mukono District). In total, 21 individual interviews and seven FGDs were conducted. The survey was conducted in 2017 (ibid.).

\section{Analysis and discussion of data}

Some descriptive statistics about the survey respondents are presented in Table 2. The majority of respondents (51 per cent) defined themselves as maize growers, and identified this as their major source of livelihood within the maize value chain. Many of the youths in this category were unaware of other value-adding activities within the maize processing chain, including aspects such as livestock feed production. Twenty-one per cent of the respondents identified themselves as transporters, who conveyed maize grain from the production villages to central storage places or from villages to bigger towns and the city of Kampala. The remaining youths (about 28 per cent) were working as grain processors, livestock feed producers, etc. Among the survey respondents, rural youths were typically maize producers and were often also involved in non-farm livelihood activities, such as small- and medium-scale maize processing and livestock feed production and distribution. In Mukono District, 79 projects were implemented under the YLP, of which more than half (53 per cent) were in the agricultural sector, usually in 


\begin{tabular}{llc}
\hline & Sector & $\begin{array}{c}\text { Youth } \\
\text { participants in } \\
\text { the survey }\end{array}$ \\
\hline 1 & Maize growers & 91 \\
\hline 2 & Transporters & 37 \\
\hline $3 \quad$ Agro-processors, distributors, seedling sales, livestock feed, etc. & 49 \\
\hline \multicolumn{2}{l}{ Total } & 177 \\
\hline Source Makumbi (2018). & \\
\hline
\end{tabular}

businesses with less need for high-level skills. Urban youths were more likely to be involved in (local) transport, processing, and marketing activities. In Kampala, the agriculture-related trade sector was where most projects were implemented.

\subsection{Problems in the YLP/YLF}

A number of key flaws have come to light, which undermined the effectiveness and impact of the YLP/YLF as a programme for enterprise development and job creation. Major problems related to the insufficient quality and detail of the business proposals submitted to the programme and awarded funds. For example, a majority of the project proposals prepared by the YIGs, including those represented in all six of the FGDs carried out for this study in Kampala and Mukono District, failed to take loan interest into account, as it was assumed by both the youths and the government that repayment of the loan would be completed within one year, and would not be subject to repayment interest. In reality, repayments typically continued beyond the first year, when they would be subject to interest at 5 per cent, but most of the fledgling entrepreneurs had not budgeted for the interest on their YLF loan. The programme finances were therefore subject to different cash flows than had been projected (Makumbi 2018).

Another problem related to the disbursement schedule. According to our interviews, many of the YIGs expected a one-time disbursement; however, the disbursements were made in tranches, as a method of controlling the programme. As some projects developed more slowly than expected, while others stalled, late claims for additional funding, and failures to claim previously allocated funds, disrupted the disbursement and repayment schedules (ibid.).

There were also problems of external monitoring of loan recipients' performance by the YLP/YLF administration. The loan recipients were supposed to submit a financial and operational report, using a prepared format, at least annually. However, in 48 per cent of cases, this was not done. The YIGs were also required to submit a justification and seek approval for any significant changes in their business plans. Such changes could be common; however, a minority ( 45 per cent) of affected businesses 
complied with this rule. The YLP/YLF was also subject to problems of fraud and bad faith. Some YIG leaders disappeared with the funds, leaving the remainder of the group with an uncertain future; in most cases, this meant that projects were not fully realised (ibid.).

The problems of budgeting and financial management within the YLP/YLF stemmed from weaknesses in the design and implementation of the small business projects proposed by applicants to the scheme. The YLP/YLF placed the responsibility on the YIGs to conceive and design viable business proposals, such as clear value propositions, goals, targets, activities, management plans, financial indicators, and monitoring systems. The quality and detail of the proposals submitted by the YIGs were often insufficient, and the youths were inexperienced. Fifty-nine per cent of the youths interviewed for this study felt that the guidance they had been given was inadequate to start and grow successful businesses (ibid.).

The budgets presented by the YIGs often neglected to take into account the effects of high inflation between the time of application and the time of loan approval and the first disbursement of funds. Groups we interviewed explained that they had applied for funds in 2014 but had not received the money until 2015, by which time the prices of some key business inputs had increased significantly. In general, inflation was problematic for all the new businesses. Inflation in Uganda leads to high operating costs, reducing business savings considerably. For example, one participant in the Bajjo Charcoal Briquette project, which received support from the YLP/YLF, complained that continual price increases on raw materials created a disincentive to add another value-adding activity into their existing business model (ibid.). ${ }^{2}$

In some cases, YIGs failed to include their basic cost-of-living expenses in their business budgets. Since at first they had no other source of income other than the YLF loan, they had to live off the project funds during the first period of investment, when the funds should have been used to invest in the new business. This was particularly problematic in view of the very small micro-loans awarded in many cases. The distribution of US\$17.38 million to 114,471 youths represented a modest pay-out of only US\$152 per recipient. This raises questions about the YLP/YLF ambition to generate adequate incomes for the loan recipients themselves, and to generate additional employment opportunities in new business enterprises, at the same time (ibid.).

Some survey respondents and key informants evidently had not perceived their business enterprises as 'projects', as such, with defined goals and timescales. Instead, many participants in YIGs perceived their YLF loans merely as a kind of subsidy or grant to support their income-generating activities in general and their cost of living (ibid.).

As well as insufficient training and guidance in business and financial management, many YIGs also complained about the inadequacy of 
the technical training that was offered by the programme. For example, youth leaders in Kampala indicated that their knowledge about quality control, storage, and processing of maize grain was narrow. This shortfall in capabilities enabled predatory middlemen within the value chain to take advantage of fledgling enterprises, imposing additional costs on their operations (ibid.).

Some informants complained about a general lack of information and advice that could help raise awareness of business opportunities, as well as the capability to engage with them. For example, one youth leader referred to the business of making fuel briquettes from dried maize cobs. Briquette-making is an enterprise found in both rural and urban areas, with varying levels of expertise. The youth leader told us, 'This briquette business has potential to grow if there was awareness among potential users who are more familiar with [conventional] charcoal.'

According to a quantitative analysis carried out by Makumbi (2018), the YLP/YLF had a small but positive impact on job creation. Eighty-one per cent of youths surveyed in Kampala and Mukono District agreed that well-supervised projects had the potential to generate jobs; however, the problems discussed above created obstacles to this outcome.

Nineteen per cent were sceptical about the potential for job creation through small- and micro-enterprise development. Almost 13 per cent of the youths interviewed reported that they were unable to compete for jobs due simply to an excess in the supply of labour. This was common among boda (motorbike transporters), who are concentrated in urban areas. The FGD in the Rubaga and Kawempe divisions in Kampala revealed that those youth fortunate to be employed resorted to working late into the night. Others resigned themselves to staying idle until an opportunity appeared.

Despite the public investment through the YLP/YLF to support small enterprise development and private sector employment, some respondents, particularly educated youths, continued to regard the public sector rather than the private sector as the ideal source of employment, and declined to take work in the private sector. Some analysts, such as Holt (2012), have blamed negative attitudes among youth for their continued unemployment. Nonetheless, many of the barriers to employment were structural, especially lack of knowledge and inadequate information flows, which shaped perceptions and created obstacles to full participation of youth in employment. This insight reflects the finding by Ukachukwu (2014), that inadequate access to information contributes to the persistence of youth unemployment.

\section{Conclusion and recommendations}

The NYP endeavours to provide strategies for youth employment in the private sector. However, the reported study (Makumbi 2018) found that the majority of the youth were involved in relatively low-skilled labour activities, such as maize production and transportation. The study also identified a number of problems in the design and implementation of 
the YLP/YLF programme, thus hindering the successful launch and expansion of viable small- and micro-enterprises that could generate employment for rural and urban youth. Launching a successful business involves sophisticated skills of project planning and financial management, which are areas where youths may need support. This support would be additional to the technical advice and guidance needed to help youths engage in specific business sectors, such as the maize value chain.

The majority of youth-led enterprises supported by the YLP/ YLF remain engaged only at the lowest levels of the maize value chain, where the potential for value addition, and therefore viable income generation and job creation, is minimal. Going forward, the NYP should be more proactive in identifying potential employment opportunities for higher skilled workers within the maize value chain, and provide resources that would enable participation therein. In addition to funding, the NYP should support youth by raising awareness levels about employment opportunities, enhancing vocational and entrepreneurial skills, and providing advice and guidance on business opportunities and market linkages. The maize value chain as a whole also remains undeveloped, comprising only a limited part of the value-adding agribusiness industry in Uganda. Supportive government policies should help to develop the maize value chain in the country.

\section{Notes}

* This issue of the IDS Bulletin was produced in partnership with Mastercard Foundation.

1 Ndejje University, Kampala, Uganda.

2 Personal interview with YLP fund recipient, December 2016.

3 Personal interview, November 2016.

\section{References}

Adesugba, M.A. and Mavrotas, G. (2016) Delving Deeper into the Agricultural Transformation and Youth Employment Nexus: The Nigerian Case, NSSP Working Paper 31, Washington DC: International Food Policy Research Institute (IFPRI), www.ifpri.org/publication/delvingdeeper-agricultural-transformation-and-youth-employment-nexusnigerian-case (accessed 15 October 2018)

Aghasili, O.U. (2015) 'Fuel Choice, Acute Respiratory Infection and Child Growth in Uganda', Open Access Theses 564, West Lafayette IN: Purdue University, ProQuest Dissertations Publishing, https://docs.lib.purdue.edu/open_access_theses/564/ (accessed 15 October 2018)

Ahaibwe, G. and Mbowa, S. (2014) Youth Unemployment Challenge in Uganda and the Role of Employment Polices in Fobs Creation, Africa in Focus blog, 26 August, www.brookings.edu/blog/africa-in-focus/2014/08/26/ youth-unemployment-challenge-in-uganda-and-the-role-ofemployment-policies-in-jobs-creation/ (accessed 15 October 2018)

Atinc, T.M. et al. (2005) World Development Report 2006: Equity and Development, Washington DC: World Bank, http://documents.worldbank.org/curated/en/435331468127174418/ 
World-development-report-2006-equity-and-development (accessed 15 October 2018)

Brooks, K.; Zorya, S.; Gautam, A. and Goyal, A. (2013) Agriculture as a Sector of Opportunity for Young People in Africa, Policy Research Working Paper 6473, Washington DC: World Bank, https://openknowledge. worldbank.org/handle/10986/15605 (accessed 15 October 2018)

Dalipagic, I. and Elepu, G. (2014) Agricultural Value Chain Analysis in Northern Uganda: Maize, Rice, Groundnuts, Sunflower and Sesame, Kampala: Action Against Hunger | ACF International, www.actionagainsthunger.org/sites/default/files/publications/ Agricultural_value_chain_in_Northern_Uganda_Maize_rice_ groundnuts_sunflower_and_sesame_03.2014.pdf (accessed 15 October 2018)

Diao, X. (2010) Economic Importance of Agriculture for Sustainable Development and Poverty Reduction: Findings from a Case Study of Ghana, Policies for Agricultural Development, Poverty Reduction and Food Security, Paris: Organisation for Economic Co-operation and Development (OECD), www.oecd.org/agriculture/agricultural-policies/46341169.pdf (accessed 15 October 2018)

Edquist, C. (2011) 'Systems of Innovation: Perspectives and Challenges', African Fournal of Science, Technology, Innovation and Development 2.3: 14-43

Holt, A. (2012) 'Negative Attitude of Young People are Closing Doors to Jobs Says Survey', Charity Times, 17 May, www.charitytimes.com/ ct/negative_attitudes_young_people_are_closing_doors_to_jobs_ says_survey.php \%20.php (accessed 15 October 2018)

Karnani, A. (2007) 'Microfinance Misses its Mark', Stanford Social Innovation Review, https://ssir.org/articles/entry/microfinance_ misses_its_mark\# (accessed 15 October 2018)

Kilimani, N. (2017) 'Youth Employment in Developing Economies: Evidence on Policies and Interventions', IDS Bulletin 48.3: 13-32, http://opendocs.ids.ac.uk/opendocs/handle/123456789/12987 (accessed 28 June 2018)

Kluve, J. (2016) A Review of the Effectiveness of Active Labour Market Programmes with a Focus on Latin America and the Caribbean, Research Department Working Paper 9, Geneva: International Labour Office Kumar, D. and Kalita, P. (2017) 'Reducing Postharvest Losses during Storage of Grain Crops to Strengthen Food Security in Developing Countries', Foods 6.1: 8

Magelah, P. and Ntambirweki-Karugonjo, B. (2014) Youth Unemployment and Fob Creation in Uganda: Opportunities and Challenges, Infosheet 26, Kampala: Advocates Coalition for Development and Environment (ACODE), www.acode-u.org/Files/Publications/infosheet_26.pdf (accessed 15 October 2018)

Makumbi, B.R. (2018) 'The National Youth Policy and Job Creation in Uganda', unpublished $\mathrm{PhD}$ thesis, School of Business Administration, Nkumba University

Nabbumba, R. and Bahiigwa, G. (2003) Agricultural Productivity Constraints in Uganda: Implications for Investment, Research Series 151127, Kampala: Economic Policy Research Centre (EPRG), 
https://ideas.repec.org/p/ags/eprcrs/151127.html (accessed 15 October 2018)

Ranum, P.; Peña-Rosas, J.P. and Garcia-Casal, M.N. (2014) 'Global Maize Production, Utilisation and Consumption', Annals of the New York Academy of Sciences 1312.1: 105-12

Reeg, G. (2015) Micro and Small Enterprises as Drivers for Fob Creation and Decent Work, Discussion Paper 10/2015, Bonn: German Development Institute

Republic of Uganda (2001) The National Youth Policy: A Vision for Youth in the 21st Century, Kampala: Ministry of Gender, Labour and Social Development, www.youthpolicy.org/national/Uganda_2001_ National_Youth_Policy.pdf (accessed 15 October 2018)

Semakula, J. and Kashaka, U. (2017) 'Youth Loans: 80 in Trouble', New Vision, 5 February, https://archives.visiongroup.co.ug/nationalnews/35715-youth-loans-80-in-trouble (accessed 1 July 2017)

UBOS (2017) 2017 National Governance, Peace and Security (NGPS) Survey, Kampala: Uganda Bureau of Statistics, www.ubos.org/wp-content/ uploads/publications/08_201807_2018Governance_Peace_and_ Security_2017_PPTPresentation.pdf (accessed 15 October 2018)

UBOS (2015) 2015 Statistical Abstract, Kampala: Uganda Bureau of Statistics, www.ubos.org/wp-content/uploads/ publications/03_2018Statistical_Abstract_2015.pdf (accessed 15 October 2018)

Ukachukwu, N.A. (2014) 'Assessment of the Private Sectors' Contributions to Youth Empowerment among Youths in Rivers State, Nigeria', Singaporean fournal of Business Economics and Management Studies 2.6: 20-26

Vision Reporter (2018) 'OPM to Coordinate Vision 2040', New Vision, 10 April, www.newvision.co.ug/new_vision/news/1317058/opmcoordinate-vision-2040 (accessed 15 October 2018)

World Bank (2015) Toward Solutions for Youth Employment: A 2015 Baseline Report-Overview, Washington DC: World Bank, https://openknowledge.worldbank.org/handle/10986/23262 (accessed 15 October 2018) 


\title{
Skills Gaps and Mismatches: Private Sector Expectations of Engineering Graduates in Ethiopia'
}

\author{
Jerusalem Yibeltal Yizengaw ${ }^{1}$
}

\begin{abstract}
This article investigates skills gaps and mismatches of engineering graduates. Sustained growth of the Ethiopian economy has created demand for construction work, yet despite the labour demand and engineering graduates seeking employment, employers identify skills gaps hindering their ability to employ them. The study uses key informant interviews with engineering graduates, lecturers, and private sector employers, and document analysis to collect data on the skills gaps and mismatches. The article argues that, while skills gaps are largely caused by poor design of the higher education curriculum and corrupted recruitment practices, the precarious nature of the construction sector and macroeconomic instability limit graduate employment even further. It suggests that education providers work collaboratively with employers to make the curriculum fit for purpose, and that government both makes more realistic and long-term plans for the construction sector, and increases university funding, with an emphasis on quality and practice-focused graduate teaching and learning experiences.
\end{abstract}

Keywords: private sector, construction, youth, graduates, engineering, skills gap, higher education curriculum, (un)employment.

\section{Introduction}

In recent years, Ethiopia has registered a remarkable economic performance, with annual growth of gross domestic product (GDP) averaging 10.3 per cent per year from 2005 to 2015 . Ethiopia aspires to become a middle-income country by 2025 (FDRE 2016) and also aims to sustain its current economic growth through its second Growth and Transformation Plan (GTP II) (ibid.). A key component of the GTP II is the construction sector, which is at the heart of enhancing national competitiveness and creating employment opportunities. During the GTP I period (2010/11-2014/15), the construction industry grew at an average of 28.7 per cent per annum, increasing its share of GDP from 4 per cent in 2009/10 to 8.5 per cent by 2014/15 (ibid.). The sector also employs 11 per cent of the total formal sector employment (CSA 2014). 
Given its labour-intensive nature, employment in the construction sector is expected to grow. This is reflected in the ambitious GTP II targets for the sector; for example, total road length is planned to increase from $110,414 \mathrm{~km}$ in $2014 / 15$ to $220,000 \mathrm{~km}$ by $2019 / 20$, and a total of $2,741 \mathrm{~km}$ of national railway network is expected to be constructed by 2019/20 (FDRE 2016). Although most of the GTP plan is state-led and state-financed, a significant portion of this work is expected to be delivered by the private construction sector through contracts (ibid.). The sector, however, suffers from a low level of capacity and skills, weak performance of contractors and consultants, high costs of construction materials, and the prevalence of rent-seeking behaviours (FDRE 2016; EEA 2008).

This article focuses on skills gaps and mismatches. This is an area that the Government of Ethiopia has also been focusing on through expanding higher education which emphasises science, technology, engineering, and mathematics (STEM) against the broader areas of social sciences (a 70:30 split in favour of STEM). The number of universities in Ethiopia increased rapidly from two in the 1990s to 44 in 2016, and total enrolment on undergraduate degree programmes grew from 420,387 in 2009 to 778,766 in 2016 (FDRE/Ministry of Education 2017). However, the quality of higher education in creating competitive graduates has been highlighted as a major problem (Salmi, Sursock and Olefir 2017); and the general root of the problem stems from the expansion and dynamism of the Ethiopian higher education system.

While the number of graduates has been growing, evidence from a 2013 survey showed that the unemployed working-age population in Ethiopia was 1,981,165, with an unemployment rate of 4.5 per cent (CSA 2014). The differentials of unemployment by gender showed that the female unemployment rate (6.5 per cent) was more than double as compared to their male counterparts (2.7 per cent) (ibid.). Youth unemployment is as high as 20 per cent (Wossen and Ayele, this IDS Bulletin), with unemployment particularly concentrated among the 15-29 years age group. This is the age range which the Ethiopian youth policy regards as 'youth' (FDRE 2004), even though non-governmental organisations (NGOs) and civic associations in Ethiopia and other countries use various ranges for the concept of 'youth' from the standpoint of the purpose which they represent and activities they undertake. For example, the United Nations (UN) defines youth as persons between 15 and 24 years and the World Health Organization (WHO) defines it as 10-24 (FDRE 2004). Again, experiences of other countries indicate different age ranges to define youth (see e.g. Ayele, Khan and Sumberg 2017).

Ethiopia has one of the highest rates of graduate youth unemployment in East Africa (Addis Standard 2017). For example, a 2015 tracer study of Bahir Dar University (BDU) shows that out of the 1,301 young engineers included in the study, 35.4 per cent were unemployed (BDU forthcoming, 2018). While data on graduate (un)employment are anecdotal, some studies (e.g. Mncayi 2016 and Salmi et al. 2017) suggest that graduate engineers are among the growing number of unemployed 
youth. The adverse consequences of youth unemployment on families and society at large is evident; for example, partly triggered by the youth unemployment crisis, Ethiopia has recently experienced major political unrest, which led the government to impose two states of emergencies (Addis Standard 2017; BBC 2018). Though the initial spark for these unrests was potential land-grabbing, one of the causes admitted by the government was youth unemployment (Africa Renewal 2017). Besides, regional inequalities in infrastructure provision, poor performance of flagship projects (such as hospitals), unlawful displacement of farmers, lack of rule of law, absence of civil society fora, and lack of vibrant media have all contributed to the flaring up of public disappointment and hence the unrest (Addis Standard 2017). The government also took what appears to be a knee-jerk solution to curb the unrest and allocated 10 billion birr (around US $\$ 400$ million) to create job opportunities, particularly for young people (ibid.).

Researchers such as Gebremariam (2017) and Gebru (2017) call for overhauling the economy and creating better employment opportunities for unemployed youths and graduates in the country. Otherwise, if the problem is left to chance, a mismatch between education and employer expectations in Ethiopia could have serious long-term repercussions - particularly because Ethiopia is the second most populous African nation, with over 70 per cent of its population under the age of 30, and with over 150,000 graduates each year (Africa Renewal 2013; Korpela 2017). In light of the key role youth are expected to play in the sustained political and economic stability of the country, and the importance of taking a closer look at the plight of the youth and possible solutions to the chronic problem of youth unemployment, there are complaints heard from employers in Ethiopia that their expectations are not met in finding proper graduates of tertiary-level education who are both competent in theoretical knowledge and also able to practise it efficiently (Salmi et al. 2017). Under these circumstances, it is therefore imperative to explore the causes of skills gaps and mismatches among graduate engineers and identify possible solutions with a view to enhancing employment in the sector as well as economic development of the country.

The remainder of the article is organised as follows. Section 2 reviews the literature on the status of youth (un)employment and the private construction sector. Section 3 outlines the methods used in the study, while Section 4 presents and discusses the findings. Section 5 concludes and provides policy recommendations.

\section{The status of youth (un)employment and the private construction sector in Ethiopia}

Research shows that Africa's youth population is rapidly growing and is projected to double to over 830 million by 2050 (AfDB 2016). Demographic projections also show that 1 billion more young people will enter the job market over the next decade (Kilimani 2017). This demands for state and non-state actors to expand the social and economic sectors and provide employment opportunities progressively 
for youth (Gebremariam 2017). In developed countries such as the USA and Japan, private firms invest more proportionally and are more responsive to change in investment opportunities than are public firms (UNCTAD 2017). But in developing countries like Ethiopia, public sector investment is dominant while the relative role of private investment in economic growth is in its infancy (Melese 2012). Yet the Ethiopian construction industry has contributed much to reducing poverty (FDRE 2016), for instance through increasing employment expansion through small- and medium-enterprise development and job creation through the construction of low-cost houses (Tefera 2013). Despite the key roles that the private sector can play to drive economic growth and thus eradicate poverty (World Bank 2018), the degree of youth absorption in Ethiopia through employment is found to be low (Yizengaw 2016).

The notions of 'youth bulge' and 'demographic dividend' have also become key aspects of the narrative around youth and employment policy (Ayele et al. 2017). While 'youth bulge' refers to the situation where a large share of the population comprises children and young adults, the notion of 'demographic dividend' is built around the potential that the youth can generate social and economic growth (ibid.). Alongside these narratives are also concerns about the 'risky behaviours' among unemployed and underemployed youth who are often exposed to unprotected sex, abuse of alcohol and drugs (ibid.), and political and social instability (Gebremariam 2017).

Ethiopia prides itself on achieving double-digit economic growth over the past decade (FDRE 2016). However, this growth has not sufficiently addressed the unemployment challenge. While unemployment dropped from 20.4 per cent in 2010 to 16.8 per cent in 2016, it still remains significant and youth unemployment is even more pronounced (Wossen and Ayele, this IDS Bulletin; World Bank 2018). The construction industry is labour-intensive and has grown over 20 per cent in the past decade, even faster than the overall growth of the economy (FDRE 2016). Due to the fact that it provides jobs, especially for less-skilled labourers, the sector's contribution to poverty reduction has been noted (Tefera 2013). What is more, given the booming construction works across the country, the sector also visibly provides employment opportunities for engineering graduates (CSA 2013). However, as noted above, studies show that over 35 per cent of the 2015 engineering graduates were unemployed (BDU forthcoming, 2018).

The broader literature suggests that volatile economic growth accompanied by a poorly educated workforce and skills shortages risks the employability of graduates (World Economic Forum 2014). Further, Aring (2012: 5) underlined that skills gaps are caused by two major factors: (1) a qualitative skills mismatch where employers do not find graduates with employable skills even when they have the right qualifications on paper, and (2) a quantitative mismatch where not enough graduates are educated and trained at the required levels, 
or they out-migrate to countries where they can earn higher wages. According to McGuinness, Pouliakas and Redmond (2017), skills mismatches are caused by three factors:

1 Macroeconomic skills mismatch: differences between the jobs on offer and the broad qualification levels of the pool of unemployed people;

2 Specific skills shortages: employers' inability to find workers with a specific skill or occupation; and

3 On-the-job skills mismatch: differences between employed individuals' skills and the skills needed to perform their job.

McGuinness et al. (2017) further refer to 'vertical mismatch' - measured in terms of over-education, under-education, or over-skilling and under-skilling - and skills gaps - measured in terms of unfilled and hard-to-fill vacancies. Based on the above theoretical background, this article thus discusses the causes of skills gaps and mismatches.

\section{Research methodology}

This study employed a qualitative research approach. It used document analysis and in-depth interviews to generate data on the presence of skills gaps and mismatches and the reasons thereof. In total, the study draws on 38 interviews conducted over May-June 2018 with:

Sixteen university lecturers working at Addis Ababa and Bahir Dar universities, both of which are pioneers of producing engineering graduates in Ethiopia. Based on UNESCO's (2012) rating scale, lecturers' assessments of graduate employability were rated as high $=3$, medium $=2$, and low $=1$. The lecturers were quizzed on the presence of employable skills among engineering graduates.

Twelve owners and/or managers of eight small to large enterprises in the construction sector (drawn from Addis Ababa and Bahir Dar). They responded to questions concerning the private sector expectations of engineering graduates alongside the presence of skills gaps and mismatches.

Ten engineering graduates who were employed in paving roads and streets and undertaking major construction work such as upgrading inner roads, roadsides, and walkways. They were asked questions regarding the causes of skills gaps and mismatches.

Finally, the author's doctoral study (Yizengaw 2016) was also used as a secondary source of data.

\section{Data analysis and findings}

4.1 Skills gaps and mismatches among engineering graduates

Sixteen lecturers from Addis Ababa and Bahir Dar universities were asked to rate the presence of employable skills among their engineering students, ranked from high to low (see Table 1). 
Table 1 Presence of employable skills among engineering graduates in Addis Ababa and Bahir Dar universities, as perceived by their lecturers, 2016/17 academic year

\begin{tabular}{|c|c|c|c|}
\hline \multirow{2}{*}{ Employable skills } & \multicolumn{3}{|c|}{ Frequency and percentages of responses } \\
\hline & High & Medium & Low \\
\hline Subject-specific technical ability & & $6(37 \%)$ & $10(63 \%)$ \\
\hline Ability to use new information & $4(25 \%)$ & $8(50 \%)$ & $4(25 \%)$ \\
\hline Prior exposure to the work & & & $16(100 \%)$ \\
\hline Understanding business realities & & $7(43.7 \%)$ & $9(56.3 \%)$ \\
\hline Ability to construct logical arguments & & $11(68.7 \%)$ & $5(31.3 \%)$ \\
\hline Ability to execute tasks independently & & $4(25 \%)$ & $12(75 \%)$ \\
\hline Problem-solving skills & & $6(33.3 \%)$ & $10(66.6 \%)$ \\
\hline Ability to apply knowledge to new situations & $2(12.5 \%)$ & $3(18.7 \%)$ & $11(68.7 \%)$ \\
\hline Flexibility in accepting new things & & $7(43.7 \%)$ & $9(56.3 \%)$ \\
\hline Negotiation skills & & $3(18.7 \%)$ & $13(81.2 \%)$ \\
\hline
\end{tabular}

Table 1 clearly shows that except for one highly rated skills area (the ability to use new information), the graduates' skills were rated as medium or low, with subject-specific technical skills particularly rated as either low (63 per cent) or medium (37 per cent). Graduates were poorly rated in terms of their abilities to apply knowledge to new situations, having prior exposure to engineering work, and understanding business realities. Graduates' abilities to execute tasks independently and their problem-solving skills were also rated as low. It is also important to note that, although the technical demands of a graduate may vary, an engineer, irrespective of their specialisation, must be equipped with soft engineering skills such as negotiation in order to cope with new challenges in the changing engineering field. However, the graduates were rated poorly even in these soft skill areas.

Moreover, interviews with the lecturers clearly revealed that their students had much better theoretical than practical knowledge, which meant that students were barely equipped with practical and employable skills on graduation. Therefore, at least from the perspective of university lecturers, the skills levels among engineering graduates at both Addis Ababa and Bahir Dar universities were either low or medium at best.

In-depth interviews with owners and managers of private construction businesses showed that many of the graduates who they employed (or came to them in search of employment) hardly had the skills to handle budget preparation, contract and subcontract management, material requirement plans, or even warehouse management. Many also 
explained that fresh graduates required job-related specific courses and trainings before starting work because the level of skills gained at university did not meet their expectations. One of the construction companies' general managers ${ }^{2}$ noted that the graduates in question were of 'high profile on papers [sic] but not in reality'. Another reiterated that 'some of the newly recruited engineering graduates were unfit to perform simple engineering works that we expected graduates to do... we had to train them from one to six months to get them [to] make a good start'. ${ }^{3}$ These responses confirm the lecturers' responses and indicate that higher education teaching did not respond appropriately to the employers' expectations and requirements. On paper, some of these graduates were 'over-qualified' and 'entitled' to demand relatively higher wages than less-skilled labourers, but they did not do the jobs any better. In this regard, one of the interviewed private company owners explained that 'graduates even with grade points 3.5 and above are not found much better as we expected'. ${ }^{4}$ Others highlighted that such graduates add a cost to their businesses because they have to retrain them and this affects the performance of their businesses, including producing sub-standard products.

I also asked engineering graduates about their employable skill sets. A graduate of BDU explained the skills mismatch he experienced working as a bricklayer in a small business:

Our work specification includes earth work, sub-base construction, drainage ditch openings, shade building, etc. What we [fellow graduates and I] studied and what we are doing are different. There are also others [engineering graduates] who perform totally different jobs than they were trained in, like salesmen and saleswomen, hotel receptionists, [and] stores-keepers. Some others are inactive. ${ }^{5}$

Those engineers who were bricklayers (working on cobblestone projects $)^{6}$ in and around Bahir Dar claimed that they possess 'more and completely different skills than their current job requires', and that the deployment of engineering graduates to manual work reveals 'a skills mismatch' where an overly educated graduate does 'basic and manual work'. Almost the entire engineering graduates interviewed stated that the jobs they were working on could easily be conducted by trainees or graduates of Technical Vocational Education and Training (TVET). This, therefore, raises the question as to why the government focuses so much on expanding university education that is not addressing quality, and I argue that the quality of higher education has to be looked into as an urgent policy matter.

\subsection{Causes of skills gaps and mismatches}

The findings in the previous section clearly suggest some causal factors for skills gaps and mismatches. These include:

Limitations of the higher education curriculum: When it comes to the specific engineering curriculum, its relevance to the world of work is of paramount importance because, as argued by Thi Tuyet 
Tran (2014), engineers are involved in the implementation, application, operation, design, development, and management of projects and processes. This is despite the fact that the type of work that engineers do will vary depending on the chosen field of study such as chemical, civil, electrical, materials, mechanical, or industrial engineering. Regarding the relevance of the curriculum, an owner of a small firm and former graduate of BDU remarked,

I looked and looked for jobs relevant to my training for years but I [was] unable to find it. Even to create my own, the way how I was trained is not supportive to think far beyond job searching in public institutions. As a last resort, I organised myself with friends and started working on small-scale inner roads maintenance work, initially for subsistence reasons but now it is more rewarding. ${ }^{7}$

Another former graduate of Addis Ababa University stated strongly how government officials insist that engineering graduates are involved in jobs such as cobblestone projects. This, according to the interviewee, 'undermines the five-year-long preparations at the university and wastes the knowledge and skills obtained at the university'. So far, the interviewee is of the opinion that 'the concerns of these higher officials may be useful if it urges universities to revisit their curriculum according to the demands of employers'. ${ }^{8}$ As curriculum and pedagogics matter most of one's entire career, higher education needs to be responsive in its curriculum and methodologies with the promise of teachers in embedding and teaching entrepreneurship courses to their students. While some of the former graduates insisted that they have the right skills, some of the employers do not find them relevant and blame the poorly designed curriculum and a lack of resources to prepare graduates for work after graduation. The perceptions held by employers and university lecturers and their evaluations of the graduates' skills are that these are largely based on principles and theories. This clearly suggests that the curriculum is poorly designed and does not address the expectations of employers.

Precarious nature of the construction sector: A large part of the construction industry boom in Ethiopia is due to state-led and state-financed construction projects such as dams, roads, and railways. However, the sector is vulnerable to contract delays and underfinancing, and even cancellations of major projects. Under these circumstances, according to one of the interviewed graduates, 'private contractors struggle to hire and retain graduates'. ${ }^{9}$ As another employer noted, the difficulties in hiring and retaining graduates are even more 'accentuated by the inability or lack of willingness of some graduates to take multiple positions (or multitasking) ${ }^{\prime} \cdot{ }^{10}$ Yet another employer noted that, given 'we have to make profits and survive; we expect our staff to take two or more simple tasks that are in the domain of the construction industry'. ${ }^{11}$ The view of the interviewee was that enterprises are able to create more spaces for graduates in different positions so long as the latter are willing to take them. 
Lack of quality higher education: One of the interviewed lecturers expressed 'to think about quality graduates we need to have adequate resources in higher education institutions. In the reality, there are limitations in resources to increase quality in university educations $[s i c]$ '. ${ }^{12}$ The engineering graduates also highlighted insufficiency of funding while they were on campus or studying. They noted that their lecture theatres and workshops were poorly equipped; for example, insufficient tools and equipment to undertake practical learning. They also explained that their libraries did not hold relevant and sufficient books. Some even went on to say that their teaching staff were not properly trained. These, I argue, are plausible reasons that undermine quality learning at the universities.

Corrupted recruitment practices: All of the graduate interviewees noted the challenges associated with securing jobs immediately after graduation due to lack of opportunities in both the private and public sectors. They also noted that the longer they remain out of jobs, the more likely they are to become deskilled which further reduces their chances of being employed. While this has been a challenge, graduates noted what they regarded as unacceptable recruitment practices in both the private and public sectors, such as 'starting to fill vacancies from the family circle by those private construction enterprises ${ }^{13}$ but not advertising openly, and procedures that are corrupt and lack transparency. Specifically, one of the interviewed graduates remarked that 'employers should be fair and give equal chances for all job applicants while recruiting alongside supporting continued growth of their staff by educating them and providing the necessary rewards in terms of pay, benefits, and work environment'. ${ }^{14}$

Factors related to the macroeconomic condition: Employers noted that their business operations often experience shortages of foreign exchange and raw materials, with one business owner stating that, 'due to foreign exchange shortages, we were not able to import key construction materials... and this affects our operations and the number of staff we hire and retain'. ${ }^{15}$ On the other hand, one of the interviewed private construction company managers explained that,

the macroeconomic environment tends to fail to use engineering graduates in productive sectors as immediately as possible. As a result, those minds and hands shaped to contribute a lot for the national and international socioeconomic dynamics remain to be idle for some time with the adverse effects of expired knowledge and skills. ${ }^{16}$

In relation to this, another interviewed private construction business owner added,

the macroeconomic situation of the country was characterised by shortage of hard currencies. Consequently, the inputs for the running projects are inconsistent and the numbers of construction projects appear to shrink from time to time which in turn affects the employment of youth graduates. ${ }^{17}$ 
To add to this reflection, the goal of achieving full employment among other macroeconomic goals is an important one in many developing nations where unemployment and underemployment have been a major cause and consequence of widespread poverty (Sodipe and Ogunrinola 2011). Above all, this research uncovered several strategies that employers used to address skills gaps, including:

Outsourcing: Some employers outsourced a significant part of their work, partly due to a shortage of skilled staff. One of the companies I visited, for example, subcontracted no less than 15 per cent of its operations to another contractor. As it happened, the subcontractors were either graduates of TVET centres or universities. Employers did believe that they were contributing to graduate employment generation directly or indirectly, through subcontracting as well as through involving graduates with quite a range of activities, including building shades and fences, and making bricks.

Skills imports: Employers and graduates alike commented on the practice of 'skills imports', particularly by foreign-owned companies. These companies bring qualified staff from abroad and hire a semi-skilled or unskilled domestic workforce. This was reiterated by one of the general managers of a foreign-owned company, who said 'our company hired engineers from abroad not from the domestic ones'. ${ }^{18}$ This provides a clue that there are situations where foreign direct investment may not contribute to the absorption of youths who are graduates but yet unemployed, unless there are mechanisms to urge them to leave some positions for local youths. Otherwise, the probability of transferring knowledge and skills of engineers from developed or developing countries to the underdeveloped ones will remain a longterm vision. This may likely be due to their having less regard for the available skills among graduates. I argue that this practice, particularly if widespread, limits the possibilities for skills transfers as graduates do not work directly with expatriate staff.

Short-term training: Employers I interviewed noted that they routinely provide short-term training for new employees, particularly graduates. Often the training they offer helps graduates adjust to the working conditions in their respective companies, but this comes at a cost - both financially and also because there is no guarantee of making the new recruit commit to the company.

Coaching: I have noted many instances of skills mismatches where graduates are placed in positions that have nothing to do with their university training. I have also come across cases where senior staff coach new staff, particularly those deployed in areas that they were not trained in. Some of the employers noted that this practice saved them time and resources that would have been spent on organising formal training for new staff. 


\section{Discussion and conclusions}

This study explored private construction sector employers' expectations of engineering graduates, focusing on how these expectations are not being met due to skills gaps and mismatches, and the reasons for this. I also explored the strategies companies used to bridge skills gaps.

I found that, while employers in the private (as well as public) construction sector expect to employ well-equipped and adaptable engineering graduates, universities produce graduates mainly equipped with theoretical knowledge but short in practical skills. Skills gaps manifest in technical skill areas as well as communication and teamwork skills, problem-solving skills, and so forth. On the other hand, widespread deployment of graduates to manual works such as bricklaying clearly shows the presence of skills mismatches, which undermines years of university-level training. In a nutshell, expectations of private construction sector employers are found to be unmet, and the root cause of the problem points to weakness of the university engineering curriculum which, it appears, has not been designed to address the needs of employers. It should also be noted that the observed new ways of working and more frequent changes in the world of jobs (by necessity or opportunity) call for a broader set of skills.

Therefore, the higher education curriculum needs to be responsive to the interests of employers and take planned action to equip graduates with the required and up-to-date employability skills. For the most part, efforts for the development of employability skills and attributes should be integrated within the curriculum. The fact that teaching and learning at the universities has been inadequately funded has also contributed to a low level in quality of graduates. In response to this, emphasising and recognising the importance of teaching quality, it is important to encourage teachers to devote time and effort in modern methods of teaching (Salmi et al. 2017). In relation, the most recommendable approach to support and reward teaching excellence is the use of targeted funding; this is successfully used in a number of developing and developed countries (ibid.). Moreover, private contraction work is dependent on government contracts and the availability of foreign exchange to import contraction materials. More often, contracts to the private sector were either delayed or underfinanced. These, coupled with shortages of foreign exchange and raw materials, have limited the sector's ability to hire and retain graduates.

Moreover, recruitment practices, particularly within the private sector, lack transparency and equal employment opportunities. In this regard, it is not uncommon to see many graduates being hired through friends and family circles, worsening the unemployment conditions for many talented graduates who lack such (it has to be said, unethical) connections. Consequently, employers should abide by the merit-based code of conduct upon recruitment of graduates. 
The strategies employers reported to use to overcome challenges of skills gaps and skills mismatches, are: outsourcing, skills imports, short-term training, and substituting or co-coaching. Nonetheless, the study highlighted the need to improve the quality of graduate-level education in universities. While the expansion in higher education and in the engineering sector in particular is commendable, this has to be matched by high graduate standards. Quality has to be a number one priority, and students need to be taught practical and entrepreneurial courses. In other words, more emphasis should be placed in the higher education institutions to bridge skills gaps and mismatches of the graduates and to produce competitive and compatible graduates who can meet private sector expectations.

Encouragement of engineering graduates to seek out jobs by setting up their own businesses and providing the necessary support should not be left to chance, but is the concern of policymakers, universities, and all other stakeholders. I recommend that the Ministry of Education, universities and faculties, and employers (both private and public sector) work collaboratively to create more spaces for graduates and also serve society. Further, educators, political leaders, and the media have to devote time, resources, and attention towards private sector growth to enhance chances for youth employment opportunities.

\section{Notes}

* This issue of the IDS Bulletin was produced in partnership with Mastercard Foundation.

1 Bahir Dar University, Ethiopia.

2 Personal interview, May 2018.

3 Personal interview, May 2018.

4 Personal interview, May 2018.

5 Personal interview, June 2018.

6 The youth often organise themselves in micro and small enterprises and undertake minor town and city roads, pavements, etc.

7 Personal interview, May 2018.

8 Personal interview, May 2018.

9 Personal interview, May 2018.

10 Personal interview, June 2018.

11 Personal interview, May 2018.

12 Personal interview, June 2018.

13 Personal interview, May 2018.

14 Personal interview, May 2018.

15 Personal interview, May 2018.

16 Personal interview, June 2018.

17 Personal interview, June 2018.

18 Personal interview, June 2018. 


\section{References}

Addis Standard (2017) 'Commentary: Protest-Driven "Economic Revolution": Can It Solve Bread and Butter Questions?' 20 March, http://addisstandard.com/commentary-protest-driven-economicrevolution-can-solve-bread-butter-questions/ (accessed 5 June 2018)

AfDB (2016) Fobs for Youth in Africa: Strategy for Creating 25 Million Fobs and Equipping 50 Million Youth 2016-2025, African Development Bank, www.afdb.org/fileadmin/uploads/afdb/Documents/ Boards-Documents/Bank_Group_Strategy_for_Jobs_for_Youth_in_ Africa_2016-2025_Rev_2.pdf (accessed 20 May 2018)

Africa Renewal (2017) 'Youth Unemployment: Lessons from Ethiopia', www.un.org/africarenewal/magazine/may-2013/youthunemployment-lessons-ethiopia (accessed 2 May 2018)

Africa Renewal (2013) Touth Unemployment: Lessons from Ethiopia, www.un.org/africarenewal/magazine/may-2013/youthunemployment-lessons-ethiopia (accessed 17 June 2018)

Aring, M. (2012) Youth and Skills: Putting Education to Work, background paper prepared for the Education for All Global Monitoring Report 2012, http://unesdoc.unesco.org/images/0021/002178/217874e.pdf (accessed 13 November 2018)

Ayele, S.; Khan, S. and Sumberg, J. (2017) 'Introduction: New Perspectives on Africa's Youth Employment Challenge', IDS Bulletin 48.3: 1-12, http://bulletin.ids.ac.uk/idsbo/article/view/2866 (accessed 3 August 2018)

BBC (2018) Why has Ethiopia Imposed a State of Emergency?, 21 February, www.bbc.co.uk/news/world-africa-43113770 (accessed 25 June 2018)

BDU (forthcoming, 2018) 'Graduate Tracer Study on 2015 and 2016 Graduates of Bahir Dar Institute of Technology', Bahir Dar, Ethiopia: Bahir Dar University

CSA (2014) Statistical Report on the 2013 National Labour Force Survey, Addis Ababa: Central Statistical Agency, https://searchworks.stanford.edu/ view/11682466 (accessed 5 October 2018)

C.SA (2013) Education Statistics Annual Abstract, Addis Ababa: Central Statistical Agency, www.moe.gov.et (accessed 10 March 2018)

EEA (2008) Report on the Ethiopian Economy Volume VI 2006/7: The Current State of the Construction Industry, Addis Ababa, Ethiopia: Ethiopian Economic Association

FDRE (2016) Growth and Transformation Plan II (GTP II), Addis Ababa, Ethiopia: National Planning Commission, Federal Democratic Republic of Ethiopia, https://dagethiopia.org/new/images/ DAG_DOCS/GTP2_English_Translation_Final_June_21_2016.pdf (accessed 5 October 2018)

FDRE (2004) National Youth Policy, Addis Ababa, Ethiopia: Ministry of Youth, Sports and Culture, Federal Democratic Republic of Ethiopia, www.youthpolicy.org/national/Ethiopia_2004_National_ Youth_Policy.pdf (accessed 5 October 2018)

FDRE/Ministry of Education (2017) Education Statistics Annual Abstract, Addis Ababa, Ethiopia: Federal Democratic Republic of Ethiopia, www.moe.gov.et (accessed 10 March 2018) 
Gebremariam, E.B. (2017) 'The Politics of Youth Employment and Policy Processes in Ethiopia', IDS Bulletin 48.3: 33-50, http://bulletin.ids.ac.uk/idsbo/article/view/2868 (accessed 3 August 2018)

Gebru, B. (2017) 'The Problem of Youth Unemployment in Ethiopia', Ethiopian News, 1 December, www.ethiopiaprosperous.com/2017/12/ problem-youth-unemployment-ethiopia/ (accessed 17 May 2018)

Kilimani, N. (2017) 'Youth Employment in Developing Economies: Evidence on Policies and Interventions', IDS Bulletin 48.3: 13-32, http://bulletin.ids.ac.uk/idsbo/article/view/2867 (accessed 7 August 2018)

Korpela, K. (2017) 'Wishing for Better Jobs: Understanding the Mismatch between Education and Youth Employment in Ethiopia', MA thesis in Economic Development, School of Economics and Management, Lund University, http://lup.lub.lu.se/luur/ download?func $=$ downloadFile\&recordOId $=8925631 \&$ fileOId $=8925632$ (accessed 5 October 2018)

McGuinness, S.; Pouliakas, K. and Redmond, P. (2017) How Useful is the Concept of Skills Mismatch? Geneva: International Labour Organization, www.ilo.org/wcmsp5/groups/public/---ed_emp/---ifp_skills/ documents/publication/wcms_552798.pdf (accessed 3 May 2018)

Melese, M.K. (2012) Employment Challenges in Eastern Africa in the Context of Ethiopia, Nairobi: Friedrich Ebert-Stiftung

Mncayi, P. (2016) 'An Analysis of the Perceptions of Graduate Unemployment among Graduates from a South African University', International Journal of Social Sciences and Humanity Studies 8.1: 67-83

Salmi, J.; Sursock, A. and Olefir, A. (2017) Improving the Performance of Ethiopian Universities in Science and Technology. A Policy Note, Washington DC: World Bank

Sodipe, O.A. and Ogunrinola, O.I. (2011) 'Employment and Economic Growth Nexus in Nigeria', International Fournal of Business and Social Science 2.11: 232-9

Tefera, H. (2013) 'Management Control of Projects in Construction Industry: Ethiopian Context', unpublished MBA thesis, Business Administration, Indira Ghandi National Open University, http://repository.smuc.edu.et/bitstream/123456789/1538/1/ Hailemeskel\%20Tefera.pdf (accessed 10 October 2018)

Tran, T.T. (2014) Graduate Employability in Vietnam: A Loose Relationship between Higher Education and Employment Market, Hamburg: Anchor Academic Publishing

UNGTAD (2017) World Investment Report 2017: Investment and the Digital Economy, Geneva: United Nations, www.unctad.org/en/pages/PublicationWebflyer.aspx?publicationid=1782 (accessed 17 May 2018)

UNESCO (2012) Youth and Skills: Putting Education to Work, Paris: United Nations Educational, Scientific and Cultural Organization World Bank (2018) Africa's Pulse: Africa's Economic Future, Vol. 17, Washington DC: World Bank, https://openknowledge.worldbank.org/ handle/10986/29667 (accessed 5 October 2018) 
World Economic Forum (2014) Matching Skills and Labor Market Needs: Building Social Partnerships for Better Skills and Better fobs, Davos-Klosters: World Economic Forum

Yizengaw, J. (2016) 'Higher Education and Labor Market in Ethiopia: A Tracer Study of Graduate Employment in Engineering from Addis Ababa and Bahir Dar Universities', PhD thesis, International and Comparative Education, Addis Ababa University, http://etd.aau.edu.et/bitstream/handle/123456789/3799/ Jerusalem $\% 20$ Yibetal.pdf? sequence $=1$ \&isAllowed $=y$ (accessed 5 October 2018) 


\title{
Fostering Agribusiness Entrepreneurship for Kenyan Youth through Practice-Based Education" ${ }^{+}$
}

\author{
John Muchira ${ }^{1}$
}

\begin{abstract}
Approximately 1 million Kenyan youth enter the labour market each year, a number which the formal sector has been incapable of absorbing. As a result, youth unemployment and underemployment rates are high, with two-thirds of youth aged 15-24 not engaged in the labour force. The lack of formal wage opportunities pushes these young people into entrepreneurial activities; however, due to the theoretical focus of the current education system, many secondary school-leavers do not possess the practice-based skills to start their own businesses. This article argues for building partnerships between secondary schools, largely in rural areas, and agribusinesses to foster skills-building that will enable young people to start entrepreneurial activities in the agricultural sector. It draws on interviews with agribusiness owners and stakeholders in the education sector, and survey data from secondary school students and on youth employment to identify how to improve youth employability through business-led experiential programmes.
\end{abstract}

Keywords: agribusiness, youth, entrepreneurship, experiential learning, education, training, (un)employment, self-efficacy.

\section{Introduction}

Youth unemployment remains a global challenge, with the percentage of 15-24-year-olds who are not in the labour force being as high as 70.5 per cent, 64.4 per cent, and 50.5 per cent in the Arab States, Southern Asia, and sub-Saharan Africa respectively, while the world average is 56.8 per cent (ILO 2018). Particularly in Africa, most countries continue to experience a 'youth bulge' - a situation in which more than 40 per cent of the population is 15-29 years old (Evoh 2012; Guengant and May 2013) - and have economies whose structure is incapable of benefiting from this demographic dividend. This demographic trend and the resultant economic challenges have rendered the formal sector incapable of absorbing the growing numbers 
of young Africans entering the labour market (AfDB and OECD 2012); thus, the majority of young people will likely remain working in the informal sector (Filmer and Fox 2014) or unemployed.

Similarly, both Kenya's overall population, as well as specifically its youth population, have been on the rise, with the overall population increasing from 29.7 million to 46.6 million in the last two decades (GoK 2018b). Approximately 1 million Kenyan youth enter the labour market each year without competitive skills (ILO 2014). As a result, in 2018, 65 per cent of youth aged 15-24 are not in the labour force (ILO 2018) as there are not enough job opportunities, and it is often challenging for young school-leavers to start sustainable micro and small enterprises, particularly due to a lack of the requisite skills. While the definition of who constitutes 'youth' varies within and across countries and development organisations (Ayele, Khan and Sumberg 2017), here I utilise the 2009 Kenya Population and Housing Census categorisation of youth, which encompasses people aged 15-35 years old (GoK 2010). However, the article specifically focuses on those aged 15-24 years old because the unemployment rate is most pronounced among this group of youth (ILO 2018).

Cognisant of the country's youth bulge and unemployment situation, the Kenyan government has shown interest in policy-level transformation of youth empowerment. This transformation has a key focus on youth employability, life skills, and entrepreneurship development (GoK 2018c) through programmes such as Kazi kwa Vijana (Jobs for the Youth) and the Youth Enterprise Development Fund (Sikenyi 2017). While these programmes are essential strategies for economic development and the realisation of Kenya's Vision 2030, ${ }^{2}$ they have been crippled by mismanagement and corruption (ibid.), and therefore have not contributed much to economic development or improvement of young people's livelihoods. A further strategy by the Government of the Republic of Kenya (GoK 2018c) is supporting private sector growth through various programmes coordinated by the departments of Devolution, Industrialisation, Enterprise Development, and Public Service and Youth Affairs.

Particularly, the Department of Public Service and Youth Affairs is keen to ensure stakeholder collaboration that leverages investment targeted at youth empowerment, as well as the integration and mainstreaming of youth intervention programmes in sectoral and macro policies at both the county and national levels. It is expected that the private sector, especially those specialising in agribusiness, will benefit as the government is keen to create a more enabling investment environment for this sector (ibid.). I argue that this new government approach should support experiential learning - also referred to as 'learning by doing' - through medium-sized agro-processors, and where possible, reinforce practice-based learning among schoolgoing youth by initiating collaborations with family-based micro and small agribusinesses. 
Kenya's economy has experienced continuous growth in the past two decades, from the low increases in gross domestic product (GDP) of 0.6 per cent in the early 2000s to an average annual growth of 5.56 per cent between 2013 and 2017 (GoK 2018d). Despite this growth in GDP, evident growth in the private sector, and support from the government and international organisations, youth unemployment - conceptualised in this article as the situation in which an individual is not currently working despite his/her efforts in actively looking for a job - is growing (ILO 2014), and it is considered a threat to social, economic, and political stability.

Thus, this article aims to offer insights on issues of business-led entrepreneurship development and practice-based knowledge among Kenyan youth, by exploring the potential of reinforcing their entrepreneurial identity in the agriculture sector. By entrepreneurship, I mean the process of identifying the potential opportunities for innovation, and starting and growing a business (Dhliwayo 2008). This can be done specifically through developing entrepreneurship education and training curricula, with the objective of equipping young people with entrepreneurial skills and knowledge as to how to identify business opportunities within the agriculture sector. This would enable young people to effectively engage in productive and potentially economically viable agricultural activities as a means of livelihood. This can also be done by reinforcing business-led collaboration among crucial government institutions to design effective youth experiential learning opportunities through apprenticeship programmes. It is also important to foster partnerships between secondary school systems and key stakeholders within the private sector in order to equip young people while still enrolled in secondary schools with modern agricultural practices, practical skills for identifying value chains in agribusiness, and knowledge on how to market their agricultural products. These approaches are conspicuously missing in policy dialogue, the current secondary school curriculum, and the development agenda in Kenya, and this article therefore seeks to fill this research gap.

The remainder of this article is structured as follows. Section 2 presents an overview of business-led entrepreneurship development and experiential learning, and discusses how promoting agribusiness is likely to reduce the youth unemployment rate. Section 3 discusses the methodology of the study, while the findings are discussed in Section 4. Section 5 concludes and presents some policy recommendations.

\section{Business-led entrepreneurship development through experiential learning \\ 2.1 Experiential entrepreneurship education}

Limited and lack of formal wage employment opportunities push young people into entrepreneurship as an alternative option (Amin 2009). However, these young people, especially those from developing African economies, face a daunting task as they are not equipped with the requisite entrepreneurial skills and fundamental knowledge to establish 
Figure 1 Conceptual framework for entrepreneurship development

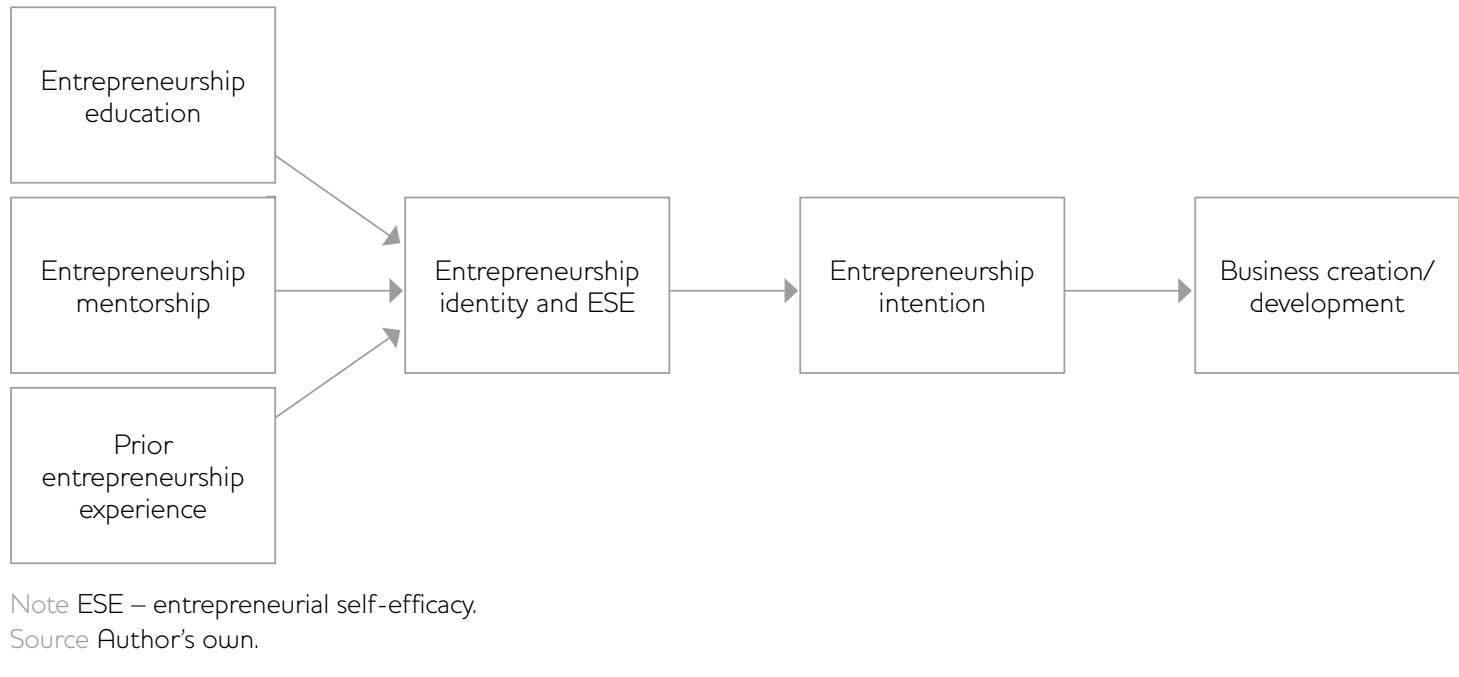

a venture or grow an already established business (Schoof 2006; Shittu 2017). Thus, it is important to understand how experiential learning 'the process whereby knowledge is created through the transformation of experience' (Dhliwayo 2008: 330) - enhances young people's entrepreneurial self-efficacy (ESE).

The framework in Figure 1 is an illustration of how entrepreneurship education, entrepreneurial mentorship, and entrepreneurship experience develop young people's entrepreneurial identity, and ESE, and consequently trigger their entrepreneurship intentions and actual entrepreneurial behaviour. ${ }^{3}$

Notably, while experiential entrepreneurship learning could be gained by the rural youth by engaging in farm activities/agribusiness skills, these activities only represent a part of what is needed because entrepreneurship development generally involves innovative practices in agribusiness, as well as exposure to other real-life practices. A formal education system that utilises practice-based opportunities such as using entrepreneurial role models in the agriculture sector or taking students on field trips is an equally effective channel to enhance young people's entrepreneurial skills. It is also worth noting that for most of the schoolgoing youth who are less likely to have started their own businesses, their entrepreneurial experience comes from being involved in family business operations. This is important as previous studies show that a positive correlation exists between prior entrepreneurial exposure gained from working in family businesses and entrepreneurial outcomes (Athayde 2009; Carr and Sequeira 2007). It has also been demonstrated that intentions are immediate precursors to the creation of start-ups/ small enterprises (Kickul et al. 2009), and therefore, identifying significant predictors of young people's ESE is a crucial step towards solving Kenya's high unemployment. 
In addition to the role of experiential learning in developing young people's rural livelihoods through entrepreneurship capabilities in agribusiness (Robinson-Pant 2016), literature on entrepreneurial identity has been highlighted as important in agriculture entrepreneurship (Fitz-Koch et al. 2018). One of the strategies that has the potential to develop entrepreneurial identity and ESE is mentorship for novice and aspiring young entrepreneurs through entrepreneurship education (Donnellon, Ollila and Middleton 2014; Rhodes and DeBois 2008). However, literature on how exactly youth mentorship works in developing countries is very limited, which is a hindrance to public policy, especially pertaining to youth entrepreneurship programmes (Shittu 2017). Thus, I posit that micro, small and medium-sized enterprises (MSMEs) in agriculture, especially in agro-processing, have the potential to enhance youth entrepreneurship outcomes. Through interactions during experiential learning opportunities, the youth will develop partnerships and other necessary social networks with those who are already in the agribusiness sector. This could enable youth to create more innovative and sustainable start-ups in this sector of the economy. Though youth are more likely to create micro-enterprises, these have the capacity to eventually grow into small and medium businesses, thus consequently creating more employment opportunities for future generations.

Besides the gap in the literature on experiential learning and youth mentorship, evidence exists on the significance of agricultural role models in motivating and preparing youth for successful careers in agribusiness (Haggblade et al. 2015). Approximately 22 per cent of the role models in Haggblade et al.'s (2015) study highlighted the importance of initiating mentorship activities with youth at early stages of their education, in primary and secondary schools. The study also recommends that it is important to link students to private sector role models who will be able to demonstrate that agriculture can be a profitable business opportunity, because 'large segments of Africa's youth remain dismissive of agriculture and disinterested in agriculturally related careers' (ibid:: 171). This is despite the fact that agriculture has historically been Africa's largest employer (World Bank 2007), and that most of the entry-level jobs which are likely to absorb the growing youth population into the labour market are projected to come from domestic agriculture and the agribusiness sector (Fine et al. 2012); this is particularly due to demand for packaged food products and value chains over the next few decades to cater for the growing urbanisation in most African countries (Haggblade et al. 2015).

Agriculture as well as other technical subjects are only taught as elective subjects at secondary school level in Kenya, with only one topic dedicated to entrepreneurship. In addition, the current curriculum inherited from the colonial system is purely theoretical and thus evidently not relevant for the less industrialised Kenyan economy. Therefore, the students are not adequately instilled with the practical skills and knowledge related to enterprising. However, studies have shown that through promoting hands-on training with medium-sized 
agro-processors and other willing agricultural enterprises, students' entrepreneurial capabilities, problem-solving skills, and other non-cognitive abilities will be developed - skills which have been proven to greatly enable the identification of entrepreneurship opportunities (Karimi et al. 2016).

\subsection{Youth employment and agribusinesses in Kenya}

In this article, agribusiness is conceptualised as a sector of the economy that involves agricultural activities such as crop farming, animal rearing, processing, adding value to agricultural products, and the trading of farm inputs. In Kenya, agribusiness MSMEs operate either formally or informally, employing a range of employees: a micro family-owned enterprise may employ five people whereas medium-sized agricultural firms and agro-processors may have 100 employees. Agribusiness is identified as a crucial economic sector as it has greater youth employment potential compared to sectors such as manufacturing and some service industries (ILO 2018).

Agriculture therefore continues to be the dominant sector of employment for the majority of youth in Kenya and in other African countries (Brooks 2012; see also Wossen and Ayele, this IDS Bulletin). Thus, in addition to practice-based entrepreneurship education, rural transformation (diversifying rural economies from agriculture activities to regional and global agri-food systems and value chains, and enhancing urbanisation (Berdegué, Rosada and Bebbington 2014; see also Wossen and Ayele, this IDS Bulletin)) is an important pathway for youth employment opportunities. This is a particularly fitting strategy as most of the youth in Kenya work in the agricultural and service sectors (Brooks et al. 2013; ILO 2018). Nevertheless, the contribution of agricultural activities to GDP, specifically those involving crop-growing, has increased from 18.4 per cent in 2013 to 24.9 per cent in 2017 (GoK 2018a).

The agriculture sector has historically provided a large percentage of employment opportunities for Kenyans, but there has been a steady decline in the last 15 years, while employment in the industry sector has seen a positive increase and the service sector has been stable (ILO 2018). Specifically, the general employment rate in the agriculture sector stands at 38 per cent in comparison to 46 per cent in 2000, while the employment rate in the service and industry sectors has averaged 48 per cent and 14 per cent respectively since 2016 (GoK 2018a). With this notable recent decline in agriculture as the main source of employment in Kenya, it is prudent to re-examine the skills and knowledge that youth are exposed to in their early stages of education. This is particularly important since a mismatch between the development of skills and demand in the labour market has been identified as a major contribution to youth unemployment (Omolo 2012). Youth currently represent 34.1 per cent of the Kenyan unemployed labour force, of which 19.2 per cent are 20-24 years old (GoK 2018a). 


\begin{tabular}{|c|c|c|c|c|c|c|}
\hline Economic activity & 2013 & 2014 & 2015 & 2016 & 2017 & Gain since $2013^{*}$ \\
\hline Agriculture & $1,254,760$ & $1,483,077$ & $1,897,347$ & $2,311,862$ & $2,442,371$ & $1,187,611$ \\
\hline Manufacturing & 506,612 & 537,999 & 588,896 & 653,839 & 648,397 & 141,785 \\
\hline Wholesale and retail trade & 380,646 & 431,985 & 473,395 & 524,303 & 588,540 & 207,894 \\
\hline Transport and storage & 378,525 & 462,457 & 510,488 & 561,757 & 599,438 & 220,913 \\
\hline Real estate & 375,588 & 417,829 & 474,318 & 532,121 & 575,347 & 199,759 \\
\hline
\end{tabular}

Table 1 shows that between 2013 and 2017, the agriculture sector was the leading source of GDP in Kenya and its contribution surpassed that of other leading economic sectors, including manufacturing, wholesale and retail trade, transport and storage, and real estate (ibid.). This indicates that agriculture is an area within the private sector that will potentially help not only reduce youth unemployment in Kenya but also enhance sustainable rural transformation.

Undoubtedly, the acquisition of practical agro-entrepreneurial skills is vital for African youth development, and it is believed that it might be 'what will make the difference between persistent poverty and sustainable livelihoods, between widespread frustrated aspirations and social stability' (Moore 2015: 195). These are timely development approaches because demand for fresh fruit and vegetables in Kenya has increased at an annual rate of 10-12 per cent during the last decade to cater for local consumption as well as regional and global value chains (ITC 2014; Krishnan 2018).

Furthermore, incorporation of value-addition mechanisms for agricultural products is likely to increase the profit-level margins of young rural agro-entrepreneurs, making agribusiness an attractive employment opportunity. However, this can only be best achieved once the youth have attained reliable experiential skills from MSMEs. Youth should therefore be exposed to alternative agribusiness activities such as diversification into horticulture, which includes fruits and vegetables (Weinberger and Lumpkin 2007). They should also be offered information on how they can engage in agro-entrepreneurship through contract farming whereby they can supply agricultural products to supermarkets, a market opportunity that has come about to cater for the rising urban population, with a projected demand of US\$1 trillion's worth of food by 2030 (Adenle, Manning and Azadi 2017).

\section{Methods and data sources}

This study uses a mixed-methods approach, utilising surveys and 12 interviews gathered from key educational stakeholders and owners of 
agribusinesses. Excerpts of qualitative interviews used in this article include:

An interview with a secondary school curriculum expert from the Kenya Institute of Curriculum Development (KICD);

Two interviews with high school principals;

Four interviews with secondary school business teachers;

Two interviews with directors of studies; and

Three interviews with agribusiness owners.

The interviews were conducted at different times between September 2016 and June 2018. The school interviews were used in examining the extent to which the formal business education curriculum instils students with effective entrepreneurial knowledge. In-depth interviews with owners of agribusinesses examined the current state of the agribusiness sector and the skill levels demonstrated by youth working in the sector, in order to inform policy recommendations on how to create more employment opportunities for young people. Eleven schools were identified from six counties in Kenya (Nairobi, Kirinyaga, Machakos, Uashin Gishu, Homabay, and Kakamega) through purposeful and convenient sampling techniques. Purposeful sampling was used to best understand the current state of entrepreneurship education in Kenya considering the socioeconomic and demographic landscape in the country.

In addition to the qualitative component, quantitative data were gathered using a survey methodology. A total of 1,324 students completed a five-point Likert-scale questionnaire that was based on DeNoble, Jung and Ehrlich's (1999) measure of ESE. This survey sought to measure young people's ESE; that is, their beliefs about business-related capabilities, which include: developing new products and services, recognition of business opportunities based on market demands, and developing relationships with potential business partners and human resource personnel to ensure growth of their business(es). Students' prior entrepreneurship experience from family-owned enterprises was the predictor and was measured by assessing their personal and demographic information as well as how they responded to the question: 'Do you help your parents in running their business[es]?'. Using a youth student sample in the study was very appropriate because they had less than six months to secondary school completion, with the majority highly likely to enter into the labour market rather than enrolling in post-secondary institutions.

\section{Findings and discussion}

\subsection{Entrepreneurship education must include practical learning}

Evidence from the qualitative data supports the need for practice-based entrepreneurship education and training as it identifies that youth do not have the appropriate skills required for innovative entrepreneurial 
activities and value-addition, whereby products are processed to increase their economic value in the competitive agricultural sector. Specifically, interviews with educational stakeholders reveal the deficiency in the current curriculum and present recommendations as to how to develop students' ESE. An interviewee from KICD underlined that there is a challenge in the basic education system as the focus is on instilling students with theoretical knowledge. He said that students 'are not taught practically... they will get very good grades [and] go to the university, but they will never get the practical information because of the theory and not practical focus. ${ }^{\text {, }}$ However, as highlighted by the same interviewee, the majority of the students never go to university but join the growing number of unemployed youth.

The lack of practice-based learning opportunities was confirmed by interviews with the high school principals and teachers. Evidence from these interviews revealed that organising experiential activities for youth could improve their entrepreneurship interest in the future as well as their success in starting their own businesses. For instance, a director of studies said:

Maybe if we change the curriculum in such a way that the teaching techniques is [sic] more practical, like Art is more practical, so we do it more experimental, more practical, in examples it will totally change students' capabilities of starting their own businesses in the future. ${ }^{5}$

Her recommendations were supported by a school principal: 'If we can be able [sic] to bring in the practical aspect of these subjects, particularly agriculture and business, these are the subjects that can make a student develop those skills of entrepreneurship. ${ }^{6}$ Her sentiments were supported by another principal who acknowledged the need for reforms which are being conducted by KICD as the current curriculum is very academic-based. Ensuring that the curriculum incorporates practical learning was strongly recommended by most of the stakeholders interviewed. For instance, a business studies teacher mentioned that 'the curriculum needs to be reviewed, we need to incorporate practical lessons in the curriculum. ${ }^{77}$ Without practical experiential learning within the education system, youth will not be exposed to modern and effective agribusiness activities.

It was evident from the interviews that the curriculum is not relevant to the realities of the business world; for instance, a director of studies in a school in the western region of Kenya said:

There is no linkage from secondary to the entrepreneurial business world. Students are never exposed to know more on how to start a business, how or what are the opportunities that are available. So, exposing them [students], maybe in a market to see how people make money and how people do business or start businesses or any entrepreneurial activities, will be [more] effective rather than teaching theoretically. ${ }^{8}$

With minimal evidence of state-led agribusiness entrepreneurship development as a strategy to reduce the unemployment rate, MSMEs 
are a potential agent of supporting rural transformation and experiential learning, as the private sector is more in touch with the enterprising aspects of the agriculture industry. Interviews conducted with agribusiness owners pointed out that youth who are transitioning into agricultural activities from schools lack innovative strategies and the practical skills to engage in agribusiness activities or to successfully identify a potential market for their products. A commercial maize farmer from Kakamega County with 24 years' experience in the sector therefore recommended practice-oriented training to be supported by central government, such as through the Ministry of Education and Ministry of Public Service, Youth and Gender Affairs, as well as the county government to improve youth skills. This was confirmed by the other two agribusiness owners from Kirinyaga County. One of these owners is a commercial farmer with over 25 years' experience ranging from coffee farming to horticultural and dairy farming, and who has more than 15 full-time employees. According to this interviewee, it is imperative for youth to be exposed to practice-based agribusiness training through apprenticeship opportunities. Participating in agribusiness apprenticeship will help the youth 'learn how to process agricultural produce, [which] will make them earn more money. ${ }^{99}$ But with the minimal evidence of such experiential learning opportunities in Kenya, this agro-entrepreneur thinks that 'the government should partner with successful and experienced agribusiness people to offer apprenticeship to the youth such as modern techniques like greenhouse farming. ${ }^{, 10}$

It was not evident from the interviews with the agribusiness owners whether the youth who acquired practice-based skills were offered permanent employment by their employers, but some of those who acquired capital were able to utilise the skills they had gained to start their own businesses. While the interviews did not clearly show youth employment outcomes through engaging in agricultural activities, the three agribusiness owners highly recommended mentorship programmes. Nevertheless, they acknowledged the challenge of having a successful youth mentorship programme without a well-structured collaboration plan between the private sector and government institutions.

\subsection{Experiential learning influences youth entrepreneurial self-efficacy}

Though the interviews with agribusiness and educational stakeholders highlighted how experiential learning contributes to the development of entrepreneurial skills and identity, the employment outcome was not very clear. Thus, I used quantitative data in which ESE is an outcome variable and practice-based experience is the predictor variable to complement the interview data. The results of the regression model are discussed in this section.

As demonstrated through the regression analysis from a survey completed by 1,324 participants enrolled in 11 secondary schools in Kenya, experiential entrepreneurship experience gained through helping in family businesses influenced students' ESE. The linear 
Table 2 Results of the regression analysis with entrepreneurial self-efficacy as the outcome variable and practical entrepreneurial experience as the predictor variable

\begin{tabular}{lccccc}
\hline Predictor variable & B & Std. Error & Beta & t & Sig. \\
\hline Constant & 92.21 & 0.50 & & 185.28 & $<.001$ \\
\hline Practical entrepreneurial experience & 4.28 & 0.61 & 0.20 & 7.08 & $<.001$ \\
\hline
\end{tabular}

regression model used to show the relationships between the predictor variable and the outcome variable is:

$\mathrm{ESE}=\beta 0+\beta$ 1 practical entrepreneurial experience $+\varepsilon_{i}$, where ESE represents entrepreneurial self-efficacy, which is the outcome variable, $\beta 0$ represents the intercept, $\beta 1$ represents the slope, and $\varepsilon_{i}$, represents the error term.

The intercept is the expected mean value of students' ESE when practical experience is zero, and the slope/gradient is the rate of change in students' ESE with the change in their practical experience.

The results are given in Table 2, with ESE being $92.21+4.28$ (practical entrepreneurial experience) + standard error. Results show that practical entrepreneurial experience is a statistically significant predictor of students' ESE, $p<.001$. The results also show that when practice-based experience was used as the outcome variable, the model was significant $\left(\mathrm{F}_{1,1201}=50.06, p<.001\right)$ and practice-based experience explained 4 per cent of the statistically significant unique variance of ESE. While this is a weak variance, measuring entrepreneurial attributes is challenging as it should involve sociological, personal, demographic, psychological, and business-related factors (Ruiz, Soriano and Coduras 2016) and this could be associated with the low variability in the model. The higher $\mathrm{F}$ value of 50.06 and its associated $\mathrm{P}$ value which is $<.001$ for alpha $=<.05$ indicates that the linear regression model has predictive capability, so I reject the null hypothesis because of that statistical significance.

Given a unit increase in practical entrepreneurial experience, ESE is equivalent to a score of approximately 96.49. Therefore, the regression model presented shows that practical entrepreneurial experience has an influence on students' ESE. This shows that there exists a positive relationship between the predictor and the outcome variable.

Among the independent variables examined in the larger study to measure predictors of students' ESE among final year secondary school students in Kenya - including level of business studies education, tribe/ethnic culture, family entrepreneurship history, family socioeconomic status, the type of school the students are attending and their gender - practical entrepreneurship experience gained from 
helping in family-owned businesses accounted for most of the variance in ESE. Therefore, integrating practical-based (experiential) learning in formal youth education and training develops young people's ESE. This is supported by previous studies which have shown that there is higher impact on students' entrepreneurial outcomes when accompanied by hands-on training experience (Anderson, Envick and Padmanabhan 2012; Kassean et al. 2015).

The present study is therefore consistent with prior studies which have shown that young people who have grown up in family businesses develop practice-based experiences which have an influence on their ESE and entrepreneurial intentions (Carr and Sequeira 2007). In addition, skills gained from helping in these family-owned businesses consequently enable school-leavers to start their own businesses in the future or support the already existing family business at later stages in life (Athayde 2009).

Developing young people's ESE is a crucial step in creating entrepreneurs. According to DeNoble et al.'s (1999) study, there is a significant positive correlation between ESE and intention (with $r=.37, p<.001$ ). Similarly, our findings support the need for practice-based entrepreneurship learning among young people as this form of exposure has an influence on the development of their ESE. Furthermore, the results of the study reveal the importance of ESE among young people, because without the self-belief that one can be successful in establishing a business, it is daunting to develop any entrepreneurial intention and subsequent action.

\section{Conclusions and policy recommendations}

Lack of self-employment skills continues to be a major impediment for young people in Kenya. With recent government surveys showing that there are not enough jobs for youth, there is a need for collaboration between the policy drivers in government, stakeholders in the private sector, and those in education and training institutions. One area that can benefit from such partnerships is agriculture because it has the potential to create more employment opportunities and improve rural youth livelihoods. Evidence from the data analysed in this article suggests the need for business-led entrepreneurship development and curricula reforms, whereby young people will not only be exposed to entrepreneurship knowledge to identify potential agribusiness opportunities, but also how to develop competitive businesses within the agriculture sector. As a strategy for solving the increasing rate of youth unemployment, this article also advocates for experiential entrepreneurship education and training as it was found to be an effective way of developing young people's ESE. While the above-mentioned strategies have the potential to foster entrepreneurship development, in order to ensure a well-structured plan in which youth acquire the relevant entrepreneurial skills, I make the following policy recommendations. 
First, with the ongoing curricula reforms spearheaded by KICD, I recommend the integration of life skills and experiential entrepreneurial elements into the basic education curriculum by involving the relevant private sectors because they generally have real entrepreneurship experience in various crucial industries. This recommendation is supported by prior studies which have shown that when practice-based education and training is incorporated into the secondary school curriculum, students get opportunities to engage in projects similar to experiences in the actual entrepreneurial environment, which consequently improves their entrepreneurial outcomes (Bell 2015; Hynes, Costin and Birdthistle 2010; Kassean et al. 2015). However, for effective entrepreneurial outcomes, I acknowledge that it will be prudent to initiate teacher-training programmes to ensure that teachers are equipped with the necessary skills and knowledge to implement the new curriculum and to positively influence students' perceptions about engaging in agribusiness activities. Also, since just the few students taking business studies and agriculture subjects are exposed to the scant educational materials on entrepreneurship and agribusiness knowledge in the current curriculum, business studies should also be made compulsory for all students up to tenth grade and agriculture made compulsory for all rural-based secondary schools.

Second, the Ministry of Education should collaborate with the Ministry of Industrialisation and Enterprise Development, and the Directorate of Youth Affairs in designing experiential learning opportunities for the youth through apprenticeship programmes. In rural Kenya, exposing youth to real-life entrepreneurial activities offered by agribusiness MSMEs will develop their ESE, as demonstrated in the regression model and will equip them with the competitive agribusiness skills as demonstrated by the interviewed agribusiness owners. Consequently, this will enable the youth to start sustainable agribusiness-related micro and small enterprises.

Lastly, I recommend the involvement of successful agribusiness owners in youth educational field trips as this will allow young people to acquire the relevant entrepreneurship skills such as venture identification, teamwork, and problem-solving, as well as life skills and critical thinking skills. Through interacting with agribusiness owners, particularly those from the local community, some young people will not only develop tacit knowledge but also acquire social networks that will potentially help them to navigate the competitive agribusiness sector in the future. Young people will also develop strategies as to how to venture in agribusiness, ranging from establishing micro-enterprises to small enterprises. These collaborative strategies with stakeholders within the business world will enhance students' analytical skills and instil them with an entrepreneurial mindset. 


\section{Notes}

* This issue of the IDS Bulletin was produced in partnership with Mastercard Foundation.

† This research was partially supported by a grant from the Jim Moran Institute for Global Entrepreneurship, Florida State University. The author is grateful to the study's participants, the two anonymous reviewers for their insightful comments, feedback from research mentors and editors, and support from peers.

1 Florida State University.

2 Kenya's Vision 2030 (GoK 2008) is a government programme that was launched in 2008 with the aim of transforming the country into a globally competitive and industrialised middle-income economy.

3 Note that business creation is not always a linear process as Figure 1 may suggest. For example, entrepreneurial intentions could be reinforced by entrepreneurial education or mentorship but those with entrepreneurial intentions could also seek mentorship to enhance their capability to create and grow businesses.

4 Interview, September 2016.

5 Interview, May 2017.

6 Interview, June 2017.

7 Interview, May 2017.

8 Interview, June 2017.

9 Interview, June 2018.

10 Interview, June 2018.

\section{References}

Adenle, A.A.; Manning, L. and Azadi, H. (2017) 'Agribusiness Innovation: A Pathway to Sustainable Economic Growth in Africa', Trends in Food Science and Technology 59: 88-104

AfDB and OECD (2012) African Economic Outlook 2012. Special Theme: Promoting Youth Employment, African Development Bank and Organisation for Economic Co-operation and Development, www.undp.org/content/dam/rba/docs/Reports/African $\% 20$ Economic\%20Outlook\%202012\%20En.pdf (accessed 11 September 2018)

Amin, M. (2009) Labor Productivity in the Informal Sector: Necessity vs. Opportunity Firms, Washington DC: World Bank

Anderson, R.; Envick, B.R. and Padmanabhan, P. (2012) 'A Practical Framework for the Continuous Advancement of Entrepreneurship Education', American Fournal of Economics and Business Administration 4.1: $65-71$

Athayde, R. (2009) 'Measuring Enterprise Potential in Young People', Entrepreneurship Theory and Practice 33.2: 481-500

Ayele, S.; Khan, S. and Sumberg, J. (2017) 'Introduction: New Perspectives on Africa's Youth Employment Challenge', IDS Bulletin 48.3: 1-12, http://bulletin.ids.ac.uk/idsbo/article/view/2866 (accessed 3 August 2018)

Bell, R. (2015) 'Developing the Next Generation of Entrepreneurs: Giving Students the Opportunity to Gain Experience and Thrive', International fournal of Management Education 13.1: 37-47 
Berdegué, J.A.; Rosada, T. and Bebbington, A.J. (2014) 'The Rural Transformation', in B. Currie-Alder, R. Kanbur, D. Malone and R. Medhora (eds), International Development: Ideas, Experience, and Prospects, Oxford: Oxford University Press

Brooks, J. (ed.) (2012) Agricultural Policies for Poverty Reduction, Paris: OECD Publishing

Brooks, K.; Zorya, S.; Gautam, A. and Goyal, A. (2013) Agriculture as a Sector of Opportunity for Young People in Africa, Policy Research Working Paper 6473, Washington DC: World Bank, Sustainable Development Network, Agriculture and Environmental Services Department, http://elibrary.worldbank.org/doi/pdf/10.1596/1813-9450-6473 (accessed 5 May 2018)

Carr, J.C. and Sequeira, J.M. (2007) 'Prior Family Business Exposure as Intergenerational Influence and Entrepreneurial Intent: A Theory of Planned Behavior Approach', Fournal of Business Research 60.10: 1090-98

DeNoble, A.F.; Jung, D. and Ehrlich, S.B. (1999) 'Entrepreneurial Self-Efficacy: The Development of a Measure and its Relationship to Entrepreneurial Action', Frontiers of Entrepreneurship Research 1999.1: 73-87

Dhliwayo, S. (2008) 'Experiential Learning in Entrepreneurship Education: A Prospective Model for South African Tertiary Institutions', Education + Training 50.4: 329-40

Donnellon, A.; Ollila, S. and Middleton, K.W. (2014) 'Constructing Entrepreneurial Identity in Entrepreneurship Education', International Fournal of Management Education 12.3: 490-99

Evoh, C.J. (2012) 'Taming the Youth Bulge in Africa: Rethinking the World Bank's Policy on Technical and Vocational Education for Disadvantaged Youth in the Knowledge Economy', in C.S. Collins and A.W. Wiseman (eds), Education Strategy in the Developing World: Revising the World Bank's Education Policy, Bingley: Emerald Group Publishing

Filmer, D. and Fox, L. (2014) Youth Employment in Sub-Saharan Africa, Africa Development Series, Washington DC: World Bank

Fine, D. et al. (2012) Africa at Work: Job Creation and Inclusive Growth, McKinsey \& Company, www.mckinsey.com/featured-insights/ middle-east-and-africa/africa-at-work (accessed 11 September 2018)

Fitz-Koch, S.; Nordqvist, M.; Carter, S. and Hunter, E. (2018) 'Entrepreneurship in the Agricultural Sector: A Literature Review and Future Research Opportunities', Entrepreneurship Theory and Practice 42.1: 129-66

GoK (2018a) Economic Survey 2018, Nairobi: Kenya National Bureau of Statistics, Government of the Republic of Kenya, www.knbs.or.ke/ download/economic-survey-2018/ (accessed 5 May 2018)

GoK (2018b) Labour Force Basic Report, Nairobi: Kenya National Bureau of Statistics, Government of the Republic of Kenya, www.knbs.or.ke/download/labour-force-basic-report/ (accessed 20 May 2018)

GoK (2018c) The Presidency, Ministry of Public Service, Youth and Gender Affairs, www.psyg.go.ke (accessed 10 May 2018) 
GoK (2018d) Quarterly Gross Domestic Product Report First Quarter, 2018, Nairobi: Kenya National Bureau of Statistics, Government of the Republic of Kenya, www.knbs.or.ke/download/quarterly-grossdomestic-product-report-first-quarter-2018/ (accessed 20 June 2018)

GoK (2010) Kenya 2009 Population and Housing Census Highlights, Nairobi: Kenya National Bureau of Statistics, Government of the Republic of Kenya

GoK (2008) Kenya Vision 2030, Nairobi: Government of the Republic of Kenya, www.vision2030.go.ke/ (accessed 10 May 2018)

Guengant, J.P. and May, J.F. (2013) 'African Demography', Global fournal of Emerging Market Economies 5.3: 215-67, http://journals.sagepub.com/doi/abs/10.1177/0974910113505792\# articleCitationDownloadContainer (accessed 4 October 2018)

Haggblade, S. et al. (2015) 'Motivating and Preparing African Youth for Successful Careers in Agribusiness: Insights from Agricultural Role Models', Fournal of Agribusiness in Developing and Emerging Economies 5.2: 170-89

Hynes, B.; Costin, Y. and Birdthistle, N. (2010) 'Practice-Based Learning in Entrepreneurship Education: A Means of Connecting Knowledge Producers and Users', Higher Education, Skills and Work-Based Learning 1.1: 16-28

ILO (2018) World Employment and Social Outlook (WESO) Data Finder, International Labour Organization, https://bit.ly/2N7T6KF (accessed 15 May 2018)

ILO (2014) Global Employment Trends 2014: The Risk of a fobless Recovery, Geneva: International Labour Organization, www.ilo.org/global/ research/global-reports/global-employment-trends/2014/ WCMS_233953/lang--en/index.htm (accessed 15 May 2018)

ITC (2014) Trade Map, International Trade Centre, www.trademap.org/ (accessed 3 August 2018)

Karimi, S.; Biemans, H.J.; Lans, T.; Aazami, M. and Mulder, M. (2016) 'Fostering Students' Competence in Identifying Business Opportunities in Entrepreneurship Education', Innovations in Education and Teaching International 53.2: 215-29

Kassean, H.; Vanevenhoven, J.; Liguori, E. and Winkel, D.E. (2015) 'Entrepreneurship Education: A Need for Reflection, Real-World Experience and Action', International Fournal of Entrepreneurial Behavior and Research 21.5: 690-708

Kickul, J.; Gundry, L.K.; Barbosa, S.D. and Whitcanack, L. (2009) 'Intuition Versus Analysis? Testing Differential Models of Cognitive Style on Entrepreneurial Self-Efficacy and the New Venture Creation Process', Entrepreneurship Theory and Practice 33.2: 439-53

Krishnan, A. (2018) 'The Origin and Expansion of Regional Value Chains: The Case of Kenyan Horticulture', Global Networks 18.2: 238-63, https://doi.org/10.1111/glob.12162 (accessed 11 September 2018)

Moore, K. (2015) 'Fostering Economic Opportunities for Youth in Africa: A Comprehensive Approach', Enterprise Development and Microfinance 26.2: 195-209 
Omolo, J. (2012) Youth Employment in Kenya: Analysis of Labor Market and Policy Interventions, FES Kenya Occasional Paper 1, Nairobi: Friedrich Ebert Stiftung

Rhodes, J.E. and DuBois, D.L. (2008) 'Mentoring Relationships and Programmes for Youth', Current Directions in Psychological Science 17.4: 254-58

Robinson-Pant, A. (2016) Learning Knowledge and Skills for Agriculture to Improve Rural Livelihoods, Paris and Rome: United Nations Educational, Scientific and Cultural Organization (UNESCO) and the International Fund for Agricultural Development (IFAD)

Ruiz, J.; Soriano, D.R. and Coduras, A. (2016) 'Challenges in Measuring Readiness for Entrepreneurship', Management Decision 54.5: $1022-46$

Schoof, U. (2006) Stimulating Youth Entrepreneurship: Barriers and Incentives to Enterprise Start-Ups by Young People, SEED Working Paper 76, Geneva: International Labour Office

Shittu, A.I. (2017) 'Promoting Youth Entrepreneurship: The Role of Mentoring', IDS Bulletin 48.3: 141-54, http://bulletin.ids.ac.uk/idsbo/article/view/2875 (accessed 3 August 2018)

Sikenyi, M. (2017) 'Does Kenya's Youth Enterprise Development Fund Serve Young People?', IDS Bulletin 48.3: 127-40, http://bulletin.ids.ac.uk/idsbo/article/view/2874 (accessed 3 August 2018)

Weinberger, K. and Lumpkin, T.A. (2007) 'Diversification into Horticulture and Poverty Reduction: A Research Agenda', World Development 35.8: 1464-80

World Bank (2007) World Development Report 2008: Agriculture for Development, Washington DC: World Bank 


\title{
Navigating Precarious Livelihoods: Youth in the SME Sector in Zimbabue
}

\author{
Simbarashe Gukurume ${ }^{1}$
}

\begin{abstract}
Since the late 1990s, Zimbabwe has experienced a protracted socioeconomic and political crisis. This crisis was marked by unprecedented unemployment rates, company closures, retrenchments, and rapid informalisation. In the face of employment uncertainties, many youth joined the burgeoning small and medium enterprises (SME) sector. This article explores private SME growth in Harare and shows how it enables young people to navigate the unemployment crisis. Based on the lived experiences of youth working in the retail and clothing SME sector in Harare, the article argues that young people deploy their agency and resourcefulness in grappling with unemployment by devising creative and inventive ways of 'getting by' through engagement with SMEs. Although SME sector growth can help create employment for youth, the nexus is complex. Both the number and quality of jobs created remain problematic. The SME sector is also politically sensitive, so young people have to navigate partisan politics as well.
\end{abstract}

Keywords: SMEs, youth employment, decent work, social navigation, private sector, youth bulge.

\section{Introduction}

This article examines how urban youth in Harare have responded to Zimbabwe's 'unemployment crisis'. The problem of youth unemployment in post-colonial Zimbabwe is well documented (Bennel and Ncube 1994; Grant 2003; Chirisa and Muchini 2011; Kang'ethe and Mafa 2015). According to some sources, unemployment rates have reached over 94 per cent (Langa 2016; Gukurume 2017; ILO 2015; Dekker 2009). Young people under the age of 35 years constitute the majority of the unemployed and underemployed in the country (Zinhumwe 2012). The economy is failing to absorb a growing number of graduates seeking employment (Garwe 2014; Mahiya 2016). Many young Zimbabweans have been pushed into precarious strategies of survival in the informal economy. The concept of precarity relates to contemporary forms of work organisation epitomised by 
meagre salaries, lack of representation, job insecurities, poor working conditions, and casualisation (Allison 2013; Standing 2015). Scholars use the concept of precarity to refer to precarious employment, jobs that are unstable and lowly paid (see e.g. Standing 2015).

This article makes three related arguments. First, the burgeoning small and medium enterprises (SME) sector not only enables youth to navigate the challenges of everyday life, but also has great potential to create jobs for young people. Second, although the SME sector has a huge potential to create employment, the quantity and quality of jobs created remain insufficient to satisfy the demand for decent and secure work among young people. Finally, the SME sector is fraught with ambiguities, where young people are earning a living, but giving up on their aspirations due to the precarities in the sector.

The article contributes to debates on challenges facing young people across sub-Saharan Africa, by examining how young Zimbabweans engage with employment and livelihood opportunities in the SME sector. It unpacks the precarities and political dynamics in the sector and how young people navigate them. The article draws on the lived experiences of young people in Harare, the capital, to understand the potential value of the booming SME sector in tackling youth unemployment in the country.

The rest of the article is organised as follows. Section 2 conceptualises and discusses the SME sector in Zimbabwe. Section 3 addresses the methodology of the study. Section 4 discusses how engagement in the SME sector enables young people to navigate socioeconomic uncertainties and the nature of jobs created in the SME sector. While Section 5 addresses the socioeconomic and political context that shapes the workings of the SME sector in Zimbabwe, Section 6 deals with the politicisation of the SME sector and its implications for job creation. Finally, Section 7 provides the conclusions.

\section{The SME sector in Zimbabwe}

The SME sector has great potential to create more jobs for youth, and is the most thriving sector in Africa (Odero 2006; Zindiye, Chiliya and Masocha 2012; Ngek and van Aardt Smit 2013) and beyond (Lukács 2005; Mandl 2017). Evidence from the European Union suggests that small businesses contribute more significantly towards job creation than do large firms (de Wit and de Kok 2014). In Zimbabwe, the SME sector represents the largest employer, especially of young people (Nyamwanza 2014; Nyoni and Bonga 2018). In 2017 alone, 13,000 SMEs registered with the Zimbabwe Revenue Authority to pay taxes (Nsingo 2017). Overall, there are over 60,000 registered SMEs in Zimbabwe, which contribute up to 60 per cent to the country's gross domestic product (GDP) (Mangudya 2017).

SMEs operate in diverse sectors, such as textiles, agribusiness, information and communications technology (ICT), and construction. Some of these 
sectors are potentially labour-intensive (Makumbi, this IDS Bulletin). SMEs are also flexible and rooted in local economies, meaning that they have the potential to create jobs in both rural and urban areas. For these reasons, the character and quality of SMEs make them central in the private sector and youth employment creation puzzle.

Unemployment in many African countries is alarming and often framed as a serious 'ticking time bomb' (Shindler 1997). This has seen the emergence of problematic discourses relating to youth 'dividends' and 'bulges', which instrumentalise young people and construct them as security threats (Flynn et al. 2017). Many scholars writing on and about young people in Africa have engaged with such discursive frames like the 'youth bulge' (Oosterom et al. 2016; Ayele, Khan and Sumberg 2017) and the 'demographic dividend' (Eastwood and Lipton 2012; Ayele et al. 2017). The youth bulge concept refers to demographics characterised by a large youth population living in an area. This body of work views the youth bulge as both an opportunity and a threat to stability, security, and economic growth in sub-Saharan Africa. Proponents of the 'demographic dividend' discourse are optimistic that the 'youth bulge' may be a potential asset for youth to drive economic growth and development in Africa and globally (DFID 2016; AfDB 2016). Like many African countries, Zimbabwe's experience reflects a wider African situation characterised by youth bulge, jobless growth, and unemployment, albeit with its own unique dynamics.

In Zimbabwe, unemployment occurred side by side with the emergence of multiple ways of getting by. Mwaura (2017) and Namuggala (2017) have also noted similar trends among Kenyan and Ugandan youth respectively. As Mwaura (2017) found, 'side-hustling' was a popular way of survival and wealth accumulation. Side-hustle denotes income-earning activities young people engage in 'on the side', normally over weekends or during their spare time, not only to supplement their income, but also to accumulate capital in anticipation for more livelihood opportunities. In Zimbabwe, a country fraught with protracted political and economic crisis, this attempt to make do and get by gave impetus to the rapid growth of SMEs in many cities (Maunganidze 2016). According to the International Monetary Fund (IMF), Zimbabwe has the second largest informal economy in the world and the informal sector is the country's biggest labour market (Medina and Schneider 2018). ${ }^{2}$ The informal sector has been called a livelihood haven' for many urbanites in the country (Kamete 2017). In 2017, Bell and Mawadza (2017) described Zimbabwe as increasingly 'an SME economy', in which small business activities have become dominant in the country's economic and commercial landscape. The Zimbabwean government has pursued a long-term strategy of support for SMEs, having established the Small Enterprises Development Corporation (SEDCO) in 1983 and a ministry for SMEs in 2005.

At independence in 1980, Zimbabwe possessed one of the strongest economies in Africa, with large-scale investment inflows in domestic 
manufacturing and agriculture, and a GDP growth rate averaging 5.5 per cent from 1980 to 1990 (Kanyenze 2003). However, the adoption of the neoliberal Economic Structural Adjustment Programme (ESAP) prescribed by the IMF and the World Bank in the early 1990s exacerbated Zimbabwe's economic meltdown (Kanyenze 2003) and from the late 1990s, Zimbabwe confronted an unprecedented socioeconomic and political crisis (Gukurume 2015). This crisis accelerated due to the government's controversial policies, and poor macroeconomic and fiscal management (Magure 2012; Gukurume 2015). It worsened in 2008, when Zimbabwe experienced a serious hyperinflation akin to the 1922-23 Germany inflation. Young people were the hardest hit by this economic crisis (Chirisa and Muchini 2011). More than 60 per cent of them endured protracted unemployment, and political and economic marginalisation (Gukurume 2017). This pushed them into the SME sector.

The SME sector now generates over half of the private sector employment in the country and generates close to 60 per cent of the country's GDP (Mangudya 2017; Nyoni and Bonga 2018). According to Mangudya (2017), the sector comprises over 2.8 million enterprises of different sizes and employs more than 5.7 million people, approximately 4.2 million of these being young people under the age of 35. Estimates of SMEs' aggregate scale, turnover, and number of employees continue to rise (Mangudya 2017).

In Harare, SMEs support the livelihoods of nearly 1 million youth who struggle to be absorbed into the dwindling public sector job market. In the context where job opportunities hardly keep pace with the number of college graduates, the sector has become an alternative space for generating livelihoods. SMEs are evidently playing a crucial role in securing and maintaining household incomes (Nyoni and Bonga 2018; Maunganidze 2016).

The SME sector is composed of firms of varying sizes and diverse types. The definitions and conceptualisation of SMEs vary from one sector to another. SMEs are normally defined based on firm size, the amount of profits, and number of workers a firm employs (Zindiye et al. 2012; Nyamwanza 2014). Popular definitions of SMEs involve formal and informal enterprises and are measured against the perceived or estimated size of the sector (Nyoni and Bonga 2018). This article focuses on formal SMEs. The most widely used definition of SMEs in Zimbabwe is that of SEDCO (2010) which defines SMEs as registered firms which employ a maximum of 100 workers and with an annual turnover in sales of a maximum of US\$830,000 (see also Zindiye et al. 2012).

In post-2000 Zimbabwe, SMEs grew rapidly due to economic collapse and the adoption of controversial anti-investor policies such as the indigenisation and empowerment policies that compelled foreign companies to cede 51 per cent of their shares to locals (Magure 2012). Maunganidze (2016) argued that the government acts as an obstacle 
and an engine of SME growth simultaneously. Although the SME sector has the potential to promote economic growth and create employment, it has remained largely underfunded and unsupported (Odero 2006). There has been a clear lack of adequate support for the SMEs in Zimbabwe, which is largely due to lack of coordination within the organisations responsible for SME growth (Maunganidze 2016).

\section{Methodology}

This article is based on qualitative ethnographic fieldwork with youth in the SME sector in Harare between 2016 and 2018. Semi-structured interviews were conducted with 40 participants (22 male and 18 female) aged between 18 and 35, and ten key informant interviews were conducted with retail and clothing SME owners. Semi-structured interviews were supplemented with data from key informant interviews, focus group discussions, and numerous informal conversations with informants. Informants were identified through snowballing and purposive sampling techniques, to select information-rich cases. Interviews were largely conducted in English, although some participants preferred to use Shona - a local language - exclusively or mixed with English. The interviews focused on young people's lived experiences and perceptions on the quality of work in the SME sector. Key informant interviews with SME owners solicited their perspectives on decent work in the sector. Some of the participants had tertiary-level education, many had a bachelor's degree, and a number had diplomas from vocational/polytechnical colleges.

This article is based on youth in retail and clothing SMEs in Harare. Clothing and retail SMEs were selected because most of them are not only thriving, but also constitute the majority in the SME sector. All the SMEs that I engaged with were formally registered and were selected based on their real and perceived potential to create more jobs. These SMEs employed between 20 and 100 workers and were growth-oriented.

\section{Young people and the SME sector: navigating between opportunity and precarity}

In analysing youth engagement in the SME sector, the concept of social navigation (Vigh 2009; Utas 2005; Honwana 2012; Oosterom forthcoming, 2019) unpacks the ways through which youth grapple with unemployment and related livelihood uncertainties. Social navigation entails a specific dialogical engagement and relationship between agents/actors (youth) and their socio-political and economic environment (Arnaut 2012), akin to Bourdieu's 'field'. In framing the SME sector as a 'field', the article adopts Arnaut's (2012) argument that young people's 'tactical agency' is embedded in, and textured by, opportunities and precarities contained in the field. In Zimbabwe, where chronic crisis and endemic uncertainties (Vigh 2008; Cooper and Pratten 2015) are common, the concept of social navigation is a compelling analytical category to understand young people's everyday life. 
In his analysis of youth navigation in war contexts, Vigh (2009) showed how young people use their agency to orient themselves towards imagined futures. Chronic crisis compels youth to consider how they can navigate constraining socioeconomic and political spaces. In Zimbabwe, party politics in the SME sector texture young people's subjectivities, yet enable them to reimagine their aspirations, time, and temporality (Masquelier 2013). I use the concept of social navigation to assert that young people find a way to manoeuvre uncertainties and unemployment. Social navigation enables us to understand youth agency in negotiating the prevailing socioeconomic and political realities. From this section onwards, empirical data on young people's experiences in the SME sector are used to discuss and unpack their agency, creativity, and ingenuity in navigating unemployment and attendant anxieties.

Young people are not only employees in the SME sector, they also own SMEs in their own right, employing other youth. Young employees and small business owners in Harare explained that engagement in the SME sector enables them to navigate socioeconomic uncertainties and hardships. Joseph, ${ }^{3}$ who was working in a clothing shop, said:

It is definitely better than just being idle and jobless at home. If I compare myself with my colleagues who are just seated at home, I can pay my rentals, buy some food and save some money to remit to my parents in the rural areas. ${ }^{4}$

Joseph explained that since he started working in the clothing shop he is no longer regarded as a rovha (loafer), a derogatory label given to young people who are doing nothing and who depend on their parents for housing, finances, and food. The term rovha is often linked to juvenile delinquency, laziness, petty crime, drug abuse, and violence. Many informants shared Joseph's dislike of being called a 'rovha'. Even though they aspired to white-collar office jobs, the potential stigma and labelling motivated them to take up anything to earn some money. By taking up any available and multiple forms of generating income, young people engage in the logic of kukiya kiya (Jones 2010). Kukiya kiya relates to multiple ways of making do and getting by, which are often at the margins of the economy and legality. Kukiya kiya is epitomised by goal-oriented improvisational economic actions. Literally, kukiya means locking up, but people use it metaphorically to refer to the many ways and activities people engage in to survive. By engaging in any sort of work, even kukiya kiya (Jones 2010), young people can earn respect and avoid name-calling. Though kukiya kiya can be viewed as a technique used by the unemployed (rovha), for my interlocutors, kukiya kiya is an alternative form of employment. This echoes the argument (Namuggala 2017) that there is a need to rethink essentialist and formalised conceptualisations of work in tandem with the meanings youth attach to what they do to survive. Irvine explained:

I had to take up a job as a till operator even though I have a sociology degree. I graduated in 2010, but my frantic efforts of getting a job were in vain. People in my neighbourhood started calling me names. I could not stand being called 
'rovha'. People think that you are lazy, so that is why I took up this short-term contract-based job in the shop as a till operator. ${ }^{5}$

Irvine noted that the job is insecure, the pay is meagre, and the working conditions are poor, but he will continue to do it to contribute to the family income.

Although the work is often precarious, employment in the SME sector enabled social mobility for some young people in Harare. Diversifying and acquiring livelihood assets is one of the myriad of strategies through which youth working in the SME sector navigate and negotiate the perceived vagaries of precarious employment. For instance, Tapiwa, who worked in a small retail shop in Harare, explained that through his savings, he managed to purchase land in Epworth (a dormitory town close to Harare) and a small car that he used as an informal taxi (mushikashika) in the city centre. Tapiwa's experience is exceptional, as through working in the SME sector he has managed to diversify his sources of income, improve his 'ontological security' by buying a property, and invest in other assets. Ontological security refers to the feeling of mastery and control over the chaotic, uncertain, and threatening conditions of everyday life (Giddens 1991; Grenville 2007; Maguire and Murphy 2016).

Ontological security strengthens young people's belief that they have the capacity and urge to fight off uncertainties and existential anxieties, which make their everyday life meaningless (Maguire and Murphy 2016). Tapiwa's income also enabled him to help with the family income. He paid his young brother's tuition fees at a local secondary school and he hoped that a better-paying job would enable him to cover the school fees for all of his siblings; this was an expectation of his parents. Other informants' work also allowed them to meet expectations. Josphat, a graduate of marketing was able to pay lobola/roora (bride wealth) and get married. He did so with the money he was making as a shop floor supervisor at the Red Bull retail shop and as a taxi driver.

Although Tapiwa was doing relatively well, with his national accounting diploma he still harboured hopes of getting a better-paying job in one of Harare's big firms:

This is not what I want to be doing for the rest of my life, I want to be a chartered accountant but as things are now I have to support my family and also try to make some money. My parents sacrificed for my education, they sold livestock to send me to school and so now it is my turn to help them even though formal and better-paying jobs are hard to come by. ${ }^{6}$

Tapiwa's friend, Timothy, also juggled two jobs in a bridal shop in town and a grocery shop during weekends at his home area in Glen View.

Tapiwa and Timothy engaged in survival strategies that involve multiple income-earning activities, hustling (Thieme 2013), and side-hustling (Mwaura 2017). In Ghana, 'hustling' is a rational strategy 
used by young people to increase their income and insure against any non-payment by employers (Yeboah 2017). Josphat co-owned a clothing shop with a business partner, Patrick. They decided to start the business together after failing to get jobs for several years. They travel to Tanzania, South Africa, and Botswana to buy clothes for resale in Harare. Before starting this business, Josphat was staying with and dependent on his parents for everything. However, through the income from his business, Josphat moved out, started renting, and got married. Josphat's experience demonstrates how SMEs allow some young people to progress and establish themselves within society. Josphat managed to navigate 'waithood' and attain the social markers of adulthood (Mwaura 2017) through engagement with the SME sector. The labour market is an important 'rite of passage' to adulthood (Honwana 2012; Oosterom et al. 2016). Without jobs, youth remain stuck/in limbo, between youthhood and adulthood (Honwana 2012; Gebremariam 2017; Mwaura 2017).

The opportunities offered by SMEs enabled young people to fulfil family responsibilities and to move on socially by renting their own home, marrying, etc. The relative success of Josphat and Patrick's business shows the centrality of social networks and collaborative potential in SME sector growth. While their case represents entrepreneurship, I contend that this is made possible through working in SMEs to raise start-up capital and expand such businesses. Importantly, their business is also a space for potential job creation for other youth. The pooling of resources and ideas helped Josphat and Patrick to boost their capital to establish their own business, overcome financial limitations, and advance their aspirations and social mobility. Indeed, the majority of participants noted that engagement with the SMEs empowered them to be active social and economic actors in their communities. The SME sector clearly plays an important role in allowing young people to navigate difficult work environments, and sometimes escape poverty and unemployment.

\section{Precarity, decent work, and the SME sector}

Although many of the participants (in semi-structured interviews) noted that the SME sector is an important avenue for alternative employment, the majority of them raised concerns about the nature of jobs created in SMEs. Locardia, a 23-year-old woman working as a till operator in a retail SME in Mbare explained that she and other workers have short-term contracts and are not paid well. After completing her sociology degree, she spent 18 months looking for a job and joined a retail shop when her friend recommended her. Although Locardia was happy to have a job, she plans to start up her own business and employ other youth. The job was to raise enough capital to start her own business. While aware of the economic and political constraints that come with forming and running an SME, Locardia said she was willing to take up the challenge.

The experiences of Locardia and other participants showed that the SME sector is associated with insecure and/or undesirable jobs. There 
is a very complicated relationship between young people's aspirations, employment preferences, and the nature of jobs available and created in the SME sector.

Similarly, poor working conditions in some of the SMEs emerged as a major issue about the level of decent work. Tadiwa highlighted exploitative practices at his workplace. When it comes to the question of 'decent work', the efficacy of SMEs in creating desirable and sustainable jobs for the youth is questionable.

\section{Politicisation of the private and SME sector}

The SME sector in Harare is deeply politicised. Politics, particularly the Zimbabwe African National Union-Patriotic Front (ZANU-PF) heavily interfere with the operations of the private sector and SMEs in Harare. The partisan influence and control of the economy is not new. The partisan allocation of resources such as jobs and market stalls was part of ZANU-PF's political mobilisation strategy (Kamete 2017; Maringira and Gukurume forthcoming, 2018; Oosterom forthcoming, 2019). For instance, Maringira and Gukurume (forthcoming, 2018) show how ZANU-PF used commercial space as a way of cementing political patronage and garnering political mileage. This study confirms these findings. In fact, during fieldwork, ZANU-PF deployed violent youth militia to control the private sector and more particularly SMEs in the Mbare and Glen View neighbourhoods in Harare. ZANU-PF uses SMEs as a way of rewarding youth who do the work of violence for the political party. Politics has played a critical role in mediating who is included and excluded in the private sector. Partisan actors mediate opportunities in SMEs (Oosterom forthcoming, 2019). Indeed, some of the participants asserted that the ZANU-PF membership card mediated access to, and ownership of, an SME. For instance, Adam explained:

For you to get a market stall in here in Mbare you have to be ZANU-PF, if you are not then there is nothing for you. They make it a point that only ZANU-PF supporters get space here. My boss is a well-known ZANU-PF supporter, so ZANU-PF politicians control everything here. ${ }^{7}$

Patrick, a member of the ZANU-PF youth league who owns a shop in Mbare also explained:

This is our stronghold; we have targeted the SME sector for our youth empowerment and indigenisation programme. As the architects of youth empowerment, we, the ZANU-PF youth, are the primary beneficiaries. We give space to patriotic youth; $M D C$ [Movement for Democratic Change] people are sell-outs and we cannot reward sell-outs, can we?

Patrick's narrative is part of ZANU-PF's broader discourse of 'patriotic history' (Ranger 2004). This patriotic history creates a binary of 'patriots' and 'sell-outs'. In this framing, patriots, the ZANU-PF youth, are rewarded by the political 'big man' (McCauley 2012), while perceived 'sell-outs' are excluded from benefits in the SME sector. My findings reveal a deep-seated patrimonialism and patronage politics in 
the everyday workings of SMEs, and in the ways in which young people gain employment and navigate the dynamics of SME politics.

Political capital was central for some young people in their entry into the SME sector in Harare. This was particularly relevant in Mbare and Glen View where ZANU-PF aligned with youth militia and vigilante groups such as Chipangano who controlled access to operating space and entrance into the SME landscape. Margret explained:

Here the passport to own a shop is to have a ZANU-PF membership card and to attend all ZANU-PF activities such as rallies and solidarity marches as well as welcoming the president at the airport from his foreign trips. If you do this, no one questions you. ${ }^{9}$

Judith also echoed Margret's views and explained, 'You have to be ZANU-PF supporter to get and maintain your business or be employed here.' ${ }^{\prime 10}$

Although partisan politics constrained some young people's entry into the SME sector, some devised innovative ways of navigating these constraints. Takunda explained:

I do not support ZANU-PF and I have never voted for them, but because I need to survive and access resources, I bought the membership card and I chant their slogans and attend their activities to make life easy for me in the market. ${ }^{11}$

My findings confirm the argument that young people's livelihood activities are intricately linked to their social lives and politics, particularly the politics that shape how SMEs operate (Kamete 2017; Oosterom et al. 2016; Maringira and Gukurume forthcoming, 2018). Indeed, since young people are embedded in social and political relationships, the ways in which they pursue opportunities for work will also be mediated by more than just their skills and demand for labour, but by how they navigate divisive national and local-level politics which (re)shape the nature of the local labour market and economy (Oosterom et al. 2016).

Many SME owners (from the study) felt that the government should provide an enabling environment for the growth of the SME sector. Some bemoaned the challenge of political interference and rent-seeking behaviour of the state. Many emphasised that to unlock the great potential of the SMEs in tackling youth unemployment, there has to be minimal political interference in the sector. One of the SME owners, Mr Jambo, explained: 'The problem we have is that the SME sector in this country is heavy political involvement and influence in how we operate. ${ }^{12}$

For SME owners, the political climate is also important for how they start, access, or run an SME. The political interference has negative implications on the growth of the SME sector and affects its capacity to contribute meaningfully to economic growth and job creation. 
Although the SME sector is by far the largest employer in Zimbabwe (Enste and Schneider 2000; Mbiriri 2010), there is a conspicuous lack of recognition and support from the state and other stakeholders, such as banks (Zindiye et al. 2012). Findings showed that many SMEs are financially excluded and lack access to financial services. An SME employer explained, 'We would want to improve the working conditions and remuneration of our workers but without enough financial support, it is very difficult. ${ }^{, 13}$

Most SMEs do not have collateral to access bank loans and other forms of credit. This undermines their capacity for growth. For the majority of SMEs, without support, labour demand will remain low, and so will the creation of more jobs. SMEs in Zimbabwe also face stiff competition from Chinese SMEs that sell cheap products (Gukurume 2018). Some interlocutors bemoaned lack of protection from unfair competition. To them, cheap Chinese products are pushing them out of business.

\section{Conclusion}

This article has explored the complex dynamics of the growing SME sector in addressing the youth employment crisis in Zimbabwe. It has looked in-depth at how the SME sector can help young people to navigate socioeconomic uncertainties. While participation in the sector can enable young people to escape poverty, the nature of the jobs created are insecure and poorly paid. These jobs are often not compatible with the dreams and aspirations of the majority of the young people. Therefore, I contend that the SME sector offers opportunities for young people, but these opportunities are often precarious. As such, for the SME sector to realise its full potential in job creation, such precarities have to be managed and addressed. Some of the precarities emanate from constant political interference, which means that young people not only have to navigate the precarious job market, but partisan politics as well. This is compounded by the operational constraints that SMEs (despite their potential) face in providing decent and non-precarious employment. Thus, there is the need for approaches to mitigate this downside of SME-driven economies, through support for private sector SME growth and strict monitoring of labour practices in the sector.

\section{Notes}

* This issue of the IDS Bulletin was produced in partnership with Mastercard Foundation.

1 PhD candidate at the Institute for Humanities in Africa (HUMA), University of Cape Town.

2 https://www.herald.co.zw/zim-has-worlds-second-largest-informaleconomy-imf/.

3 Pseudonym and all the other names used in this article are anonymised.

4 Interview 10, 15 June 2017.

5 Interview 11, 17 June 2017.

6 Interview 3, 10 May 2017. 
7 Interview 1, 10 November 2016.

8 Interview 38, 3 March 2018.

9 Interview 20, 4 March 2017.

10 Interview 26, 12 May 2017.

11 Interview 23, 10 May 2017.

12 Interview 8, 14 June 2017.

13 Interview 35, 10 December 2017.

\section{References}

AfDB (2016) Bank Group Strategy for Fobs for Youth in Africa, 2016-2025, Abidjan: African Development Bank

Allison, A. (2013) Precarious Japan, Durham NC: Duke University Press

Arnaut, K. (2012) Social Mobility in Times of Crisis: Militant Youth and the Politics of Impersonation in 2002-2011, MICROCON Research Working Paper 58, Brighton: MICROCON

Ayele, S.; Khan, S. and Sumberg, J. (2017) 'Introduction: New Perspectives on Africa's Youth Employment Challenge', IDS Bulletin 48.3: 1-12, http://bulletin.ids.ac.uk/idsbo/article/view/2866 (accessed 3 August 2018)

Bell, S. and Mawadza, C. (2017) Re-Igniting SME Development in Zimbabwe, Private Sector Development blog, World Bank Group, 31 July, http://blogs.worldbank.org/psd/re-igniting-sme-developmentzimbabwe (accessed 10 March 2018)

Bennel, P. and Ncube, M. (1994) 'Jobs for the Boys? The Employment Experiences of Secondary School-Leavers in Zimbabwe', Journal of Southern African Studies 20.2: 301-16

Chirisa, I. and Muchini, T. (2011) 'Youth Unemployment and Peri-Urbanity in Zimbabwe: A Snapshot of Lessons from Hatcliffe', International Fournal of Politics and Good Governance 2.2: 1-15

Cooper, E. and Pratten, D. (2015) Ethnographies of Uncertainty in Africa, Basingstoke: Palgrave Macmillan

Dekker, M. (2009) Livelihoods and Economic Crisis: The Case of Smallholder Farmers in Zimbabwe (1999-2008), Oxford: Centre for the Study of African Economies, University of Oxford

de Wit, G. and de Kok, J. (2014) 'Do Small Businesses Create More Jobs? New Evidence for Europe', Small Business Economics 42.2: 283-95

DFID (2016) Putting Young People at the Heart of Development: The Department for International Development's Youth Agenda, London: Department for International Development

Eastwood, R. and Lipton, M. (2012) 'The Demographic Dividend: Retrospect and Prospect', Economic Affairs 32.1: 26-30

Enste, D. and Schneider, F. (2000) 'Shadow Economies: Size, Causes and Consequences', Fournal of Economic Literature 38.1: 77-114

Flynn, J.; Mader, P. and Oosterom, M. with Ripoll, S. (2017) Employment Failing Young People? Addressing the Supply-Side Bias and Individualisation in Youth Employment Programming, IDS Evidence Report 216, Brighton: IDS

Garwe, E.C. (2014) 'Holistic Initiatives for Enhancing Graduate Employability in Zimbabwe', Research in Higher Education fournal 23: 1-12 
Gebremariam, E.B. (2017) 'The Politics of Youth Employment and Policy Processes in Ethiopia', IDS Bulletin 48.3: 33-50, http://bulletin.ids.ac.uk/idsbo/article/view/2868 (accessed 3 August 2018)

Giddens, A. (1991) Modernity and Self-Identity: Self and Society in the Late Modern Age, Cambridge: Polity Press

Grant, M. (2003) 'Difficult Debut: Social and Economic Identities of Urban Youth in Bulawayo, Zimbabwe', Canadian Fournal of African Studies 37.2-3: 411-39

Grenville, J. (2007) 'Conservation as Psychology: Ontological Security and the Built Environment', International Journal of Heritage Studies 13.6: $447-61$

Gukurume, S. (2018) 'Chinese Migrants and the Politics of Everyday Life in Zimbabwe', Asian Ethnicity (advance online publication)

Gukurume, S. (2017) '\#ThisFlag and \#ThisGown Cyber Protests in Zimbabwe: Reclaiming Political Space', African fournalism Studies 38.2: $49-70$

Gukurume, S. (2015) 'Livelihood Resilience in a Hyperinflationary Environment: Experiences of People Engaging in Money-Burning (kubhena mari) Transactions in Harare, Zimbabwe', Social Dynamics 41.2: 219-34

Honwana, A. (2012) The Time of Youth: Work, Social Change and Politics in Africa, Boulder CO: Kumarian Press

ILO (2015) Global Employment Trends for Touth 2015: Scaling Up Investments in Decent Fobs for Youth, Geneva: International Labour Office

Jones, J.L. (2010) " "Nothing is Straight in Zimbabwe": The Rise of the Kukiya-kiya Economy 2000-2008', Journal of Southern African Studies 36.2: 285-99

Kamete, A.Y. (2017) 'Pernicious Assimilation: Reframing the Integration of the Urban Informal Economy in Southern Africa', Urban Geography 39.2: 167-89

Kang'ethe, S.M. and Mafa, D. (2015) 'Exploring the Panacea and Perfidy of Indigenization as a Driver to Avert Youth Unemployment in Zimbabwe', Fournal of Sociology and Social Anthropology 6.3: 335-40

Kanyenze, G. (2003) 'The Performance of the Zimbabwean Economy, 1980-2000', in S. Darnolf and L. Laakso (eds), Twenty Years of Independence in Zimbabwe: From Liberation to Authoritarianism, Basingstoke: Palgrave Macmillan

Langa, V. (2016) '90\% of Zim Youths Unemployed', Newsday, 10 August, www.newsday.co.zw/2016/08/90-zim-youthsunemployed/ (accessed 18 August 2018)

Lukács, E. (2005) 'The Economic Role of SMEs in World Economy, Especially in Europe', European Integration Studies 4.1: 3-12

Maguire, M. and Murphy, F. (2016) 'Ontological (In)Security and African Pentecostalism in Ireland', Ethnos 81.5: 842-64

Magure, B. (2012) 'Foreign Investment, Black Economic Empowerment and Militarised Patronage Politics in Zimbabwe', fournal of Contemporary African Studies 30.1: 67-82 
Mahiya, I.T. (2016) 'Urban Youth Unemployment in the Context of a Dollarised Economy in Zimbabwe', Commonwealth Youth and Development 14.1: 97-117

Mandl, I. (2017) 'SMEs and Job Creation in Europe', in I. Mandl and V. Patrini (eds), European Born Globals: Job Creation in Young International Businesses, Abingdon: Routledge

Mangudya, J.P. (2017) Re-Igniting SME Development in Zimbabwe: Learning from Global Experiences, Harare: Reserve Bank of Zimbabwe

Maringira, G. and Gukurume, S. (forthcoming, 2018) 'Youth Patronage: Violence, Intimidation and Political Mobilisation in Zimbabwe', Africa Peace Building Working Paper Series

Masquelier, A. (2013) 'Teatime: Boredom and the Temporalities of Young Men in Niger', Africa 83.3: 470-91

Maunganidze, F. (2016) 'The Role of Government in the Establishment and Development of SMEs in Zimbabwe: Virtues and Vices', fournal of Business Administration and Education 4.1: 1-16

Mbiriri, R.P. (2010) 'Can Zimbabwe Use Its Informal Economy as a Means for Sustainable Development in the Current Reconstruction Process?', unpublished thesis, University of Witwatersrand

McCauley, J.F. (2012) 'Africa's New Big Man? Pentecostalism and Patronage in Ghana', African Affairs 112 .446: 1-21

Medina, L. and Schneider, F. (2018) Shadow Economies Around the World: What Did We Learn Over the Past 20 Years? IMF Working Paper 18/17, Washington DC: International Monetary Fund

Mwaura, G.M. (2017) 'The Side-Hustle: Diversified Livelihoods of Kenyan Educated Young Farmers', IDS Bulletin 48.3: 51-66, http://bulletin.ids.ac.uk/idsbo/article/view/2869 (accessed 3 August 2018)

Namuggala, V.F. (2017) 'Gambling, Dancing, Sex Work: Notions of Youth Employment in Uganda’, IDS Bulletin 48.3: 67-78, http://bulletin.ids.ac.uk/idsbo/article/view/2870 (accessed 3 August 2018)

Ngek, N.B. and van Aardt Smit, A. (2013) 'Will Promoting More Typical SME Start-Ups Increase Job Creation in South Africa?', African Fournal of Business Management 7.31: 3043-51

Nsingo, D. (2017) '13K SMEs Register with ZIMRA', Chronicle, 11 July, www.chronicle.co.zw/13k-smes-register-with-zimra (accessed 26 June 2018)

Nyamwanza, T. (2014) 'Strategy Implementation for Survival and Growth among Small to Medium-Sized Enterprises (SMEs) in Zimbabwe', PhD thesis, Midlands State University

Nyoni, T. and Bonga, W.G. (2018) 'Anatomy of the Small \& Medium Enterprises (SMEs) Critical Success Factors (CSFs) in Zimbabwe: Introducing the 3E Model', Fournal of Business and Management 1.2: 1-18

Odero, K. (2006) 'Small and Medium Enterprises Support System in Zimbabwe', paper presented at IDS Seminar, University of Nairobi, www.researchgate.net/publication/301216417_Small_and_ Medium_Enterprises_Support_System_in_Zimbabwe (accessed 16 August 2018) 
Oosterom, M.A. (forthcoming, 2019) 'Youth and Social Navigation in Zimbabwe's Informal Economy: "Don't End Up On the Wrong Side", , African Affairs

Oosterom, M. with Kache, C.; Mususa, D. and Pswarayi, L. (2016) The Violent Politics of Informal Work, and How Young People Navigate Them: A Conceptual Framework, IDS Evidence Report 198, Brighton: IDS

Ranger, T. (2004) 'Nationalist Historiography, Patriotic History and the History of the Nation: The Struggle over the Past in Zimbabwe', Fournal of Southern African Studies 30.2: 215-34

SEDCO (2010) Small Enterprises Development Corporation, https://search.co.zw/wiki/small-enterprises-developmentcorporation-sedco/ (accessed 12 March 2017)

Shindler, L. (1997) 'Entrepreneurs in Zimbabwe's Informal Sector', Development 40.3: 57-61, https://www.africabib.org/rec. php?RID=P00051986 (accessed 18 August 2018)

Standing, G. (2015) 'The Precariat and Class Struggle', RCCS Annual Review 7: 3-16 https://journals.openedition.org/rccsar/585 (accessed 16 August 2018)

Thieme, T.A. (2013) 'The "Hustle" Amongst Youth Entrepreneurs in Mathare's Informal Waste Economy', Journal of Eastern African Studies 7.3: $389-412$

Utas, M. (2005) 'Victimcy, Girlfriending, Soldiering: Tactic Agency in a Young Woman's Social Navigation of the Liberian War Zone', Anthropological Quarterly 78.2: 403-30

Vigh, H. (2009) 'Motion Squared: A Second Look at the Concept of Social Navigation', Anthropological Theory 9.4: 419-38

Vigh, H. (2008) 'Crisis and Chronicity: Anthropological Perspectives on Continuous Conflict and Decline', Ethnos 73.1: 5-24

Yeboah, T. (2017) 'Navigating Precarious Employment: Social Networks Among Migrant Youth in Ghana', IDS Bulletin 48.3: 79-94, http://bulletin.ids.ac.uk/idsbo/article/view/2871 (accessed 3 August 2018)

Zindiye, S.; Chiliya, N. and Masocha, R. (2012) 'The Impact of Government and Other Institutions' Support on the Performance of Small and Medium Enterprises in the Manufacturing Sector in Harare, Zimbabwe', International fournal of Business Management and Economic Research 3.6: 655-67

Zinhumwe, C. (2012) 'The Youth and Unemployment in Zimbabwe', paper presented at the National Youth Conference, Rainbow Towers, Harare, Zimbabwe, 29 March, www.ilo.org/wcmsp5/groups/ public/---africa/---ro-addis_ababa/---sro-harare/documents/ statement/wcms_227249.pdf (accessed 16 August 2018) 


\title{
Assessing the Effectiveness of Employment Programmes for Ex-Combatants: A Case Study of Nigeria's Post Amnesty Programme (PAP)'
}

\author{
Tarila Marclint Ebiede ${ }^{1}$
}

\begin{abstract}
Employment of ex-militants is an important part of disarmament, demobilisation, and reintegration (DDR) programmes in societies emerging from armed conflicts. In this article, I examine the potential of Nigeria's Post Amnesty Programme (PAP), a locally designed DDR programme, to contribute to the employment of ex-militants in the oil-rich Niger Delta region. I show that although the programme has focused on training, its design and implementation has not been informed by a clear understanding of the private sector environment where ex-militants are expected to find work in the Niger Delta. I demonstrate empirically how programmes that are designed to address employment of ex-militants can easily fall short of expectations. I suggest that a baseline understanding of the needs of private sector employers is an essential part of youth employment programmes in fragile and conflict-affected societies.
\end{abstract}

Keywords: youths, ex-militants, jobs, private sector, peace-building.

\section{Introduction}

Youth employment is one of the most urgent development challenges facing policymakers in sub-Saharan Africa. Youth unemployment in this region is about 11 per cent (ILO 2017), a proportion that seems relatively small when compared to other regions of the world but which, in the context of sub-Saharan Africa's large population, clearly designates a very large number of unemployed youth. Approximately 12 million young people enter into the workforce each year, but only about 3 million jobs are created annually (AfDB 2017). The challenge of youth employment is particularly urgent in societies that have been affected by violent conflicts, where economic development is low, infrastructure is absent, and the private sector, in which youths are expected to seek employment, is weak. 
In societies recovering from violent conflicts, the unemployment problem is particularly prevalent among youths who have been involved in fighting and have become ex-combatants in the post-conflict phase. This is one of the specific problems that reintegration programmes are designed to address (Munive 2014). Reintegration is a process whereby ex-combatants acquire civilian status through sustainable employment and incomes (United Nations 2010). The reintegration process is supposed to be facilitated by vocational skills training, job creation, entrepreneurship support, psychological reorientation, and family support (Berdal 1996). However, the available evidence suggests that reintegration programmes often fail to create sustainable employment for ex-combatants (Blattman and Ralston 2015).

Policymakers in Nigeria face the challenge of generating employment for ex-militants in the country's oil-rich Niger Delta region. In 2009, the Nigerian government implemented a disarmament, demobilisation, and reintegration (DDR) programme for armed groups in the Niger Delta, which is known locally as the Post Amnesty Programme (PAP). The PAP includes programmes designed to support knowledge and skills acquisition, financial empowerment, internships, microcredit, and education to facilitate long-term employment for ex-militants. ${ }^{2}$

The Nigerian government claims that the PAP has successfully addressed the challenge of youth unemployment among ex-militants in the Niger Delta. However, in this article, I argue that the PAP has largely failed to facilitate the rehabilitation through employment of large numbers of ex-militants in the region. There is a gap between the government's claims and verifiable figures on the employment rates of former militants. For example, the government has claimed that it registered 30,000 ex-militants in the PAP (Gist Magazine 2013), yet it has only provided training for 15,459 individuals (PAP 2015). Data on actual levels of employment resulting from the programme are scarce, but the last official figures show that only 2,072 participants in the PAP have found jobs (Omonobi 2014).

I identify three factors that account for this failure: (1) the lack of an assessment of the needs of private sector employers, (2) a flawed incentive structure for PAP participants, and (3) the lack of a politically feasible strategy for winding up the programme. As a result, the PAP has become a disguised subsidy programme for unemployed and underemployed youth in the Niger Delta, representing an open-ended burden on public finances. To improve this outcome, I argue that the PAP requires reform to achieve a better targeting of the skills and capabilities needed by employers, more effective implementation, and a clearly identified route to transition from the PAP into sustainable employment.

The article proceeds as follows. Section 2 provides an overview of the PAP. Section 3 discusses the focus on the private sector as a potential employer of youth in the Niger Delta. Section 4 analyses the implementation of the PAP and explores the available evidence on 
Table 1 The disarmament, demobilisation, and reintegration components of the Post Amnesty Programme

\begin{tabular}{|c|c|c|}
\hline Disarmament & Demobilisation & Reintegration \\
\hline Duration: 6 August-4 October 2009 & Duration: 6-12 months & Duration: $U_{p}$ to 5 years \\
\hline $\begin{array}{l}\text { Collection of arms, ammunition and } \\
\text { explosives, etc. } \\
\text { Documentation and biometrics }\end{array}$ & $\begin{array}{l}\text { Ex-militants report to camp } \\
\text { Verification and documentation } \\
\text { Transformational training } \\
\text { Peace-building and conflict resolution } \\
\text { Counselling } \\
\text { Career guidance } \\
\text { Wellness assessment } \\
\text { Reintegration classification } \\
\text { Education and vocational placement } \\
\text { Graduation and demobilisation }\end{array}$ & $\begin{array}{l}\text { Knowledge and skills acquisition } \\
\text { Financial empowerment } \\
\text { Placement programmes } \\
\text { Microcredit } \\
\text { Education } \\
\text { Reconciliation with local community } \\
\text { Conflict resolution framework/ } \\
\text { mechanism } \\
\text { Monitoring and evaluation } \\
\text { Exit of programme }\end{array}$ \\
\hline $\begin{array}{l}\text { Disarmament camps } \\
\text { Media campaign }\end{array}$ & $\begin{array}{l}\text { Transformational training centres } \\
\text { Rehabilitation camps }\end{array}$ & $\begin{array}{l}\text { Partnering government agencies, } \\
\text { NGOs, and private organisations } \\
\text { Tracking and support framework }\end{array}$ \\
\hline
\end{tabular}

Source PAP (2009). First Plan of the Presidential Committee for Amnesty, Abuja.

the employment of ex-militants in the Niger Delta. It explains how a realistic assessment of the needs of the private sector is a missing ingredient within the PAP. This has undermined the programme's principal objective to facilitate youth employment in the Niger Delta. Section 5 summarises the argument and concludes.

\section{An overview of the Post Amnesty Programme (PAP)}

Protests, agitations, and civil disobedience by youths in oil-producing communities have characterised Nigeria's Niger Delta in the last three decades (Omotola 2009). The underlying driver of these agitations is that communities are not benefiting from the oil extraction that takes place on their land. Beginning in the late 1990s, youths demanding increased development and an end to environmental degradation in the Niger Delta organised mass protests against international oil companies (IOCs) and the Federal Government of Nigeria (FGN). These protests evolved into an armed militant struggle in 2005. Youths belonging to different militant groups focused on sabotaging oil industry infrastructure and critical assets, and kidnapping expatriates working in the oil industry (Ibaba 2011). These attacks led to a significant reduction of crude oil production in Nigeria, from 2.5 million barrels per day in 2005 to about 2 million barrels per day in the first quarter of 2006 . Nigeria's oil production did not rise above 2.2 million barrels per day throughout the period of the insurgency. 
Another steep decline in production occurred in 2008, and in the third quarter of 2009, production stood at only 1.75 million barrels per day. Industry and government revenues from crude oil sales fell during this period. The government came under pressure to find solutions and bring the armed insurgency to an end (Ukiwo 2016). In May 2007, a new government, led by President Umaru Musa Yar'Adua, opened negotiations with armed groups in the Niger Delta. In May 2009, the President proclaimed an amnesty for all armed groups in the Delta. As part of the peace process, the PAP was designed as a DDR programme for militants who agreed to renounce violence and accept an amnesty (see Table 1).

Disarmament exercises were carried out by the Nigerian military in the major cities of Warri, Yenagoa, and Port Harcourt from the beginning of August to the end of October 2009. At the end of the disarmament exercise, the FGN claimed that it had identified and registered 30,000 participants in the PAP. Many ex-militants signed up for the programme when leaders of militant groups endorsed it. The former militants were accommodated in camps, in a bid to separate them from their former armed groups. Non-governmental organisations (NGOs) were contracted by the FGN to carry out reorientation programmes, which taught ex-militants peaceful methods of conflict resolution, human rights, and the rule of law. Career counselling was provided, in preparation for the reintegration phase. The first phase came to an end in 2010, having prepared the stage for former militants to reintegrate into their communities.

The committee constituted by the to oversee the PAP proposed a reintegration plan that focused on offering bespoke courses of vocational skills acquisition (PAP 2009). It was estimated initially that this plan would cost the Nigerian government US\$360 million. Over time, the cost of the training component of the PAP has increased to more than US\$1 billion. According to a PAP official, this increase resulted from changes in the design of the programme. The initial plan envisaged the provision of bespoke training exercises by the PAP itself, whereas the revised programme provided access to training opportunities, extending beyond nine months' duration, which would lead to international certifications. ${ }^{3}$

PAP participants were placed in educational institutions and training centres in Europe, North America, Asia, South Africa, and West Africa, as well as private institutions in Nigeria. Vocational training was arranged in areas such as marine technology, heavy duty equipment operations, welding, diving, agriculture, boat building, aviation, fashion design, hotel and catering, cosmetology, and hair dressing (Gist Magazine 2013). Academic training focused on undergraduate degrees such as law, political science, business management, mass communication, international relations, public administration, medicine, engineering, applied sciences, building and construction, and information and communications technology (ICT) (ibid.). 
Youth unemployment in the Niger Delta has often been blamed on a lack of education and skills. Indeed, many youths who took part in armed militancy blamed the lack of employment opportunities as a reason for joining armed groups (Oyefusi 2008). The enhanced provision of educational and vocational training in the PAP was intended to address this problem (Ajibola 2015). In particular, it was expected that these training programmes would enable ex-militants to find work in the private sector (Kuku 2012).

Although the PAP was designed to enable youths participating in the programme to find work in the private sector as a whole, the programme focused heavily on the oil and gas sectors, in particular. According to PAP officials, this emphasis was designed in response to the interest expressed by local youths to engage in the oil and gas industry in the Niger Delta. ${ }^{4}$ As will be shown in the analysis, the majority of ex-militants selected training opportunities that could enable them to seek employment in the oil industry. However, while private companies within the oil industry are the dominant private sector interests in the Niger Delta, the extent to which they are able to provide employment for youths remains contested.

\section{The private sector and youth employment in the Niger Delta}

Youth unemployment is a general challenge across Nigeria (Ismail 2016). Recent data indicate that about one third of Nigerian youths have been unable to find gainful employment (NBS 2018). The issue cuts across the country's 36 states, including the oil-rich Niger Delta. Youth unemployment rates in Rivers State (41.82 per cent) and Akwa Ibom State (36.58 per cent) are significantly above the national average, while the state of Bayelsa is slightly below the national average at 30.36 per cent. The data on youth unemployment in the Niger Delta are not a surprise as youth employment is generally a challenge in fragile and conflict-affected states (FCAS). There is a general concern that high levels of youth unemployment contribute to criminality or mobilisation for armed violence (Izzi 2013); however, there is no confirmed relationship between unemployment and crime in the long term (Janko and Popli 2015). Nonetheless, tackling youth unemployment and underemployment are seen as important objectives for building peace and stability in FGAS (Enria 2014).

The Niger Delta is a fragile and conflict-affected region. Fragility and violence in the Delta have been driven largely by the exploration and extraction of crude oil resources, which are carried out as a joint venture between the Nigerian government and private sector operators. The Nigerian National Petroleum Corporation (NNPG) represents government interests in the oil sector, alongside a number of international and national oil companies which play a significant role, especially in the exploration and extraction of crude oil, as well as the construction and operation of oil production facilities. However, while the private sector is a major player in the oil sector in the Delta, the region's dependence on oil and gas has not helped private sector growth in other areas of the economy. The Niger Delta is an example 
of the resource curse thesis, which argues that an abundance of natural resources stifles economic growth and development, and can lead to violent conflict. Scholars that have theorised on the resource curse thesis have drawn empirical evidence from sub-Saharan African countries such as Nigeria, the Democratic Republic of Congo, Zimbabwe, and Angola (Badeeb, Lean and Clark 2017).

The negative impact of natural resource conflicts on private sector growth in FCAS has significant implications for job creation and youth employment. The private sector faces particular challenges in FCAS, which are typically characterised by a weak regulatory and judicial environment, hard-to-enforce property rights, a lack of policy and fiscal frameworks, criminality and corruption, a lack of basic infrastructure and services such as electricity, high business risks, and security threats, which make it challenging for private enterprises to thrive (Eriksson Baaz, Olsson and Verweijen 2018; Mac Sweeney 2009; Peschka, Emery and Martin 2011). According to Peschka et al.:

The impact of conflict, violence, and prolonged fragility is particularly pervasive on the legitimate formal private sector. Foreign and local investors alike flee the country, taking with them longerterm capital, skills, jobs, and technology and further undermining local private sector support institutions (such as chambers of commerce)... The businesspeople who do stay face difficulty in accessing finance, are often harassed or co-opted by increasingly corrupt government and military and/or by militias, and may find it harder to import necessary goods or export their products (2011: 15).

Unsurprisingly, FGAS occupy the bottom rungs of the World Bank's Ease of Doing Business Index (World Bank 2018: 4). In FCAS, political logics often overtake the production logics that shape private sector activity in more stable societies (Castel-Branco, Cramer and Hailu 2001). Private actors may even be involved in political and economic relationships and practices that help to sustain conflict, violence, and instability (Oetzel, Getz and Ladek 2007). They may profit directly from involvement in war as providers of services and equipment to warring parties, or they may be involved in the extraction of natural resources, which is often at the heart of such conflicts.

Some analysts have identified these negative dynamics in relation to the involvement of businesses in the Niger Delta (Frynas 2001). The armed militancy that characterised the Niger Delta region was directly linked to contestation over the oil industry's activities. Key actors in this conflict were armed militants, local politicians, the FGN, and IOCs operating in the Delta. The corporate social responsibility (CSR) practices of IOCs fuelled conflicts and empowered armed militants in some communities (Ebiede 2017). IOCs reformed their CSR practices to address some of these shortcomings (Ite 2007). However, recent analysis suggests that contestation over oil resources and the activities of the oil industry continue to fuel conflict in the Niger Delta (Bendana et al. 2018). 
Revenues of regional government in the Niger Delta are derived almost exclusively from the oil sector. The government's focus on oil revenues has also limited the development of appropriate policies that can facilitate private sector growth. Oil revenues have been lost to corruption within government. Even where government funds infrastructure development, there is no evidence to suggest that such investment leads to private sector growth in the region. There is also no evidence that such investments form part of an overarching strategy to foster the emergence of private sector-led economic development in the region.

IOCs dominate the oil and gas industry in the Niger Delta. Although the industry is profitable, hydrocarbon extraction and the associated value chains do not generate many jobs for young people. In 2005, it was estimated that the oil and gas industry accounts for only about 65,000 direct and 250,000 indirect jobs in Nigeria as a whole (Fajana 2005). In 2017, the National Bureau of Statistics, Nigeria (NBS) estimated that the oil industry and extractive sector in the country employ only about 1 per cent of the entire labour force of Nigeria. This illustrates that the oil industry is not the type of private sector activity that can generate wide-scale employment in the Niger Delta.

According to the NBS, the key employers of labour in Nigeria and the Niger Delta are mainly small and medium enterprises (SMEs) in the agricultural, hotel, tourism and entertainment, food and catering, education, and transport sectors. While these sectors are flourishing, they are not fully developed. Formal private sector service delivery in the Niger Delta remains weak and is largely confined to the urban areas. The lack of infrastructure in rural areas of the Niger Delta makes it difficult for private sector actors to thrive. Even in urban areas, companies involved in manufacturing, hospitality and tourism, food, and catering lack basic and fundamental infrastructures, such as electricity supply.

The exploration and production of crude oil has polluted the environment, reducing the productivity of agricultural activities in the region (Opukri and Ibaba 2008). Yet, agriculture is the single largest employer of labour in the Delta (Nextier Advisory and SDN 2016). The absence of a thriving non-oil private sector is said to limit the 'creation of markets, and access to other factors of economic progress', which are essential to the provision of jobs for youths in the Niger Delta (ibid.: 4).

Despite these challenges, scholars and policymakers remain adamant that the private sector has an important role to play in stabilising FCAS, through the creation of jobs and the provision of financial and other resources to support local entrepreneurs (Bray 2009; Peschka et al. 2011). It is argued that development actors, including aid donors and the state, can build an effective market system with space for private sector players to operate, as part of their efforts to strengthen the economic systems of FCAS (Batley and Mcloughlin 2010). These strategies are supposed to enhance job creation in the private sector, as a contribution to the stabilisation of FGAS. 
Table 2 Reintegration training provided to ex-militants under the Post Amnesty Programme

Area of specialisation

Education:

- Nigerian universities

- Foreign universities

Welding and fabrication

Entrepreneurship

Maritime

Crane and heavy duty

Pipefitting

Boat building

Agriculture

Automobile

Electrical installation

89

Aviation:

Engineers

- Pilot (fixed wing)

- Helicopter

- Instructors

Diving 230

Drilling 197

Health, safety and environment 104

Industry automation 86

Entertainment

60

Instrumentation

46

Total

15,224

Source Office of the Special Adviser to the President on the Niger Delta, October 2015 (unpublished).

The private sector remains the largest employer of labour in the Niger Delta. Entrepreneurial individuals still seek to engage in private business activities in various sectors of the economy. The training component of the PAP makes clear that the programme was designed to steer youths towards employment in the private sector, yet this aspiration has not been achieved. It is therefore important to examine why the PAP has not been able to achieve this objective. 


\section{The Post Amnesty Programme and youth employment in the Niger Delta}

Institutions of the Nigerian government in the Niger Delta have implemented various programmes to address the youth employment challenge, including several skills acquisition and training programmes led by the Niger Delta Development Commission (NDDC) and the Ministry of Niger Delta Affairs (MNDA). In addition to these are programmes implemented by IOCs and the Nigerian Local Content Management Board (NLCMB). These programmes are meant for all youths in the Niger Delta. However, the PAP was specifically designed to address the challenge of employment among youths who have been involved in armed militancy in the Niger Delta.

The design of the PAP reflected arguments that unemployment was one of the reasons for the mobilisation of youths into militant groups (Oluwaniyi 2010). Former militants were expected to undertake both vocational and educational training. The vocational training component focused on agriculture, agro-allied processing, transportation, cold-room management, ICT, maritime services, building and construction professionals, oil and gas, and environment and sanitation. By 2015, it was estimated that 15,459 out of 30,000 registered ex-militants had undergone various PAP-sponsored training programmes, both in Nigeria and overseas (see Table 2).

With a few exceptions, such as entrepreneurship and entertainment, most of the types of training offered were aimed at skills needed within the oil industry, including welding and fabrication $(5,194)$, entrepreneurship (2,798), maritime $(1,086)$, and crane and heavy duty machinery operation $(1,030)$. As well as responding to the participants' own demands, the array of training opportunities provided was informed by government officials' assumption that oil companies would provide jobs for ex-militants. ${ }^{5}$ However, the oil industry is not a major employer of labour within the private sector in the Niger Delta. Interviews with PAP officials revealed that the programme's training component was not informed by a baseline study of employment opportunities actually available within the private sector in the Niger Delta. As a result, the focus on the oil industry did not capture the economic realities of the employment situation in the region. A study by the Foundation for Partnership Initiatives in the Niger Delta (PIND), an NGO focused on community development, made the following assertions:

The strong presence of the oil industry in the Delta has resulted in the relative shrinkage of other local industries, such as manufacturing. That is, the lure of high salaries perceived to be associated with oil sector jobs, makes all other forms of employment less desirable. Unstable markets and wide-scale importation have likewise worked to stifle other economic sectors, including agriculture, aquaculture and construction. With poor linkages between the market and vocational training (i.e. matching demand for labor with appropriately trained supply of labor) the result is a large, youthful population that is unable to find decent work (PIND 2011: 16). 
The PIND report also noted that 'in terms of skills and competencies, youth tend to fall below the required expectations of employers' (ibid:: 19). This situation reflects wider debates in the youth employment literature about balancing demand and supply factors (Darvas and Palmer 2014). Employers seek human capital that is capable of increasing their business output. However, while labour is abundant in societies with high unemployment, the specific skills needed by thriving businesses are often scarce. This mismatch between labour demand and supply is a key factor underlying the youth employment challenge in FCAS. The gap persists in programmes such as the PAP, which are designed to help youths into paid work.

The PAP incentive structure also failed to take into account the realities of the local job market. To support the livelihoods of ex-militants while they underwent training and awaited gainful employment, the PAP paid a monthly stipend worth about US $\$ 400$ to participants in the programme, from the moment they enrolled and for an indefinite period. To the young former militants, this financial incentive was one of the key attractions of the PAP. ${ }^{6}$ However, the stipend was set at a level higher than the monthly wages available locally to artisans and skilled workers. Currently, the minimum wage in Nigeria is only US $\$ 60$ per month. Although formal employment in private sector jobs is likely to pay more than the minimum wage, the types of jobs for which ex-militants have been trained are unlikely to attract monthly salaries that can compete with the monthly stipends paid by the PAP. As a result, the stipend has tended to act as a disincentive rather than an incentive to seek employment. This was recognised by a PAP official, who told me 'skilled labour can hardly really pay that much... it makes no sense to accept a job that will pay less than the monthly stipend. This is a disincentive for most of them to take up regular employment. ${ }^{7}$

The PAP was supposed to end after five years, in December 2015, but it has continued to receive government funding and support. In 2016, President Buhari extended the programme to December 2017 (Daily Post 2016). The FGN later announced that it would provide up to US\$86 million in additional funds to extend the PAP throughout 2018 (THISDAY 2017). These extensions were prompted by protests by ex-militants, who claimed that they had not been successfully reintegrated. Their protests intensified when the government briefly suspended payments of monthly stipends in 2016 (Daily Post 2016). Many former militants continue to depend on the PAP for their livelihood, and while this situation continues there is no indication that it will be politically possible for the Nigerian government to terminate the PAP without jeopardising the peace and rehabilitation process.

\section{Conclusion}

The lack of an exit plan for the PAP and the failure to achieve the objective of facilitating employment for ex-militants has created a conundrum for the FGN. I argue that the lack of an exit strategy has occurred largely because the programme failed to give adequate 
attention to the needs of private sector employers in the non-oil and gas sector, both qualitatively (the types of skills required) and quantitatively (the potential to create job vacancies and absorb workers), or to the prevailing wage rates offered by private sector employers in the region. To a large extent, the PAP has become a disguised subsidy programme for unemployed and underemployed youth in the Niger Delta. This flaw in the programme's detailed design and implementation has made it difficult to achieve a sustainable benefit. Instead, both ex-militants and successive governments have used the PAP as leverage in political bargaining in the Niger Delta.

The article has also shown that there is a mismatch between the needs of the private sector and the ambitions of young people in the Niger Delta. Youths in the region aspire to be engaged in the oil industry, but that sector is unable to meet the demand for jobs in the region. This analysis suggests that an overarching strategy is urgently needed to diversify economic development in the Niger Delta, creating a space for other kinds of private enterprise besides the oil and gas industry, and an expansion of job opportunities. In the meantime, there is a need for programmes that seek to facilitate a transition into employment to be informed by robust evidence of the economic and business realities on the ground. It is not enough for the government to set out to train young people, welcome though such opportunities may be. These trainings must be based on a clear needs assessment of private sector employers as well as the aspirations of young people.

Despite the challenges that have been identified with Nigeria's PAP, the need for these types of programmes remain urgent. However, the design and implementation of such programmes needs to be innovative and grounded in empirical understanding of the context of societies that have experienced armed conflicts. Programmes that are not based on this detailed analysis cannot guarantee employment for youths, including those who have experienced armed conflict. While it remains important to mobilise the private sector as a generator of employment for youths in FCAS, it is important to clarify how this mechanism would work in practice. Any programme that seeks to stimulate youth employment, in which the private sector will be a key player, should focus on both the demand and supply sides of the labour relationship between business employers and youths seeking employment.

\section{Notes}

* This issue of the IDS Bulletin was produced in partnership with Mastercard Foundation.

1 Centre for Research on Peace and Development, KU Leuven, Belgium.

2 www.osapnd.gov.ng/ndap.

3 Interview with DDR official, 13 February 2014, Abuja, Nigeria.

4 Interview with DDR official. In addition, the PAP established an Oil and Gas Committee to facilitate the employment of ex-militants in the oil industry. 
5 Interview with DDR official, 13 February 2014.

6 Interview with ex-militant, 5 November 2014.

7 ibid.

\section{References}

AfDB (2017) Fobs for Youth in Africa: Strategy for Creating 25 Million Jobs and Equipping 50 Million Youths, 2016-2025, Abidjan: African Development Bank

Ajibola, I.O. (2015) 'Nigeria's Amnesty Program: The Role of Empowerment in Achieving Peace and Development in Post-Conflict Niger Delta', Sage Open 5.3: 1-11

Badeeb, R.A.; Lean, H.H. and Clark, J. (2017) 'The Evolution of the Natural Resource Curse Thesis: A Critical Literature Survey', Resources Policy 51: 123-34

Batley, R. and Mcloughlin, C. (2010) 'Engagement with Non-State Service Providers in Fragile States: Reconciling State-Building and Service Delivery', Development Policy Review 28.2: 131-54

Bendana, A.; Ebiede, T.M.; Okigbo, P.; Kahlmeyer, A. and Sato, E. (2018) 'Developing a Community-Based Security (CBS) System for Petroleum Sector Assets and Infrastructure in the Niger Delta of Nigeria', unpublished final report submitted to the European Union Delegation in Abuja, Nigeria

Berdal, M. (1996) 'Disarmament and Demobilization After Civil Wars', Adelphi Papers 36.303

Blattman, C. and Ralston, L. (2015) 'Generating Employment in Poor and Fragile States: Evidence from Labor Market and Entrepreneurship Programs', SSRN Electronic Fournal, https://papers.ssrn.com/sol3/papers.cfm?abstract_id=2622220 (accessed 14 August 2018)

Bray, J. (2009) 'The Role of Private Sector Actors in Post-Conflict Recovery: Analysis', Conflict, Security and Development 9.1: 1-26

Castel-Branco, G.N. and Cramer, C. with Hailu, D. (2001) 'Privatization and Economic Strategy in Mozambique', in T. Addison (ed.), From Conflict to Recovery in Africa, Oxford: Oxford University Press

Daily Post (2016) 'Buhari Extends Amnesty Programme until December 2017', 16 February, http://dailypost.ng/2016/02/16/buhariextends-niger-delta-amnesty-until-december-2017/ (accessed 22 August 2018)

Darvas, P. and Palmer, R. (2014) Demand and Supply of Skills in Ghana: How Can Training Programs Improve Employment and Productivity? Washington DC: World Bank

Ebiede, T.M. (2017) 'Beyond Rebellion: Uncaptured Dimensions of Violent Conflicts and the Implications for Peacebuilding in Nigeria's Niger Delta', African Security 10.1: 25-46

Enria, L. (2014) Real fobs in Fragile Contexts: Reframing Youth Employment Programming in Liberia and Sierra Leone, London: International Alert

Eriksson Baaz, M.; Olsson, O. and Verweijen, J. (2018) 'Navigating "Taxation" on the Congo River: The Interplay of Legitimation and "Officialisation", Review of African Political Economy 45.156: 250-66 
Fajana, S. (2005) Industrial Relations in the Oil Industry in Nigeria, Sectoral Programme Activities Working Paper 237, Geneva: International Labour Organization (ILO)

Frynas, J.G. (2001) 'Corporate and State Responses to Anti-Oil Protests in the Niger Delta', African Affairs 100.398: 27-54

Gist Magazine (2013) Amnesty: 3 Years On, Official Publication of the Presidential Amnesty Programme, Abuja: Presidential Amnesty Programme

Ibaba, I.S. (2011) 'Terrorism in Liberation Struggles: Interrogating the Engagement Tactics of the Movement for the Emancipation of the Niger Delta', Perspectives on Terrorism 5.3-4: 18-32

ILO (2017) World Employment Social Outlook Trends 2017, Geneva: International Labour Organization

Ismail, O. (2016) 'What is in a Job? The Social Context of Youth Employment Issues in Africa', Fournal of African Economies 25.suppl 1: $37-60$

Ite, U.E. (2007) 'Changing Times and Strategies: Shell's Contribution to Sustainable Community Development in the Niger Delta, Nigeria', Sustainable Development 15.1: 1-14

Izzi, V. (2013) 'Just Keeping Them Busy? Youth Employment Projects as a Peacebuilding Tool', International Development Planning Review 35.2: $103-17$

Janko, Z. and Popli, G. (2015) 'Examining the Link between Crime and Unemployment: A Time-Series Analysis for Canada', Applied Economics 47.37: 4007-19

Kuku, K. (2012) Remaking the Niger Delta: Challenges and Opportunities, Croydon: Mandingo Publishing

Mac Sweeney, N. (2009) Private Sector Development in Post-Conflict Countries: A Review of Current Literature and Practice, Cambridge: Donor Committee for Enterprise Development (DCED)

Munive, J. (2014) 'Invisible Labour: The Political Economy of Reintegration in South Sudan', fournal of Intervention and Statebuilding 8.4: 334-56

NBS (2018) Employment Sector Report, Labour Force Statistics, Vol. 2, Abuja: National Bureau of Statistics, Nigeria

Nextier Advisory and SDN (2016) Markets for Development in the Niger Delta: Recommendations for the Way Forward, Abuja: Nextier Advisory and Stakeholder Democracy Network

Oetzel, J.; Getz, K.A. and Ladek, S. (2007) 'The Role of Multinational Enterprises in Responding to Violent Conflict: A Conceptual Model and Framework for Research', American Business Law Fournal 44.2: 331-58

Oluwaniyi, O.O. (2010) 'Oil and Youth Militancy in Nigeria's Niger Delta Region', Fournal of Asian and African Studies 45.3: 309-25

Omonobi, K. (2014) 'From Creek Warlords to Experts in Oil \& Gas: The Story of Ex-Niger Delta Militants', Vanguard, 17 December, www.vanguardngr.com/2014/12/creek-warlords-experts-oil-gasstory-ex-niger-delta-militants/ (accessed 3 August 2018)

Omotola, J.S. (2009) 'Dissent and State Excesses in the Niger Delta, Nigeria', Studies in Conflict and Terrorism 32.2: 129-45 
Opukri, G.O. and Ibaba, I.S. (2008) 'Oil Induced Environmental Degradation and Internal Population Displacement in Nigeria's Niger Delta', Fournal of Sustainable Development in Africa 10.1: 173-93

Oyefusi, A. (2008) 'Oil and the Probability of Rebel Participation among Youths in the Niger Delta of Nigeria', Fournal of Peace Research 45.4: 539-55

PAP (2015) Press Release of the Presidential Amnesty Programme, Abuja: Presidential Amnesty Programme

PAP (2009) First Plan of the Presidential Committee for Amnesty, Abuja: Presidential Amnesty Programme

Peschka, M.P. with Emery, J.J. and Martin. K. (2011) The Role of the Private Sector in Fragile and Conflict-Affected States, background paper for World Development Report 2011, http://web.worldbank.org/archive/ website01306/web/pdf/wdr_background_paper_peschka_0.pdf (accessed 2 November 2018)

PIND (2011) A Report on Niger Delta Region Youth Assessment, Abuja: Foundation for Partnership Initiatives in the Niger Delta

THISDAY (2017) 'FG Releases Additional N30bn for Amnesty Programme', 7 May, www.thisdaylive.com/index.php/2017/05/07/ fg-releases-additional-n30bn-for-amnesty-programme/ (accessed 22 August 2018)

Ukiwo, U. (2016) 'Timing and Sequencing in Peacebuilding: A Case Study of the Niger Delta Amnesty Programme', in A. Langer and G.K. Brown (eds), Building Sustainable Peace: Timing and Sequencing of Post-Conflict Reconstruction and Peacebuilding, Oxford: Oxford University Press

United Nations (2010) Second Generation Disarmament, Demobilization and Reintegration (DDR) Practices in Peace Operations: A Contribution to the New Horizon on Challenges and Opportunities for UN Peace Keeping, New York NY: Department of Peace Keeping Operations

World Bank (2018) Doing Business 2018: Reforming to Create Jobs, Washington DC: World Bank, www.doingbusiness.org/content/ dam/doingBusiness/media/Annual-Reports/English/DB2018Full-Report.pdf (accessed 8 November 2018) 


\section{Glossary}

ACODE Advocates Coalition for Development and Environment [Uganda]

ACP African, Caribbean, and Pacific

ADRA Adventist Development and Relief Agency [USA]

AfDB African Development Bank [Côte d'Ivoire]

APRA Agriculture Policy Research in Africa [UK]

AUC African Union Commission [Ethiopia]

BDU Bahir Dar University [Ethiopia]

BIAT Boosting Intra-African Trade

CBS community-based security

CFTA Continental Free Trade Area

CIAT International Center for Tropical Agriculture [Colombia]

CSA Central Statistical Agency [Ethiopia]

CSF critical success factor

CSR corporate social responsibility

DCED Donor Committee for Enterprise Development [UK]

DDR disarmament, demobilisation, and reintegration

EDRI Ethiopian Development Research Institute

EEA Ethiopian Economic Association

EHPEA Ethiopian Horticulture Producer Exporters Association

EPRC Economic Policy Research Centre [Uganda]

EPZ export processing zone

ERP Economic Recovery Programme

ESAP Economic Structural Adjustment Programme

ESE entrepreneurial self-efficacy

ESRC Economic and Social Research Council [UK]

ESS Ethiopian Socioeconomic Survey

EU European Union

FAO Food and Agriculture Organization of the United Nations [Italy]

FCAS fragile and conflict-affected states/settings

FGD focus group discussion

FGN Federal Government of Nigeria

GDP gross domestic product

Ghc Ghanaian cedi

GoK Government of Kenya

GTP Growth and Transformation Plan [Ethiopia]

ha hectare

HUMA Institute for Humanities in Africa (University of Cape Town)

[South Africa]

ICE International and Comparative Education

ICT information and communications technology

IFAD International Fund for Agricultural Development [taly]

IFPRI International Food Policy Research Institute [USA]

IITA International Institute of Tropical Agriculture [Kenya]

ILO International Labour Organization [Switzerland] 
ILRI International Livestock Research Institute [Kenya]

IMF International Monetary Fund [USA]

IOC international oil company

ISSER Institute of Statistical, Social and Economic Research [Ghana]

ITC International Trade Centre [Switzerland]

K4D Knowledge, Evidence, and Learning for Development

KICD Kenya Institute of Curriculum Development

Ksh Kenyan shilling

LACA Land and Agriculture Commercialisation in Africa [Ghana]

LSMS-ISA World Bank Living Standards Measurement Study-

Integrated Surveys on Agriculture

MDC Movement for Democratic Change [Zimbabwe]

MNDA Ministry of Niger Delta Affairs

MoE Ministry of Education [Ethiopia]

MoP Migrating out of Poverty [UK]

MSE micro and small enterprises

MSMEs micro-, small-, and medium-sized enterprises

MT metric tonne

NBER National Bureau of Economic Research [USA]

NBS National Bureau of Statistics [Nigeria]

NDDC Niger Delta Development Commission

NGO non-governmental organisation

NGPS National Governance, Peace and Security

NLCMB Nigerian Local Content Management Board

NLFS National Labor Force Survey

NNPC Nigerian National Petroleum Corporation

NYP National Youth Policy [Uganda]

OECD Organisation for Economic Co-operation and Development

[France]

PAP Post/Presidential Amnesty Programme [Nigeria]

PIF project interest form

PIND Foundation for Partnership Initiatives in the Niger Delta

PSFU Private Sector Foundation Uganda

SAP Structural Adjustment Programme

SEDCO Small Enterprises Development Corporation [Zimbabwe]

SME small- and medium-sized enterprises

SOC state-owned company

SSA sub-Saharan Africa

STEM science, technology, engineering, and mathematics

STEPS Social, Technological, and Environmental Pathways to

Sustainability

TVET Technical Vocational Education and Training

UBOS Ugandan Bureau of Statistics

UEUS Urban Employment Unemployment Survey

UGX Ugandan shilling

UN DESA United Nations Department of Economic and Social Affairs

[USA]

UNDP United Nations Development Programme [USA]

UNECA United Nations Economic Commission for Africa [Ethiopia] 
UNESCO United Nations Educational, Scientific and Cultural Organization [France]

UNU-WIDER United Nations University World Institute for Development Economics Research [Finland]

USAID United States Agency for International Development WDI World Bank Development Indicators

WESO World Employment and Social Outlook

YIG youth interest group

YLF Youth Livelihood Fund [Uganda]

YLP Youth Livelihood Programme [Uganda]

ZANU-PF Zimbabwe African National Union-Patriotic Front 
This page is intentionally left blank 
This page is intentionally left blank 
Volume 49 (2018)

No. 1 Value Chains for Nutrition in South Asia: Who Delivers, How, and to Whom?

No.1A Inclusive Peace and Security

No. 2 Accountability for Health Equity: Galvanising a Movement for Universal Health Coverage

No. 3 Emerging Economies and the Changing Dynamics of Development Cooperation

No. 4 The Millennium Villages: Lessons on Evaluating Integrated Rural Development

\section{Volume 48 (2017)}

No. 1 Sex Education in the Digital Era

No. 2 Interrogating Decentralisation in Africa

No. 3 Africa's Youth Employment Challenge: New Perspectives

No. 4 Courting Catastrophe? Humanitarian Policy and Practice in a Changing Climate

No. 1 A Has Universal Development Come of Age?

No. 5-6 Green Power for Africa: Overcoming the Main Constraints

\section{Volume 47 (2016)}

No. 1 Opening Governance

No. 1 A Connecting Perspectives on Women's Empowerment

No. 2 Development Studies - Past, Present and Future

No. 3 Ruptures and Ripple Effects in the Middle East and Beyond

No. 4 Foresight in International Development

No. 5 Power, Poverty and Inequality

No. 2A States, Markets and Society - New Relationships for a New Development Era

No. 6 Engaged Excellence

Periodical ID statement The IDS Bulletin (ISSN 0265-5012 print) is published bi-monthly in January, March, May, July, September and November. Mailing agent: Gary Edwards, Institute of Development Studies, Library Road, Brighton BN1 9RE, UK.

Tel: +44 (0)1273 606261 idsbulletin@ids.ac.uk

Postmaster Send all address changes to IDS Bulletin, Gary Edwards, Institute of Development Studies, Library Road, Brighton BN1 9RE, UK. Tel: +44 (0)1273 606261 idsbulletin@ids.ac.uk

Journal customer services For ordering information, claims and any enquiry concerning your journal subscription please contact Gary Edwards, Institute of Development Studies, Library Road, Brighton BN1 9RE, UK. Tel: +44 (0)1273 606261 idsbulletin@ids.ac.uk

Print details Printed in the UK by Nexus Design \& Print Ltd, 26 Bramber Road, Worthing, West Sussex BN14 8QB, UK.

Delivery terms and legal title Prices include delivery of print journals to the recipient's address. Delivery terms are Delivery Duty Unpaid (DDU); the recipient is responsible for paying any import duty or taxes. Legal title passes to the customer on despatch.

ISSN 0265-5012 (print), 1759-5436 (online) 


\title{
Youth Employment and the Private Sector in Africa
}

\author{
Editors Seife Ayele, Dominic Glover and Marjoke Oosterom
}

Volume 49 | Number 5 | November 2018

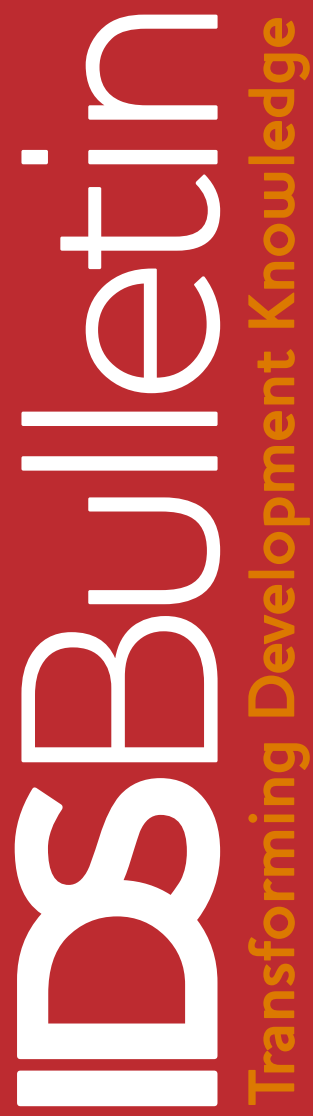

Clementina Oluwafunke Ajayi In Memoriam

Introduction: Youth Employment and the Private Sector in Africa Seife Ayele, Marjoke Oosterom and Dominic Glover

Ethiopia's Agricultural Transformation: Agribusiness' Contribution to Reducing Youth Unemployment

Tesfamicheal Wossen and Seife Ayele

Labour Casualisation and Youth Employment in Ghana's Formal Private Sector Gertrude Dzifa Torvikey

Uganda's National Youth Policy and Job Creation for Youth Rita Makumbi

Skills Gaps and Mismatches: Private Sector Expectations of Engineering Graduates in Ethiopia

Jerusalem Yibeltal Yizengaw

Fostering Agribusiness Entrepreneurship for Kenyan Youth through

Practice-Based Education

John Muchira

Navigating Precarious Livelihoods: Youth in the SME Sector in Zimbabwe Simbarashe Gukurume

Assessing the Effectiveness of Employment Programmes for Ex-Combatants: A Case Study of Nigeria's Post Amnesty Programme (PAP)

Tarila Marclint Ebiede

'There is a shift within donors and institutions

to involve the private sector in addressing

youth unemployment... in order to seize the "demographic dividend" of a young population.' 